Illinois State University

ISU ReD: Research and eData

Theses and Dissertations

2-18-2015

\title{
Transitioning To A Standards-Based Grading Model At The Middle Level: A Case Study
}

Jeffrey Scott Szymczak

Illinois State University, jeff.szymczak@gmail.com

Follow this and additional works at: https://ir.library.illinoisstate.edu/etd

Part of the Educational Administration and Supervision Commons

\section{Recommended Citation}

Szymczak, Jeffrey Scott, "Transitioning To A Standards-Based Grading Model At The Middle Level: A Case Study" (2015). Theses and Dissertations. 314.

https://ir.library.illinoisstate.edu/etd/314

This Dissertation is brought to you for free and open access by ISU ReD: Research and eData. It has been accepted for inclusion in Theses and Dissertations by an authorized administrator of ISU ReD: Research and eData. For more information, please contact ISUReD@ilstu.edu. 


\title{
TRANSITIONING TO A STANDARDS-BASED GRADING MODEL
}

\section{AT THE MIDDLE LEVEL: A CASE STUDY}

\author{
Jeffrey S. Szymczak
}

139 Pages

May 2015

Report card grades have long been a part of the system of communication used in our schools to signify student achievement. Letter grades have been with us for centuries, but it was not until recently that educators began recognizing there may be a better way to communicate what a student knows and can do for parents and other schools. While standards-based grades have been common at the elementary level, middle and high schools have been slow to put them to use.

This phenomenological case study was of a seventh and eighth grade school in northeast Illinois in 2013 in the third year of a transition to a standards-based report card. The research question in this study was: "How did the middle level educators describe their experiences in moving from a traditional grading system to a standards-based approach to grading?" Staff ( $n=14)$ were interviewed, meetings observed, and documents reviewed to provide an overview of what happened during the transition to a report card that showed what students knew and could do.

Wilderness Middle School (a pseudonym) utilizes a six-page computerized report card to communicate students' academic abilities. The report card has maintained an achievement grade that continues to be used for eligibility and honor roll recognition. 
This hybrid approach reportedly has diminished the importance conveyed by the standards. While the staff has become more intimate with the Common Core State Standards, the new report card has not translated into changes in behavior about grades by parents or students.

Changing to a standards-based approach to grading is a difficult adaptive change that should not be underestimated. Without a strong purpose message, transitioning to a standards-based approach to grading may prove difficult. Having a clear message from the onset may help in the planning and execution of changing the approach to a middle school report card. 
TRANSITIONING TO A STANDARDS-BASED GRADING MODEL

AT THE MIDDLE LEVEL: A CASE STUDY

JEFFREY S. SZYMCZAK

A Dissertation Submitted in Partial

Fulfillment of Requirements

for the Degree of

DOCTOR OF PHILOSOPHY

Department of Educational Administration and Foundations

ILLINOIS STATE UNIVERSITY

2015 
Copyright 2015 Jeffrey S. Szymczak 


\section{TRANSITIONING TO A STANDARDS-BASED GRADING MODEL}

AT THE MIDDLE LEVEL: A CASE STUDY

JEFFREY S. SZYMCZAK

COMMITTEE MEMBERS:

Dianne Gardner Renn, Chair

Lydia Kyei-Blankson

Guy Banicki

Neil Sappington 


\section{ACKNOWLEDGMENTS}

I would like to thank my committee, the cooperation of the school studied, Connie Smith, and all those who never doubted this paper would happen. Thank you to all the students and staff at Mooseheart Child City \& Schools, Inc. for your support over the past two years.

This is dedicated to all those who have been adversely affected by a teacher's grade and the teachers and school leaders who have chosen to improve their students' lives by changing their grading practice.

J. S. S. 


\section{CONTENTS}

Page

ACKNOWLEDGMENTS $\quad$ i

CONTENTS

TABLES $\quad$ V

FIGURES $\quad$ vi

CHAPTER

I. THE PROBLEM AND ITS BACKGROUND 1

Statement of the Problem 1

Shift to a Standards-Based System $\quad 2$

Grading at the Secondary Level 4

Challenges When Moving to a Standards-Based Environment 6

Purpose of the Study $\quad 8$

Research Questions 9

Definition of Terms $\quad 10$

Delimitations and Limitations $\quad 11$

$\begin{array}{ll}\text { Significance of the Study } & 12\end{array}$

II. REVIEW OF RELATED LITERATURE 14

$\begin{array}{ll}\text { Educational Reform Movement } & 14\end{array}$

Standards-Based Reform Movement 16

Governors' Summit 18

Common Core State Standards Movement of 2010

$\begin{array}{ll}\text { History of Grading } & 23\end{array}$

$\begin{array}{ll}\text { Grading Components } & 26\end{array}$

Product $\quad 27$

Progress 27

Process 27 
$\begin{array}{ll}\text { Standards-Based Approach } & 28\end{array}$

Implications for a Change to Standards-Based Grading 31

$\begin{array}{ll}\text { Professional Development } & 37\end{array}$

III. RESEARCH DESIGN 39

Methodology $\quad 39$

Research Questions $\quad 40$

Qualitative Study $\quad 40$

Case Study 41

Sampling Procedures $\quad 43$

School Site Selection $\quad 43$

District and School-Level Information $\quad 46$

School Overview 46

Within Case Sampling of Documents, Interviews, and Observations 47

$\begin{array}{ll}\text { School Structure } & 50\end{array}$

Report Cards at Wilderness Middle School 51

Data Sources and Collection Approaches 52

Interview Participant Selection $\quad 54$

Participants $\quad 54$

Interviews $\quad 56$

Data Analysis Procedures $\quad 57$

Ethical Considerations and Personal History $\quad 58$

Summary $\quad 59$

$\begin{array}{ll}\text { IV. FINDINGS } & 60\end{array}$

Theme 1: Creating Systemic Changes_-Possibilities and Challenges 62

Conceptual Challenges $\quad 63$

Logistical Challenges $\quad 64$

Theme 2: Challenges with Implementation $\quad 70$

$\begin{array}{ll}\text { Conceptual Challenges } & 70\end{array}$

Logistical Challenges $\quad 72$

Summary and Discussion of Major Findings $\quad 77$

iii 
V. CONCLUSIONS, IMPLICATIONS, AND RECOMMENDATIONS

Review of Purpose $\quad 80$

Review of Design $\quad 81$

What Has Been Learned $\quad 81$

Limitations of the Study 83

$\begin{array}{ll}\text { Conclusions } & 83\end{array}$

Conclusion 1: Have a Well-Defined Purpose to the New Report Card 84

Conclusion 2: Development-Bring the Community Along 86

Conclusion 3: Go All In - Resist a Hybrid Approach 87

Conclusion 4: Have a 3-5 Year Written Plan for Change 89

Conclusion 5: Employ a Pilot Program 90

Implications for School Leaders $\quad 91$

Recommendations for Further Practice 94

Concluding Remarks 95

$\begin{array}{ll}\text { REFERENCES } & 96\end{array}$

$\begin{array}{ll}\text { APPENDIX A: Letter of Consent } & 107\end{array}$

APPENDIX B: Observational Grading Protocol Framework 110

APPENDIX C: Wilderness Report Cards 112

APPENDIX D: Wilderness Seventh and Eighth Grade Learning Objectives 125

APPENDIX E: Interview Protocol 132

APPENDIX F: Survey Protocol 134

APPENDIX G: Principal Survey Protocol 136

APPENDIX H: Principal Letter of Support 138 


\section{TABLES}

Table $\quad$ Page

1. Observational Protocol Framework 49

2. Profiles of Respondents 56 


\section{FIGURES}

Figure

Page

1. Cycle of Improvement at Wilderness Middle School 


\section{CHAPTER I}

\section{THE PROBLEM AND ITS BACKGROUND}

There may be no symbol more iconic in American public schools than the report card letter grade. Receiving a letter grade from a teacher at the end of the quarter or semester is a rite of passage that has been the practice in education for nearly two centuries (Brookhart, 1994; Guskey \& Bailey, 2001; Marzano, 2000; Whitney, Culligan, \& Brooksher, 2006).

Current traditional grading practices often require teachers to compute an average for a student, apply that to a district grading scale, and assign a letter grade to each average. Students are then given this letter grade to represent learning over a specified period. In effect, the grade seems to have evolved into the scorecard for our teaching and learning environment.

\section{Statement of the Problem}

Traditional practices make it difficult to ascertain what the letter grade represents. Some letter grades often pose a blend of achievement, compliance, and improvement (Brookhart, 2011b). Grades are an imperfect proxy for learning. Guskey, Swan, and Jung (2011) stated, "Grades have long been identified by those in the measurement community as prime examples of unreliable measurement" (p. 53). Despite these limitations of grading, traditional grading typically demands the use of a letter or number. The trend of traditional grading practices could soon change. 
Beginning in 2014, under a new federal initiative in 46 states, the Common Core State Standards (CCSS) was implemented to provide a clear understanding of what is to be taught and learned. The curriculum is designed to deliver consistency in teaching of math and English. An examination will be applied by using identical standardized tests to evaluate student learning. Parents, students, counselors, and principals will soon face the task of trying to explain a reading or math grade of "A" when the student cannot show proficiency on the state standardized assessment.

The new CCSS assessments will uncover a problem in our current system. What will happen when scores on these new assessments do not correlate with a teacher's classroom grade? How will classroom teachers defend any discrepancies? Educators will need to apply the best practices in grading in order correlate results on local practices and state reporting. Future grading will likely need to be a measurement comparable to the developing new standards.

\section{Shift to a Standards-Based System}

National subject specific standards have been a part of the teaching landscape for over a half a century (Marzano \& Kendall, 1996). National organizations in language arts, math, science, social science, physical education, music and the arts have designed curricular standards. With 45 states originally agreeing to the implementation of the CCSS, it may require schools and districts to review present grade reporting systems. Current traditional grading practices include antiquated, unreliable, and inconsistent measures of student learning (Guskey et al., 2011). Creating compatibility between grades and a national assessment under the CCSS may become crucial (Council of Chief State School Officer's and Governor's Association for Best Practices, 2010). 
An assessment that measures growth within standards provides a logical description of what a student is to be measured against (Guskey, 2011). Converting to a standards-based system approach to curriculum and assessment, a change in our beliefs about grading will also become necessary (Reeves, 2007). In a standards-based approach to grading, the learner demonstrates what is to be mastered and is awarded a grade after showing evidence of mastery. Grades thereby represent an explicit level of achievement rather than the behaviors and disposition of the learner. The student's compliance, cooperation, and progress are not part of the letter grade that indicated a level of mastery (Guskey, 2011).

Despite mounting pressure regarding the limitations of traditional grading practices, making the change to a standards-based system of grading seems difficult (Brookhart, 2011b; Guskey \& Bailey, 2001). Marzano (2000) warned educational leaders that caution must be applied when moving from the old grading system to the new:

If a district or school wishes to make changes in current grading and reporting practices, then it is well advised to provide high logic for the new system along with a thorough accounting of the inadequacies of the old system. (p. 2)

Perhaps by moving the conversation to a standards-based approach to grading, focus can be on student learning (Brookhart, 2011a). Making the transition to a new system of grading can be so perilous that Doug Reeves (2009) used grading as an example in his book about leading change in schools. The chapter entitled "The Flywheel: Getting Short-Term Wins to Sustain Long-Term Change” (pp. 94-109) highlights the change in grading practice of one high school that became a turnaround school. Ben Davis High School's practices show the impact a successful change in a 
grading system can have on a school's culture.

Our schools have been organized to ensure attendance and compliance from students. This overreliance on attendance and compliance, rather than learning, has hampered engagement and student productivity (Schlechty, 2005). A standards-based approach to grading requires teachers to base grades on measurement against specific criteria. Learning outcomes are specifically defined as what is to be mastered and at what grade level. Standards for learning like these have already been adopted in the Common Core State Standards in math and language arts.

Standards-based grading also helps eliminate the omnibus grade that attempts to measure many elements in learning at once, such as product, progress, and process. It narrowly focuses on academic factors only. Non-academic factors, such as homework, work habits, responsibility, attendance, and attitude, are reported separately (Marzano, 2000).

These non-academic factors are frequently not part of the elementary grading landscape. Parents of students in the primary grades receive written feedback, which is often more descriptive and accurate than grades (Guskey, 2006; Guskey \& Bailey, 2001). A parent of a kindergartener often knows if a child understands colors, numbers, and letters. The elementary level reporting system is clear, non-ambiguous, and timely. Communication between home and school becomes less apparent as a child ages (Brookhart, 1994).

\section{Grading at the Secondary Level}

For many, when reaching the sixth grade, grades are typically represented by a single letter or number. While this change is considered an acceptable practice, it does a 
poor job of communicating learning to families. A more efficient way to communicate with families and students may be provided by a standards-based approach.

The principles and practices that enable schools to successfully navigate the change from traditional letter-grade reporting to standards-based grades are largely unexplained by researchers, particularly at the secondary level. Examining teachers' impressions while making the change to standards-based grading has implications for schools. Johnson (2001) noted that, "Changing to standards-based report cards may mean that teachers have to literally change the way they think when assigning student's grades" (p. 1).

While scholarship exists about the effectiveness of standards-based grading at the elementary level, research at the middle and secondary levels is scarce. Teachers at the secondary level have long employed a system of grading that has been described by many as capricious and arbitrary (Brookhart, 1994, 2011a; Guskey, 2004, 2011; Marzano, 2000; Reeves, 2011). Teachers have included extra credit, practice in the form of homework and the use of zeros to assure compliance in the classroom. These practices can lead to inflated grades and increased numbers of students who are identified with disabilities (Jung \& Guskey, 2007).

Grading practices at the middle school level still tend to center around accumulating points or using mathematical averages. For example, 500 points for the quarter are turned into a letter grade; 380 points would translate to a B on the report card. Elements of product, progress, and process are often combined into a single letter grade at the end of each quarter or semester (Guskey, 2004a; Marzano, 2001; O'Connor, 2007). 
Understanding the change and how we approach a change from the traditional model of grading to a standards-based approach could be of benefit to the thousands of secondary schools contemplating on making this significant move (Erickson, 2011; Hargreaves \& Fullan, 2009; Reeves, 2011). Studying a middle school that has successfully navigated the change process and reporting practice to a standards-based model should afford assistance to others embarking on this change.

The middle school setting tends to allow for a more collaborative environment by affording teachers regular meeting time to discuss the needs of a common grouping of students called a team (Grenda, 2011). Despite this apparent advantage, locating middle schools that have been using a standards-based approach to grading has been difficult. Locating studies about these schools is harder still. An exhaustive search in April 2012 indicated that the practice of standards-based grading in Illinois middle-level schools is very rare. So how do educators in the middle school setting address the challenges and then describe experiences of moving from a traditional grading system to a standardsbased one?

\section{Challenges When Moving to a Standards-Based Environment}

At its simplest, the practice of report card grading is a communication tool used by teachers to convey to students, parents, and others how a student is doing in a particular class over a given time period (Brookhart, 2011b). Grading provides information to parents, to other schools, and to the student.

The heart of this study was identifying the challenges and benefits for a middlelevel school that was moving to a standards-based system. It was designed to investigate the complexities and variables of implementing the change between grade reporting 
systems. Colby (1999) stated that the standards-based reporting system increased student learning: "Primary emphasis changed from what is taught to what students learn. We were able to make clear decisions about what we needed to teach, how and to whom we would teach it, and how we would assess it" (p. 53).

Under our present system, a student's grade often includes product, progress, and process components (Guskey, 2011). The teacher in a standards-based grading system is interested in the level of mastery as measured against a particular standard. Susan Brookhart (2011b) stated, "Standards-based grading is based on the principle that grades are not about what students earn; they are about what students learn" (p. 12). What is it that a student knows or can do at the moment in time? Extra credit, homework, and points earned are no longer part of the equation in calculating the grade for the class.

In a standards-based approach to grading, learning is at the front end. Explicitly stated expectations help reduce teacher bias and require an assessment of learning as measured against a predetermined standard. Examples such as "the student can count by two up to 30 " or "the student can identify primary colors" are easily recognized in most primary school report cards.

Implementation of a standards-based approach can change the way schools function, but not all of the changes will be received positively (McMunn, Schenck, \& McCloskey, 2003). Grade inflation will be revealed when compliance and extra credit values are removed from the grading process. Schools will likely see a dip in state test scores that are reported to the public, and parents will need to be convinced of the longterm benefits of a standards-based approach. Doug Reeves (2007) stated, "Those who implement change in assessment, grading, and professional practice and policy risk not 
only confrontation, but also unpopularity, social isolation, public humiliation, and ultimately, even their livelihoods" (p. 9).

The shift to a standards-based grading method presents a significant challenge for educators, but it is one that others have successfully navigated for years (Marzano, 2010). Public accountability requires schools to reflect student learning. Winger's (2005) work shows that traditional grading systems are not to be particularly accurate or effective at promoting learning. With public accountability measures only increasing since $A$ Nation At Risk was published, the study of how schools transformed reporting was very relevant.

Successful transitions to standards-based grading have been accomplished. Standards-based grading has been used in the Canadian provinces for many years, but only the state of Kentucky in the U.S. is presently in the process of a statewide reportcard reform movement (Guskey et al., 2011). The process of transitioning teachers and parents in Kentucky to a new system of grading has been slow and measured. Work began after the CCSS was adopted by Kentucky in 2010, and only three pilot districts were selected to participate in 2011-12. Plans include up to 20 additional districts in 3 to 5 years. A unique aspect of the Kentucky initiative is not only that it is statewide, but it also is changing $\mathrm{K}-12$ at the same time.

\section{Purpose of the Study}

Scholars in the area of assessment and learning have long supported a reorganization of traditional grading practices (Brookhart, 1994 \& 2011b; Guskey \& Bailey, 2001; Marzano, 2000; O’Connor, 2002/2009; Reeves, 2011; Wormeli, 2006b). The purpose of this study was to uncover a different way to assess student learning at the middle level by breaking from the traditional letter grade system and utilizing a 
standards-based approach to grading.

An exploration of one middle school that successfully moved to a standards-based grading practice might help reveal the challenges and issues teachers are faced with while making the transition. Knowledge of the resources needed, time allocation, and leadership roles in making the change may help others attempting this type of change.

The culture surrounding grades requires examination. An imprecise system exists in which grades are improperly used as a scorecard of learning. Educators must explore new ways to assess student learning that more accurately reflect what students know and can do. While not an easy change, the Common Core State Standards provide educators with a unique opportunity to improve assessment measures and grading.

\section{Research Questions}

This study was mainly concerned with the move from traditional grading practices to those of standards-based grading; investigating how the change occurred was also the focus. The primary question guiding the research for this study was: How do middle school educators describe experiences when moving from a traditional grading system to a standards-based grading system?

The following sub-questions were also addressed:

1. How do educators describe the change process from traditional to standardsbased grading?

2. What are the major challenges and successes educators face while changing to a standards-based reporting system?

3. What impact has standards-based grading had on teaching and learning in the school? 


\section{Definition of Terms}

While several of these terms may be familiar to the reader, they are defined to remove ambiguity for this study.

Common Core State Standards - Common Core State Standards is presented as a proper noun. The standards are the program approved by the state that wanted to qualify for federal money in 2010. The states joined a consortium to pool dwindling state resources for the development of new learning standards in mathematics and English language arts (Council of Chief State School Officers \& National Governors Association for Best Practices, 2010).

Standards-based - Standards-based is a term used to describe a particular curriculum goal written by a state or national organization. It is commonly measured through a state assessment that uses the following terminology: meeting, not meeting, or exceeding.

Standards-based education-Standards-based education is learning that takes place under a set of previously defined benchmarks. Traditionally, these standards have been established by statewide decision makers and subject-specific experts.

Standards-based grading-Standards-based grading is a term used to describe the practice by a teacher or school of measuring student abilities in the classroom in comparison to a set of standards. A grade is summed up against the criteria for a particular standard. Behaviors and effort are reported separately. A student is graded only on what he/she knows or can do. Category headings can vary, but include descriptors such as adequate, competent, exceeds, exemplary, making progress, meets, proficient, satisfactory, and secure. 
Traditional grading - The term traditional grading is used to refer to a point or percentage system resulting in a single letter grade representing any and all components of learning, including some conditions of learning such as attendance. It does not have a consistent definition of which components comprise the grade, but it usually includes compliance, scholastic achievement, and attitudes. Grades are often displayed by a number between $0 \%$ and $100 \%$, or $\mathrm{A}, \mathrm{B}, \mathrm{C}, \mathrm{D}, \mathrm{F}$, or I.

\section{Delimitations and Limitations}

The researcher is not stating that the findings are transferable or right for all educators attempting to move to a standards-based grading model. As with most qualitative research studies, a limitation of this study is the propensity to draw conclusions too broadly. The relationship of one experience to another may not be applicable to future experiences (Seidman, 1991; Stake, 1995).

This study may apply to some or many middle-level schools only. Both the participants and the task considered may not be relevant to larger populations or similar functions. Studying a school and a particular task, such as grading, involves considerable complexity. The findings of this study may not be right for every school that intends to undertake a grade reporting change. A successful study should provide valuable information for schools and districts that intend to undertake the change from traditional grading to one of the standards-based practices. If the practice of standards-based grading can become ingrained in the teaching and learning practices at one middle-level school, is it replicable to other middle-level schools?

In a study such as this, some ambiguity and complexity is included so arriving at a universal conclusion is unrealistic. The primary benefit of this study is the conceptual 
description of how educators can make this change in grading practices. This study's new information can be useful in guiding others to the research and practice about a middle school's transition to standards-based grading.

\section{Significance of the Study}

This research focused on a middle school's change processes regarding the grading of students. Change in grading is often met by educators and parents with resistance. Current research indicates that changing the grading system is no small task (Guskey 2009b; Marzano, 2006). The results of this study may contribute to the knowledge regarding changing to a standards-based grading system in middle-level schools. Findings may describe the changes required that successfully institutionalize that new grading practice for teachers. These results may be beneficial to researchers, parents, students, teachers, and principals.

While many elementary schools have measured student performance against standards for decades, there is little evidence that middle-level schools employ the same method (Marzano \& Kendall, 1996). The research about middle-level grading practices is on the increase. The results of this case study may reveal a pattern or strategy that can be replicated by a middle school attempting to move to a standards-based grading practice.

In the next chapter, this study will reveal current knowledge on the history of grading, standards, and the implications for systemic changes in schools. Chapter III will outline the case study methodology used for this dissertation. Sampling procedures, including the selection of the school studied and participants interviewed, will be explained. In Chapter IV, the findings will be unveiled using a framework of two specific 
themes. Finally, in Chapter V, what was learned is shared using a 5-point conclusion. The paper ends with some implications for school leaders and researchers. 


\section{CHAPTER II}

\section{REVIEW OF RELATED LITERATURE}

This chapter systematically reviews the scholarship related to schools switching from traditional to standards-based grading practices at the middle-level. The review provides the background necessary to investigate grading, standards, and the complex implications for educational leaders who plan to move toward a standards-based grading system. This review is organized into three major sections. The first provides an overview of the political framework surrounding the standards movement during the past half-century. An understanding of the roles of assessment and the modern standardsbased movement is necessary in order to have any possibility of changing an educational icon such as grading. The second section is a review of the history of grading practices and the role those assessments have played. The grading system most familiar has been prevalent for well over two centuries in America. Is there a better way to report achievement levels that communicate and measure student learning so that no child is left behind? The final section focuses on the framework of change and implications for educational leaders who are creating a change in grading practices.

\section{Educational Reform Movement}

The United States' national response was swift and significant to the perceived military threat of the launch of Sputnik by the Soviet Union in October of 1957. The National Defense Act of 1958 was the country's reaction to that type of social and economic challenge. The space race set off panic in the defense community that quickly 
pointed the finger squarely at an outdated and inadequate national math and science curriculum. Since the Sputnik launch, public education has often been the scapegoat for our country's social and economic ills (Klein, 2003).

In this post-Sputnik era, President Lyndon Johnson signed the Elementary and Secondary Education Act (ESEA) into law in 1965. The ESEA was another attempt to provide an educational answer to the social problems facing America. While the goal of the ESEA was to help equalize educational opportunities, the United States remained segregated by policy and practice in how it provided for its children. In the end, the ESEA became a staple piece of legislation used in creating a framework for special education laws. Decades later, this framework led to the No Child Left Behind Act (NCLB) of 2002 and later developed into The Race To The Top (RT3) program and the Common Core State Standards introduced in 2010.

Between the first release of the ESEA and the most recent reauthorization in 2007, a 1983 document entitled A Nation At Risk: The Imperative for Educational Reform (ANAR) was released by the U.S. Department of Education's Commission on Excellence in Education (NCEE). Educational movements often have a definable action that provides the political motivation for change. The document concluded that the very wellbeing of the United States of America was in jeopardy, both economically and militarily, because the public schools were not preparing students for the global market. Our nation's very security would depend on fixing problems in education (National Commission on Excellence in Education, 1983).

The U.S. Department of Education was not responding to the crisis in the public schools (Hamilton, Stecher, \& Yuan, 2008; Joseph, 2001). However, not everyone agreed 
with the conclusions noted in the ANAR report. In The Manufactured Crisis (Berliners \& Biddle, 1995), it was argued the educational crisis was a ruse to divert attention from the social and economic problems of the mid-1980s. The belief was that those conservatives who favored a voucher system were politically motivated to attack public education. In a voucher system, parents are given a voucher that is used to purchase part of their child's education. Vouchers can be used in any qualifying school, public or private. Voucher systems are one way to use public dollars in education for private schools. This underpinning has been a consistent theme for those trying to reform public education since ANAR appeared in 1983 (Kohn, 1992; Kozol, 2005; Popham, 2004; Ravitch, 2010; Spring, 1997, 2010). However, regardless of the motivation, a new movement was created to address concerns raised by ANAR.

\section{Standards-Based Reform Movement}

ANAR states the goal of education is to instill civic virtue and provide equal educational opportunities through universal access. All students would come to school ready to learn and reach universal proficiency. According to the 18-member NCEE panel, U.S. graduation requirements needed strengthening, students needed more time in school, and teacher salaries should be increased and include 11-month contracts requiring a more rigorous measurable standard required. The thought was that these recommendations would lead to more attention given to attendance and compliance issues along with the concept of learning standards and the standards-based movement.

The contention of ANAR was that standards created in the 1970s had low student expectations, resulting in poor student performance and grades that were an indicator of progress. According to the ANAR document, "Grades should be indicators of academic 
achievement so they can be relied on as evidence of a student's readiness for further study" (NCEE, 1983). While it is difficult to measure teachers' grading practices, states reacted in the mid-1980s by raising graduation requirements, increasing teacher certification standards, and increasing the amount of time students attended school.

As ANAR renewed the debate over the concept of voluntary national standards, the philosophy to centralize or decentralize became a political question to be answered by national policy (Marzano \& Kendall, 1996; Peterson, 2010; Ravitch, 2010). When ANAR referred to "a rising tide of mediocrity" (p. 3), it served as the tolling of a bell to get the attention of the business and education communities (Massell, 2001). ANAR alarmingly noted that a change was needed in the structure of the public education system. If education was the engine driving our economy, it needed retooling quickly. ANAR blamed the loss of manufacturing sector jobs with an outdated school system (DarlingHammond, 2010; O’Connor, 2009).

In 1986, a document by the Carnegie Forum, A Nation Prepared: Teachers for the $21^{\text {st }}$ Century (1986), attempted to create subject-specific standards. The definition of standards came to mean, "What do we want students to know and be able to do?" (Ainsworth, 2003, p. 22). Unfortunately, in the early development of standards, there was little co-ordination, and researchers found over 200 standards and 3,000 benchmarks needing to be taught (Marzano, 2006). Mandated content required at least $71 \%$ more instructional time in the classroom (Marzano \& Kendall, 1996). While the new Common Core State Standards are more focused with an emphasis on both college and career readiness, it remains to be seen how they may change grading processes. Efforts to 
implement standards in the past have had little notable positive impact on grading practices (Kohn, 2011).

\section{Governors' Summit}

Knowing the states have the constitutional responsibility for providing education to children, President George H. W. Bush used the Governors' Summit on Education, held in Charlottesville, Virginia, in 1989, to begin framing the question of standards on a national level. After the summit, for the first time in our history, education became a national issue that was controlled at the state level. Using the national economic and defense interests, the Governors' Summit began defining our educational priorities. Local control was not working for a nation at risk. The Governors' Summit was an early attempt to nationalize educational standards. Unveiled by President George H. W. Bush, the America 2000 program once again jumpstarted the modern standards-based reform movement. The summit, providing the political support for change, and paved the way for providing the funding needed to write what eventually became the Goals 2000 Program under the Clinton Administration in 1994.

The first formal attempt to complete a rewrite of standards was when the National Council of Teachers of Mathematics (NCTM) drafted a national curriculum in 1987. When published in 1989, this document redefined what it was students should know and when students should know it. Rote memorization was replaced by a problem-solving strategy format (Diegmueller, 1995). The new mathematics standards were not without

critics, but they were adopted before other subjects were released (Marzano \& Kendall, 1996). Almost immediately, the development of more rigorous standards started. The newly released NCTM: An Agenda for Action (1980) sparked a brief debate. The 
predecessor to modern standards, the report discussed how math should be taught. Its wide support of the use of calculators and a problem-solving approach eventually spelled doom for many of its recommendations (Klien, 2003).

Between 1983 and 1994, development of content standards by associations, consortiums, committees, and national councils was occurring in many subject areas. Assessments about whether these standards were attained lagged behind for decades (Marzano \& Kendall, 1996; Peterson, 2010). It would require the accountability movement of the 1990s before assessment development made significant gains (Klein, 2003). The new version of standards clarified both expectations and performances but still lacked specifics and led to political debates about what should be included for each subject area (Ainsworth, 2003; Barton, 2009; Cherniss, 2008; Hamilton et al., 2008; Pollack, 2009; Meier \& Wood, 2004; Peterson; Schmidt, Houang, \& Shakrani, 2009).

After heated debate and the U.S. Senate vote of 99-1 against the history standards, most standards were then written to avoid any controversy (Marzano \& Kendall, 1996). Missing were concrete descriptors and references. What was to be learned was often not clearly stated as measurable skills. Therefore, ambiguity helped standards advocates avoid controversy and became the preferred policy when creating new standards (Ravitch, 2010). Here is an example of one Illinois middle school standards:

Understand the roles and interactions of individuals and groups in society. Explain how social institutions contribute to the development and transmission of culture. (Illinois State Board of Education, Illinois State Legal Statute 18.B.3b) Understand the roles and influences of individuals and interest groups in the political systems of Illinois, the United States and other nations. Describe roles and influences of individuals, groups and media in shaping current Illinois and United States public policy (e.g., general public opinion, special interest groups, formal parties, media). (ISLS 14.D.3) 
Reporting how well a student understands complex objectives such as ISLS 14.D.3 is no small task. Individual state adoptions began in 1994. While the question "What do we want students to know?" could be answered, the instrument to measure what students know was still years away. As Ravitch (2010) stated, "Without specificity and clarity, standards are nothing more than vacuous verbiage" (p. 20).

The original intent for creating a voluntary national curriculum was to coordinate what was being taught from Alaska to Florida. While adoption of a national curriculum remains unlikely, accountability may force individual states to cooperate in adopting new guidelines. The federal government continues to acknowledge that state and local control is paramount in the creation of the American public education system. However, this acknowledgment has not prevented the federal government from strengthening its role in public education since 2002 .

Forty-nine states developed their set of standards, which were categorized by outcomes, goals, expectations, learning results, or standards beginning in the 1990s. By 2008, the final state, Iowa, joined the national standards movement (O’Connor, 2009). While the states have long maintained a constitutional obligation to provide a free and appropriate education to all children, the federal government continues to attempt to provide the monetary incentives to embrace a national curriculum (Marzano \& Kendall, 1996).

Higher level thinking skills are a requirement of the modern economy and are no longer just another path to a better job. The past paradigm of schools allowing some students to succeed and some to fail is no longer acceptable (Darling-Hammond, 2010). The Governors' Summit first attempted to generate the political clout to create a more 
centralized curriculum to meet student needs in the job market. While the expectations have certainly changed since the summit, the goal has not.

\section{Common Core State Standards Movement of 2010}

In 2010, the Common Core State Standards were released in an attempt to nationalize the student learning experience. In 2014, the PARCC and Smarter Balanced assessments are going into effect. Perhaps the CCSS will deliver on the promise of standards that are fewer, clearer, and higher. However, early criticism of the CCSS cautions that they do not guarantee an increase in rigor or fundamentally change public schooling (Porter, 2011). In June 2010, the mathematics and language arts core learning standards were released after a 6-month review process. The core standards were seen as an attempt to nationalize the curriculum due to the collaborative nature through which they were created (Ravitch, 2010). A consortium of states banded together to save time and resources by creating a voluntary set of standards.

These next generations of K-12 standards attempted to address the $21^{\text {st }}$ century learner. The hope was that better preparation for students would lead to more success in college and the workplace. CCSS focuses specifically on what a child knows or can do. Goals or specific strategies are intentionally avoided. An integrated model of reading encourages a more student-centered learning experience. The new standards require students to reflect on what they read and to personalize the reading experience.

According to the Association of Supervision and Curriculum Development web site as of 2012, 45 states had agreed to the new CCSS.

While the creation of standards and accountability was still a purview of state and local government, NCLB was a law that included the federal government as a monitor of 
both standards and accountability. Assessment was a tool that measured each state's curriculum (Peterson, 2010; Popham, 2004; Ravitch). Severe sanctions could occur against local school districts that failed to meet target scores for their schools. Federal law under NCLB created a system where most school would be classified as failing by 2014.

The directive from the Obama administration, unveiled by Secretary of Education Arnie Duncan, is called Race To The Top (RT3). It was introduced as part of the American Recovery and Reinvestment Act of 2009 (ARRA). States competed for 3.4 billion dollars in federal funding through a grant-writing program. One of the most significant changes in RT3 is its requirement that $50 \%$ of a teacher's evaluation will be determined by student achievement. The student growth model measures student achievement at the beginning and end of the school year and holds the teacher accountable for the achievement growth of his/her students. The rationale for the RT3 program is spelled out in its purpose statement by the U.S. Department of Education:

Adopting standards and assessments that prepare students to succeed in college and the workplace and to compete in the global economy; Building data systems that measure student growth and success and inform teachers and principals about how they can improve instruction; Recruiting, developing, rewarding, and retaining effective teachers and principals, especially where they are needed most; and Turning around our lowest-achieving schools. (United States Department of Education, 2009)

Interestingly, the method the federal government plans to use to achieve these goals is similar to what many teachers use in grading student performance. Through RT3, the federal government wants the states (and educators) to follow a more prescribed method of education within the conventionally locally controlled school boards. The federal 
government is still seeking compliance, and ANAR still exerts influence after a quarter century.

After all these years, nationally defined standards have evolved into a more nationally directed curriculum (Ravitch, 2010). However, while curriculum efforts have changed, grading practices have remained relatively stagnant (Guskey, 2011).

\section{History of Grading}

Marzano (2003) noted that the system of classroom grading is well over 100 years old, with little or perhaps no scientific support for its continuation. Teacher grading practices are in large part a system of handed-down practices with little or no consistency (Brookhart, 1994). Since the 1983 ANAR report was first issued, there has been much development in the area of learning standards, but very little change in how teachers measure those standards. It remains common practice to use a single letter grade to represent learning at the secondary level (Guskey, 2004b; Marzano 2001; O’Connor, 2007; Peterson, 2010). Despite the evidence that solid quality assessment practices can raise levels of a student's performance, classroom teachers are still not promoting effective practices for grading (Black \& Wiliam, 1998; Hattie, 2009; Marzano, 2003; O’Connor, 2009; Stiggins, 2002).

What has not seemed to change much in the past 30 years is the way secondary educators tend to grade (Ardovino, Hollingsworth, \& Ybarra, 2000; Butler \& McMunn, 2006; Erickson, 2010; Guskey, 2006; McNunn et al., 2003; Shepard, 1995; Stiggins, Arter, Chappuis, \& Chappuis, 2004; Wagner \& Kagan, 2006). This stagnancy in grading practices reflects, in part, how we structure our schooling. Although our present system 
dates back to Yale University in 1780 (Marzano \& Kendall, 1996), it was a tool expertly designed for an age yet to come.

Schools of the early $20^{\text {th }}$ century were structured much like the businesses of the industrial revolution. If mass production built the steam engine, then why not apply it to the world of education with equal effectiveness? Educators have created a system of annual checkpoints and prerequisite course elements that moves students along from one year to the next, similar to that on a manufacturing assembly line.

For those who followed the work of Frederick Winslow Taylor (1916/2005), efficiency could be gained in a system that was scientifically managed. A school system that could eliminate ambiguity and subjectivity in students' work would help create the division of labor needed in an industrial society. Teachers could accurately "sort and sift" students who would be relegated to physical labor and those who would be destined for further education and white-collar work.

The original 4.0 grading scale that began at Harvard in approximately 1877 and classified students into "divisions," would morph by 1897 into the system we are familiar with today. Mount Holyoke began using a 5-letter system with "A" meaning excellent and "E” signifying a failing mark (Brookhart, 2004; Marzano, 2000; O’Connor, 2005; Reeves, 2008). In the early 1900s, elementary teachers continued to use anecdotal progress evaluations to assess students; high school teachers began using percentages as a way to document student progress in specific subject areas. These scales helped to quantify teachers' decisions made about student placement into college or the workplace. Secondary schools began investigating and researching changing these grading practices as early as 1912 (Brookhart, 2004; Whitney et al., 2006). 
Shortly after World War I, teachers began using both a 3-point (excellent, average, and poor) and 5-point (A, B, C, D, or F) scale. By 1930, grading on a curve became a common practice. Students were placed in order based on performance or proficiency (Marzano, 2007; Wagner \& Kegan, 2006). While the research about teaching and learning has changed and improved the profession significantly, there is little evidence that teachers' grading practices have changed in the past half-century (Marzano, 2006).

While the practices employed today can harm students, present grading systems will not easily become uprooted and be replaced with a more accurate system (Brookhart, 1994; Erickson, 2010; Guskey, 2004a; Marzano, 2000; Romanoski, 2004; Whitney et al., 2006). Low grades can result in increased special education placements and diminished student interest in learning and thinking (Jung \& Guskey, 2007; Kohn, 2011). According to the Alliance for Excellent Education, a Washington-based policy and research organization, failing grades cost the United States $\$ 330$ billion in purchasing power in 2007 (Reeves, 2009). Students who drop out are often relegated to the lowest paying jobs.

There is still often no relationship between what is expected from a student and what is measured in the classroom (Stiggins, 2002). As teachers become more competent with learning standards, it is unclear whether they will have the will to change the century-old practices of grading.

Ineffective practices have not improved learning (Guskey et al., 2011). Grades often offer too much information through a single symbol (Winger, 2005). Despite evidence and research about school reform, the areas of assessment and grade reporting 
have not changed significantly in the last 50 years (Brookhart, 1994; Grant, 2007;

Guskey, 2009a; Marzano, 2006; O'Connor, 2009; Reeves, 2004; Wormeli, 2006a).

Grading practices continue to be a capricious and arbitrary attempt to measure evidence of student learning (Brookhart, 1994; Guskey \& Bailey, 2001; Marzano, 2000;

O’Connor, 2007, Wormeli, 2006b).

One area of change that did occur in the past decade is how teachers calculate grades. By the mid-1990s, computers aided in calculating number grades and computerized grading became the norm. In addition, in the middle of the first decade of

the $21^{\text {st }}$ century, we saw adaptation of computerized grade books that are transparent and are viewed by students and parents online.

\section{Grading Components}

Grades still reflect an inconsistent randomness that is usually based on the philosophy of the instructor (Guskey \& Bailey, 2001; Marzano 2000; Marzano, 2006; Whitney et al., 2006). Effort, homework completion, general attitude, participation in classroom discussion, proper class attire, bringing the proper materials, and compliance with the teacher are all elements that teachers often rely on as part of a grade each term.

Despite little evidence for continued use as an efficient and effective practice, these traditional grading practices have been a "third rail" in education (Erickson, 2011). According to Kohn (2011), criticism of grading is a constant, going back to the 1930s. Changing arbitrary grading practices and moving to a standards-based report card takes courage (Guskey, 2009b, 2011; Marzano, 2001; Marzano \& Hefleblower, 2011). If we hope to succeed in this endeavor, we have to evaluate the usefulness of traditional structures of teaching. 
In the present grading system at most schools, teachers continue to include nonacademic behaviors in the child's final grade. School system reliance on measuring compliance and attendance does not meet the needs of learners in the $21^{\text {st }}$ century (Schlechty, 2005). Grades should communicate to parents, students, and other educational institutions a level of mastery of the content that has been achieved by the students (O'Conner, 2002; Reeves, 2004; Wormeli, 2006a).

Traditional grading is a complicated mix of past practice, tradition, and individually defined expectations. While no perfect system likely exists, grading systems must include clarity of purpose when they are designed (Guskey, 2011). It usually involves three elements that become one dimensional as they become configured into a single letter grade.

Product. When achievement is measured against predetermined goals and objectives, we can begin to rely on consistency in grades. Instead, "the state's educators, and state's citizens, truly do not know what's going to be assessed each year" (Popham, 2004, p. 79). This component should be a direct reflection of what the student knows or can do.

Progress. Since grades are often teachers' shorthand about a student's performance over time, they can be fraught with errors. Often, the average score for the period is what gets reported on a report card. A weak beginning may doom a student's chance for a passing grade in the class. Missing assignments due to a family crisis in the middle of a term may result in a mathematically unrecoverable low grade.

Process. Process includes items such as effort, attitude, homework completion, note-making, and participation. A high degree of subjectivity exists in evaluating the 
learning process, and this can be manipulated by the instructor (O'Connor, 2005). Other factors than student academic achievement, such as effort, compliance, attendance, culture, and behavior, often enter into a grading decision (Adams \& Kirst, 1998; Berridge, 2006; Guskey 2004a; Marzano \& Kendall, 1996). For students who "play school" well, this opportunity to inflate a grade is real. If a teacher uses the grading process to attain compliance from students, it will often not have much to do with the learning process.

Routinely, grades are still used for sorting students for grouping, motivational use, and a delayed form of feedback. Traditional grading tends to diminish interest, reduce the quality of student thinking, and create a system where students prefer the easiest tasks (Kohn, 1998, 2011).

What are needed are systems that assist and promote the learning process. Winger (2005) stated, “Once we have clarified what knowledge, skills, reasoning, and connections we believe are essential in our classrooms, we can choose components based on this essential learning on which we will base our grades" (p. 62). Ironically, how we grade in the future may need to look more like the way we graded in the past.

\section{Standards-Based Approach.}

The anecdotal progress evaluations of the late 1880s may be the answer in structuring today's classroom grading procedures for the high-stakes tests required by RT3. Descriptive feedback, such as that found in many of the standards-based reporting formats, provides more specific information than traditional grades (Marzano, 2000).

The transformation of moving to standards-based grading at the secondary level will require risk-takers, problem-solvers, and massive amounts of collaboration 
(Leithwood \& Steinbach, 1991). School leaders likely will have to transform their philosophy and beliefs before they can transform their schools. If the teachers' classroom curriculum, instruction, and assessment are not standards-aligned, it is probable that grading practices will not be either (Marzano, 2000). The result may be students who do well on their report card, yet fail to meet proficiency standards set forth by the state on high-stake tests.Creating a system of grading to best meet the needs of secondary school students is not a simple undertaking (Marzano, 2006; Yung \& Guskey, 2006). Grades are used to evaluate student work, to motivate, serve as a transaction for student work, as a method for promotion and retention, and as a communication tool (Brookhart, 2004).

It is noted that grading alone does not improve student learning (Marzano, 2000). The Hippocratic Oath begins, "First, do no harm." Perhaps we should follow the same advice when grading. Traditional purposes of grading include, but are not limited to, communication to parents regarding the progress of student learning, feedback to students for use in self-evaluation, and incentives for students to learn (Stiggins, 2001).

Traditional systems also use grades to help identify and select students to enter appropriate programs, like special education and gifted, and to exit grade levels (Brookhart, 2004; Guskey, 2002; Guskey \& Bailey, 2001; Jung \& Guskey 2007; Marzano 2000, 2006; Marzano \& Kendall, 1996; O’Connor, 2002; Reeves, 2004). These uses are founded on the assumption that teachers' grading practices are reliable, consistent, and valid; yet educators' grading methods vary widely, often within the same grade, school, or district (Marzano, 2000).

When unclear expectations and subjectivity collide, the results for students can be devastating (Brookhart, 2004; Erickson, 2010; O’Connor, 2002). Schools in America 
should be places where children acquire the tools necessary to get ahead and improve their lives. When schools crown "winners" and "losers" through competitive grading practices, such as grading on a curve or valedictorian programs, we do harm (Romanoski, 2004). Competitive grading practices may also provide a false sense of success for the students who earn them. Success in school does not always translate outside the organization we call school. The concept that competition creates innovative products in the marketplace and will bring out the best in students is not grounded in research (Kohn, 1992, 2011).

It is when we define competency through the use of standards, and then assess the progress against those standards, that we can objectively begin helping students (Guskey, 2009a; Marzano, 2006). We need to root out the use of nonacademic components in grading practices, such as zeros and poor behavior in class (Berridge, 2006; Brookhart, 2004; Guskey, 2006, 2011; Marzano, 2006; O’Connor, 2007; O’Connor \& Wormeli, 2011; Reeves, 2004; Wormeli, 2006a). It is important that we begin working with practitioners, students, and parents to educate them about standards-based grading practices. Until we begin to measure what students actually know and can utilize, we will not fully engage learners in the educational process (Deddeh, Main, \& Fulkerson, 2010; Marzano, 2000, Wormeli, 2006a).

The goal of a standards-based grading system is to communicate to the parents, students, and educators the achievement reached by an individual as measured by predetermined specific grade-appropriate standards (Berridge, 2006; Marzano \& Kendall, 1996). The standards-based movement may be more accurately referred to as the standards-referenced system, because it measures students in relation to known individual 
performance standards. While standards-based education is not perfect, it may be the best means to clarify what we want students to know.

Changing to standards-based grading is not a journey to take alone or without support (Deddeh et al., 2010; Marzano, 2000; Schlechty, 2005). Standards-based grading practices incorporate solely summative assessments; an adjustment period will be needed for everyone involved. In addition to teachers and parents, those students who rely heavily on extra credit or homework completion to bolster a grade will need support and alternate systems put in place for a smooth transition.

Deddah et al. (2010) found that students with a traditional "C" grade had standardized scores ranging from $47 \%$ to $94 \%$, too wide a range. Grades in the classroom often do not correlate with standardized that results (Marzano, 2000). This disparity must be eliminated without harming learners. The individuals in schools who are most responsible for creating an environment for a change of this magnitude are the principals and superintendents (Marzano, 2003). Changing the system of grading is not for the timid and requires special knowledge, training, and expertise. It is a complicated change that needs to be thought through by educational leaders.

\section{Implications for a Change to Standards-Based Grading}

Diagnosing the change that is needed and then working together to learn together is a complex process, but one that enhances that learning capabilities of everyone, including leaders (Heifetz, Linsky, \& Grashow, 2009). A transformational principal, a principal who works to promote grading-practice reform, must be acutely aware that changing to a standards-based grading system is a double-loop learning activity that will involve a commitment to ongoing improvements that cause us to question again and 
again (Argyris \& Schön, 1978). The change will be complicated by long-held organizational views adhered to by the teachers, students, and parents. The change process must be undertaken with great care and in a collaborative manner. Organizational traits that are similar to those found in schools with distributive leadership characteristics may provide the best environment to support complicated changes in a topic like grading (Grenda, 2011).

This change is more than simply modifying the existing system that teachers have been using. Moving toward a grading system that is new to parents, students, and teachers is difficult and involves a new understanding of education based on a new logic. As Marzano (2000) stated,

If the district or school wishes to make changes in current grading and reporting practices, then it is well advised to provide a strong logic for the new system along with a thorough accounting of the inadequacies of the old system. Proposed changes must be communicated to all interested parties: educators and noneducators alike. Additionally, the proposed changes should be well thought out and well tested before they are implemented on a wide scale. (p. 2)

Guskey (2005) and Heflebower, Hoegh, and Warrick (2014) described a blueprint for developing a change to standards-based grading. Identify the purpose of the report card, then what is expected to be learned throughout the change and when it is to be mastered. Ask yourself, what is the purpose of grading? With whom is the teacher communicating with through grades?

The new Common Core State Standards curriculum may help make this process easier. It unburdens schools, districts, and individual states from the responsibility and resources needed to create new standards. Focus can then be placed on establishing performance indicators using student work. Defining what is acceptable and exemplary 
work so the student knows what is expected is an important step in making a change. As with traditional grading practices, gradients in student work will certainly exist. Creating benchmarks and assessments for each goal and standard will be required. Creating reporting forms for teachers to communicate student progress will also be required. Standards-based grading will be likely seen as a disruptive innovation to those within the school system (Schlechty, 2002). It is the principal who will be required to ensure that the change in grading practices maintains direction and focus to sustain the change's momentum with staff, parents, and students.

Similar to Marzano, Schlechty cautions leaders not to proceed alone when creating such disruption. Principals should begin these initiatives prepared to collaborate and proceed carefully. Bringing as many constituents aboard as possible can facilitate a better transition when making large changes. It may be necessary for leaders to regroup and try a new approach. A common mistake, when implementing a change, is spending too much time or energy on meeting the needs of the saboteurs and resisters. Instead, attention should instead be put on supporting the innovation (Heflbower et al. (2014); Marzano, 2006; Reeves, 2008; Schlechty, 2002).

Understanding the change process is essential for an educational leader. According to Fullan (2001), change may be understood but is seldom controlled. Heifetz (1994) reminds us that a successful change process uses past experiences of the organization to provide direction, protection from external threats, and order during the change process. Changing an element of schooling such as the grading system will not only require courageous leadership, but will also require a principal to be aware of the level of professional development of the staff (Marzano, 2000). According to Fullan 
(2001), educational leaders need to understand the culture within their school, know what the staff values, and promote a collaborative environment. The trust and experience teachers have with their leader can contribute to making a change as significant as a new grading system easier.

While some may see the change as a welcomed improvement, others certainly will be evaluating the support for maintaining the status quo. Most prevalent in schools is what Schlechty (2005) refers to as "benign neglect." It is most likely that, while no outward signs of disapproval are made, old practices will reemerge behind the classroom door when the implementation dip occurs. It is not that behavior that is agreed upon, but what is put into practice that must be measured.

It is imperative that staff, students, and parents understand not only what is being changed, but also why it is being changed (Marzano, 2006, Muhammad, 2009;

O'Connor, 2009). Teachers must be open to using a different method to assess their students in middle level schools: different from how they were graded, from what the parents expect to see reported, and from what their students have come to expect. For example, the use of grades as a behavior motivator and as a record of compliance will have to end. Teachers may need professional development not only in grading practices, but also in unexpected areas, such as classroom management. Making these changes can have a measureable positive effect on student achievement (Hattie, 2009).

When administrators know and understand the objectives and goals at building levels, there can be a positive correlation to improved student learning. (Marzano, Waters, \& McNulty, 2005). Instructional methodologies, such as standards-based 
programs, may translate into even higher student achievement gains as measured by standardized test scores (Hattie 2009; Marzano, 2005).

The principal needs to balance the needs of the organization with the needs of the individual. People do not ordinarily change because someone wants them to, but because they are forced to change (Anderson, 1997; Bass, 1998; Burns, 2003; Hafer, 2000; Hallinger, 2003; Koerner, 1988). John Maxwell (2000) wrote, "People change when they hurt enough that they have to, learn enough that they want to, [and] or receive enough that they are able to" (p. 146). Disruption and uncertainty need not be harbingers of doom. The ideas we fear most in our organizations may be the same ideas needed to awaken our creativity (Wheatley, 1992). When principals can convey a clear vision for the direction of their district, it becomes easier for the fellow principals, teachers, parents, and students to navigate challenges, such as standards-based grading.

If a principal sees the change to standards-based grading as merely technical, a fellow principal who is leading the change may have a nearly impossible task. It may be tempting to treat this process as a set of technical issues to be solved quickly so they can move on. There is also a tendency to want to wait before moving toward a change. Reeves (2006) wrote:

The wait for buy-in can be interminable because leaders fail to acknowledge the truth that behavior precedes belief. In other words, the cycle of organization improvement is not "vision, buy-in, action" but rather "vision, action, buy-in, and more action." The buy-in does not occur until employees first see the results of their action. (p. 96)

It is important for principals to have a clear understanding of the difficulties facing teachers when making a change toward standards-based grading. This change will challenge the staff by changing habits of behavior, attitudes about grading, and perhaps, 
even values. The work of Ron Heifetz (1994) on technical and adaptive challenges becomes important at this point.

A technical challenge in education is as simple as creating a calendar, schedule, or budget. It is important work; it can be practiced, and the outcome is often somewhat predictable. Technical changes are often linear in design and have defined correct and incorrect aspects. The path to adaptive change is usually much more irregular. Numerous observations may be required before people in an organization are ready to interpret what they have seen. Adaptive change is often slow to implement (Heifetz et al., 2009). Successful implementation of the change to a standards-based system will likely involve an adaptive approach. Organizations often cling tenaciously to existing structures (Muhammad, 2009). In schools this often applies to scheduling, personnel, curriculum, and grading. Of these four items, grading often has the longest tenure and is the hardest to change (Marzano, 2001).

The standards-based movement is a relatively recent initiative, and most parents of school-age children are unaware of its existence, implementation, purpose, or value (Marzano, 2005). Principals need to recognize and assist other administrators in dealing with the adaptive changes (Fullan, 2009). Principals also need to provide direction, protection, orientation, and conflict resolution while understanding the norms of the community in which they work (Fullan, 2001; Heifetz, 1994). The principal may be able to provide a more systematic approach to reform when changing to standards-based grading (Smith, O’Day, \& Cohen, 1991).

What the principal needs to be able to do is to support a standards-based grading platform, because it enhances student learning (Marzano, 2006; Pollock, 2009). No one 
can bludgeon people to greatness. Coercion only leads to temporary compliance at best. With the change in grading practice, having common planning time where teachers can meet and discuss the issues of curriculum and grading is critical (DuFour et al., 2004). Professional development is one of the tools for making a systemic change, such as to a new grading system, successful.

\section{Professional Development}

Providing building principals and staff the professional development opportunities and other resources they need to become successful using the Common Core State Standards in a data-driven rich environment is imperative (Brookhart, 2011a; Marzano \& Heflebower, 2011). Failure to provide resources for a principal to help staff will likely result in an unsuccessful change to a standards-based grading model (Muhammad, 2009). Teachers often do not resist the change as much as they do the process of change (Kohn, 2004). What is equally important is the professional development provided to teachers as a grading change is contemplated. The social structure may be in need of evolving (Lindahl, 2010). A principal should take a reflective path with student learning at the heart of professional development. How a leader uses time and money will show support for the initiative. Elmore (2002) stated,

Accountability systems don't cause schools to improve; they create the conditions in which it is advantageous for schools to work on specific problems, to focus their work in particular ways, and to develop new knowledge and skills in their students and staff. (p. 23)

Since resources are usually distributed at the district level, the need to coordinate the mission to change grading practices is a logical path. Changing a practice as old and misunderstood as grading is difficult and needs support beyond that which exists at the 
building level. Mechanisms that provide for school-wide decision making may prove very useful for educational leaders attempting the change grading practices. Principals should prepare themselves for the challenges that lie ahead in changing this third rail in education. Change will require a high level of trust from staff, students, and parents within a collaborative structure in order to find acceptance and success (Muhammad, 2009).

Small, faculty-led debates on the impact of changing grading practices can provide principals with the insight and two-way communication needed to create a successful change. The middle school format with teacher teaming at the core of its structure may provide the best platform for significant changes (Grenda, 2011).

The literature on standards and grading is growing, but there is little on how to transition for secondary schools (Guskey, 2004b). The next chapter defines the study for this dissertation of how one middle school in Illinois attempted the change to a standardsbased approach for their report card. The research design used to uncover what happened at this one school called for a specific qualitative approach. 


\section{CHAPTER III}

\section{RESEARCH DESIGN}

While not entirely absent, standards-based grading is neither common practice in middle-level schools at this time in Illinois or a change to be taken lightly. Cherniss (2008) stated that nothing may be as radical as moving to a standards-based report card, "It is changing an age-old approach to assessing children from the traditional letter grades A, B, C, D, F, to a scoring system that rates children on individual standards" (p. 6). Locating a school where standards-based reporting had been in place long enough to use as a case study was challenging. This chapter describes the process of sampling the case of a middle school that committed to making a change and what happened in light of this difficult switch from traditional grading.

\section{Methodology}

The use of a case study for this dissertation was chosen as a means to see standards-based report cards as a reform in a context in which a change occurred (Yin, 2009). The case study's purpose is to generate a deep understanding of the subject being studied (Stake, 1995). While this case study on standards-based grading practices may not be typical of all schools using standards-based grading, the reader will gain a deeper understanding of standards-based grading as it developed at this middle school. This chapter describes the design components of the case study, including research questions and the rationale for the research design. Also included are the methodology, population 
and sampling procedures, participant selection, and data collection and analysis. The interviews, documentation, and record review are explained and summarized.

\section{Research Questions}

While this study was concerned with the move from traditional grading practices to those of standards-based grading, its focus was on how the change occurred in one particular school. The primary question guiding the research was: "How did middle school educators describe their experiences of moving from a traditional grading system to a standards-based grading system?” Answering this single question provided an overview of educator perspectives that emerged as three themes, implying three subquestions. The themes that emerge with further explanation in the next chapter include:

1. How do educators describe the change process from traditional to standards-based grading?

2. What are the major challenges and successes educators face while changing to a standards-based reporting system?

3. What impact has standards-based grading had on teaching and learning in the school?

\section{Qualitative Study}

A phenomenological approach in the qualitative research tradition supported the uncovering of experiences and the meanings they represent for one school shifting from a traditional approach in grading to a standards-based approach (Merriam, 1998). The researcher used a case study for data collection in order to examine the experiences of staff members during the process of change in the approach to grading. 
The phenomenological approach allowed the researcher to arrive at perspectives closest to the subjects' points of view. These experiences are what Creswell (2003) referred to as the "essence" of experience. Studying a small group of teachers extensively began to develop patterns and uncover deeper meaning. The design of this study intended to give a rich and historical description and then offer an interpretation of what happened that allowed the middle school community to attempt a change in grading that most do not dare. What was it like to experience a change to standards-based grading?

A case study "is an exploration of a bounded system over time through detailed, in-depth data collection involving multiple sources of information" (Creswell, 1998, p. 61). Questions in this study were limited and framed to gather a better holistic understanding in the process of change within the system of the school studied (Stake, 1995). With the approval of ISU's Institutional Review Board, the researcher studied the perceptions and experiences of educators who went through the process of changing their grading procedures to a standards-based approach and the responses of significant members of the school community. The gathering of evidence to study the research questions included interviewing school and district personnel, reviewing school policies and procedures documents, and observations of teacher meetings, all discussed below.

\section{Case Study}

Based on epistemological grounds, the case study methodology provided the researcher an insight in understanding teachers and making sense of their world and their experiences. "A case study design is employed to gain an in-depth understanding of the situation and meaning for those involved" (Merriam, 1998, p. 19). Here, teachers attempted to explain their experiences with required new changes in their schools grading 
process. As Creswell (2003) stated, "Qualitative research is emergent rather than tightly prefigured" (p. 183). In this study, the story of the experiences of the school staff was allowed to emerge, helping the researcher form categories and develop themes about the change process. The task of qualitative research is to explore a topic that challenges the mind and perplexes us. Interviews with participants who could reflect on this process of change were an essential component of the study. The researcher conducted interviews at a location and time convenient for the participants.

The design of the interview process included principles set forth by Kvale (1996), providing an interview, in order to document the meaning participants created from their individual perspectives. Kvale refers to this mode of understanding as "life world" (p. 29). The research employed a semi-structured interview format allowing for fluidity and flexibility by the participants and interviewer during sessions. Participants' experiences and positions often played a role in the depth of the answers and for this reason follow-up question were often asked.

This qualitative case study was heavily reliant on the researcher serving as "the primary instrument for gathering and analyzing data" (Merriam, 1998, p. 20). Participants were interviewed in order to explore and uncover the history of their change to a standards-based grading practice. The researcher's role was that of a teacher, advocate, evaluator, biographer, and interpreter. The qualitative researcher, as a teacher, is charged with advancing the knowledge and expertise of the study's reader. The reader may learn what roads to follow or avoid for future exploration. While the case study is evaluative by definition, it must uncover the life history of the participants. It was the researcher's goal to interpret and uncover new meaning through the stories and evidence collected (Stake, 
1995). This case study was used to explore the process and events leading to and through a change in the fundamental way middle school educators graded their students.

\section{Sampling Procedures}

Purposeful sampling was used for this study. Both the school to be studied and the staff members employed within the school were selected to help the researcher better understand the problem and help answer the research questions posed (Creswell, 2003). Two levels of sampling were used for this study: (a) sampling from the set of middle schools that completed a transition to standards-based grading, and (b) sampling within the chosen case to select artifacts, interview participants, and observations of meetings and events for developing a case study about transitioning middle school. Both levels are discussed below.

\section{School Site Selection}

The first criterion for selection was that the middle school had to provide an obvious opportunity to learn. The review of online resources helped identify potential sites that needed: (a) to have been involved in a transition to standards-based grading and (b) provide sampling within the chosen case to gather artifacts, interview participants, and observing meetings and other events for developing this case study. The first sampling sought potential cases among middle schools with populations of students from sixth to eighth grade that have been using a standards-based approach for at least 2 years. The search was completed in April 2012 using the Illinois Interactive Report Card website to find a school to study. The web-based database utilized by the Illinois State Board of Education indicated that, of the 3,876 public schools in Illinois, 311 were classified under "middle." For this study, the median configuration in Illinois for middle- 
level schools has a population between 400-1,000 students. The researcher had familiarity with the schools in the enrollment range from 400-1,000 students and would likely be able to understand some nuances about how a school this size functions.

The researcher was left with 64 potential schools in the pool for the study. Next, websites of the 64 schools were visited; a review of public documents, such as handbooks, helped eliminate some schools. When conducting a search using the school's online student handbook and using key words such as "grading" or "report cards," 47 schools were found to be using traditional grading practices and were eliminated from consideration in the study. These schools displayed traditional grading scales or traditional letter grades as part of their online handbooks.

The 17 remaining schools stated they used a standards-based grading approach on their web pages. These schools tended to go into greater detail when explaining their grading practices. This was a useful indicator because standards-based practice is relatively new. The schools were descriptive of their practices and defined relevant terminology for their community.

Illinois has undergone several waves of standards-based reform that made schools appropriate for sampling. Practical issues and researcher familiarity with statewide policies that influence standards-based reform forced a change in sampling criteria to a study on middle schools in Illinois. This criteria change was not a matter of convenience, but rather a sampling frame based on the policy environment and access to the research site by an Illinois-based researcher. For example, the Common Core State Standards (CCSS) were adopted in Illinois as a new set of statewide standards in 2010, meaning the 1998 standards-based system would need to be updated. Considering standards were to 
change again, the researcher needed to find a school that had used the former Illinois State Learning Standards long enough to see what the change meant and how people characterized it; that limited the sampling further.

The two final schools reviewed were both located in northeast Illinois. A contact was made to each principal after asking a few questions (Appendix G). Both schools were willing to have a study conducted at their school. After meeting with both principals about how their buildings were configured and touring each building, a clear choice began to emerge (Appendix H). The researcher applied the observational protocol framework (Table 1) to narrow further the location of the study. The final selection was Wilderness Middle School (a pseudonym).

Wilderness Middle School had the infrastructure in place to taking on a difficult challenge like standards-based report cards. For this study, it was imperative to find a school with the collaborative elements already in place. Wilderness Middle Scholl already practiced interdisciplinary teaming and recently began regular PLC meetings. Observations of these meetings helped in the validity of the information discussed during interviews. Important meaning in this case study arrived from reoccurrence (Stake, 1995). Having the collaboration time already built into their contractual day made it easier for the staff to meet as an interdisciplinary team. The district had already committed the resources to hire the additional teachers required to run a middle school schedule. The additional step of adding a late start weekly so subject specific teacher could collaborate made the move to a new reporting system more likely to succeed. Collaboration in Wilderness was not just an idea, it was a practice. It was one practice that made them the right choice for this study. 


\section{District and School-Level Information}

In an attempt to find a school that fit the sampling criteria for this study, it became apparent that the policy and practice of standards-based grading remains rare, despite years of standards-based reform. The assistant superintendent for the case district summed up the difficulty in finding schools using standards-based grading when they were searching for help in implementation, as he noted, "When you Google Wilderness Middle School, it must pop-up near the top, so it's interesting that many other districts around the country are starting to look at this as an option" (Mason interview, May 24, 2013). In addition, the decision was made on Wilderness Middle School because school demographics and grade configurations were most similar to the researcher's experience.

\section{School Overview}

Wilderness Middle School is part of a preK-8 suburban/rural elementary school district. The district included just over 3,200 students with a mobility rate of $7 \%$ and a low-income population of $25 \%$. The district reported a 5-year teacher retention rate of $98 \%$; the average teaching experience of 12 years was slightly below the state average of 12.9. Of the staff, $62.8 \%$ had earned at least a master's degree (above the state average of $61.7 \%$ ), and the average teaching salary of near $\$ 52,000$ was below the state average of $\$ 54,308$ (www.iirc.net).

Wilderness Middle School contains just fewer than 800 students and draws from a diverse socioeconomic population that includes $70 \%$ Caucasians and $18 \%$ Hispanics. The population at Wilderness Middle School has been stable over the past 7 years, and class sizes have averaged nearly 25 the past 3 years. 
Wilderness Middle School maintains a middle school model of organization but has a traditional nine-period, 42-minute bell schedule while on a trimester calendar. A full teaching load includes six classes, a lunch, personal preparation period, and an interdisciplinary team time. Teachers can meet daily in interdisciplinary teams of five to eight members who are responsible for about 125 students. During meetings, teachers discuss coordination of curriculum, student discipline, and calendar events. In addition, the teachers meet once per week for an hour by discipline through an early dismissal scheduled throughout the school year.

\section{Within Case Sampling of Documents, Interviews, and Observations}

Once the school was selected, this case study relied on documents, interviews with individuals who worked during the transition period, and observations of meetings and events over a 1-month period in May of 2013. A meeting with the principal helped to select staff members who were available to be interviewed during school hours and participated when the change to a standards-based approach occurred.

Artifacts and documentation were obtained to enhance the data generated by this qualitative research study. Artifacts included minutes of faculty meetings, the school's and district's public website, Board of Education policies, school report card data, school improvement documentation, and teacher handouts. The collecting of this data took place before, during, and after the interviewing process.

Information from teachers about their current grading practice provided insight into the change process. Differences between the teachers, departments, and teams provided evidence about the systemic changes made by the school's staff. Internal documents included minutes and agendas from August 2012 until May 2013. Team 
minutes, faculty meetings, and professional learning community documents were reviewed during and after the school visit in May 2013. Historical documentation included reports to the Board of Education in the form of school improvement documents, teacher and student handbooks, internal memorandum unique to grading changes, and several report cards.

The observational protocol framework described the artifacts using a three-part rubric. An abbreviated example can be seen in Table 1 and a copy of the entire protocol included in Appendix B. The figure includes items that most closely resembled traditional grading practices compared to those practices seen in schools using standardsbased grading, and finally items that were found during the transition. These last noted artifacts had elements of both traditional grading and movement toward a standardsbased grading process. Documents included standards-based report cards (Appendix C) plus the foundation of what the report cards were assessing. The learning objectives (Appendix D) for both seventh and eighth grades outlined the specifics as to what was to be covered during each academic year at Wilderness Middle School. These documents were used in teacher planning and reflected the standards-based report card. This practice was evident in the teacher meetings attended at Wilderness Middle School in May 2013. 
Table 1

Observational Protocol Framework

\begin{tabular}{l}
\hline Traditional Grading \\
\hline Included in grade: Includes \\
many extraneous elements that \\
are included in the grading \\
process. These may include \\
attendance, attitude/behavior, \\
participation, extra credit, \\
homework/practice, and \\
tests/quizzes, projects.
\end{tabular}

Teacher practice: Grading is a function of "tradition" and is rarely thought of as problematic. Arithmetic such as "averaging" or "point total" are the two popular methods to configure a grade. Little or no discussion is held on the subject. Problems are seen as with the student (i.e., the student is lazy, has low abilities or skills, or is a behavior issue).

Report cards: A single letter or number represents all elements of grading. The document is rarely longer than one page. This type of report card most students and parents are accustomed to seeing.

Transitional Grading

Included in grade: Staff is often struggling with elements of traditional grading. Some traditional elements begin to be eliminated, but grades are not yet tied to a discernible learning standard. Elements like attendance, attitude/ behavior, participation, extra credit, and homework/practice are scrutinized but not necessarily abolished.

Teacher practice: Staff is often investigating different ways to grade their students. The impact of removing homework and extra credit. Discussion on viewing grades as a method to separate ability levels from the calculation of grades may be discussed.

Report cards: Letter grades are often accompanied by comments or another symbol to express effort, progress, or attitude. This type of report card may be 2-3 pages in length.
Standards-Based Grading

Included in grade: Educators would be focusing on measuring students against only the designated standards. Extraneous elements are all but eliminated from the grading.

Teacher practice: Staff is looking to connect activities and learning to a set of identified standards. They are looking to find the best learning experiences to maximize a student's learning. When one experience does not work, they collaborate to find others.

Report cards: Reporting systems compare a student's work to a standard. Each subject area may have several indicators noted. This reporting system could be more than 2-10 pages in length. 


\section{School Structure}

Wilderness Middle School follows a middle school philosophy that embraces a distributive form of teacher leadership that encourages ongoing collaboration. While the principal creates the structure of the organization and makes final decisions, when it comes to the daily operation of the building, a sense of shared responsibility is common. On Fridays the teachers meet by subject, and this collaboration contributes to building a school culture. With a staff turnover of less than $2 \%$, confidence exists within the staff to provide a developmentally rich environment for their students. In addition, the schedule at Wilderness is designed to provide teachers the opportunity to collaborate daily in interdisciplinary teams for 42 minutes. Core academic teams consist of a language arts teacher, who sees students for a block of time ( 84 minutes), math, science, and social studies teachers. Some teams have special education staff members who also meet as part of the interdisciplinary team. Observation of team meetings indicated that the primary purpose was the curriculum and care of students. Teachers of Team Moose, Team Eagle, and Team Salmon (pseudonyms) meet before students arrive each day and provide agendas, keep minutes, and attend to the logistics and events of the school calendar.

Two years ago, Wilderness Middle School searched for a method to enable teachers who teach the same discipline to be able to meet regularly to talk about curriculum and assessment data. The parents of the district were approached with the promise of increasing assessment results if the community agreed to allow for an early dismissal each Friday. Now each Friday the teachers meet, by subject area, one hour before the contractual day ends. These meetings are focused on student assessment data and curriculum decision-making. 


\section{Report Cards at Wilderness Middle School}

The goal of "increasing the number of standards-based grading practices in the district" was indicated in the 2009/10 school and district improvement plans. The school improvement plan showed that members from each of the six middle school teams served on a committee with the goal of reviewing current research on grading and homework practices. After sharing their findings with the staff and developing a new grading philosophy, the committee members would present plans to administration. In 2010/11, an improvement plan called for training the staff on the new report card. Initial training was held on both achievement and standards-based grading. In the following year, several changes were implemented, and a new report card was developed. The new standardsbased report card was used with parents and students in 2011, after a review by the committee.

The report card (Appendix C) was eight pages in length and included an achievement grade published as A, B, C, D, U, I. The U replaced a tradition F and demonstrated below a $60 \%$ understanding of a skill and/or concept. Next, learning objective descriptors were used to express students who exceeded (4), showed proficiency (3), had a basic understanding (2), or did not meet and was below basic proficiency (1). There was a column for each trimester and a heading for the subject taught.

Reading was the first of the subjects displayed on the report card. Students were marked either At, Above, or Below standard. Under the Reading heading were four subheadings with the sub-standards listed under them. Reading was divided into literature (with 9 sub-standards), informational texts (10), and speaking and listening (7). 
The final heading was soft skills, called learning learner characteristics. The six soft skills included cooperation, following directions, respect, effort, and completing work. Language Arts followed the same format with three areas, including language (19), writing (26), and the same five learner characteristics. For mathematics, the report card included five categories, including ratios and proportional relationships (7 sub-standards), the number system (11), expression and equations (six), geometry (six), statistics and probability (13), and the same five learner characteristics. Science had a list of seven learner objectives and social science six learner objectives. Both had the five learner characteristics.

In the fall of 2012, grading was being completed by teachers using an online program customized by the school's information data vendor, PowerSchooltm. The new report card was popular with staff who lauded its efficiency to support grading. For the fall of 2013, due in part to recommendations by the staff, the number of standards reported on was reduced. Wilderness Middle School uses PowerSchooltm as the communication portal with families and maintains an interactive electronic presence on their webpage. The school chose PowerSchooltm in part for the ability to customize the report card to their needs.

\section{Data Sources and Collection Approaches}

Internal documentation was volunteered by the principal and teachers based on their understanding of the scope of this dissertation; the staff members provided minutes and agendas without reserve. The principal made available her personal notations on school improvement plans, Board of Education presentation documents, and staff 
meeting agendas. She also explained the schools 2012-3 calendar and how early release days were used to improve the schools grading practices.

Past district newsletters were offered and had information on goal setting, indicators on progress but did not provide any information on the standards-based grading initiative at the middle school. The assistant superintendent and principal both provided copies of the Wilderness Middle School's grading policy as part of their handbook. A pamphlet that is distributed to each parent was also used to describe the assistance parents are offered about the new grading system, but an agenda from a seventh grade orientation for incoming new students dated February $5^{\text {th }}$ was void of any discussion on standards-based grading. It did include a full page on the school's extracurricular eligibility policy.

The handbook was shared and included the Wilderness Middle School's eligibility policy and a list of student awards. In addition, both the 2011-2 and 2012-3 versions of the report card were shared and reviewed.

Team documents included a 10-page packet on the student-led conferences the school utilizes in November each year. The packet included student reflection worksheets about each of their classes and self-assessment on the student's strengths and weaknesses. The team also shared completed data team meeting collection sheets. The worksheets included student pre and posttest data and were paired with teacher class worksheets that were used to drive instruction. Teams also created spreadsheet data to track individual student progress and examine progress against the CCSS. Exam item analysis reports were shared with the researcher. Completed after each test, they showed learning connected to the CCSS. Teams of teachers used this data at the observed by the 
researcher. Material provided by N.W.E.A. through the Measure of Academic Progress (M.A.P.) assessment was also seen used by both interdisciplinary teams during the day and PLC teams Friday after students were dismissed. No material requested by the researcher was denied.

Additional demographic information was retrieved from www.iirc.net website compiled by the state of Illinois with input from the district and school. This provided data on the student population, instructional setting, class size, teacher information, revenue sources, and performance on the Illinois State Achievement Test (discontinued after the 2013-2014 school year).

\section{Interview Participant Selection}

\section{Participants}

The school selected included a seventh and eighth grade population and 49 fulltime teachers. The middle school staff composition included 45 full-time teachers (of the District's 193 teachers), eight inclusionary aides, a social worker, coordinator of instructional services, school psychologist, literary coach, technology coach, librarian, a dean of students, an assistant principal, and principal. Preliminary identification of participants at the chosen school was selected based on experience, subject taught, and willing participation.

Preliminary identification of participants at the chosen school was selected based on experience, subject taught and availability. The case study was looking to recruit teachers in a variety of subjects and had a range of experience levels to get a better understanding of the process of change regardless of experience. Teachers had an appointed time for each interview. If the interviews went beyond the time allotted, the 
principal was accommodating and arranged for coverage until the session concluded.

Interviews began with the principal. At the conclusion of individual interviews with potential participants, each was asked for names of other members of the organization, past and present, who they believed would have valuable information to share regarding the grading change process at the school. Few provided specific names to the researcher, stating any teacher in the building could help. Staffers were asked the same questions with anonymity promised to each interviewee.

All potential participants were given an informational letter and a letter of consent (Appendix A) at the beginning of their initial interview, where they were told the interview would be audio-taped. The letter of consent included an outline of the study's purpose, the intended procedure for interview data collection, an explanation of informed consent, and confidentiality protections.

Table 2 depicts demographic data for the 13 educators who participated at the time of the study in 2013 in the order in which they were interviewed. This information includes the participant's gender, assignment for the school district, and years of experience both in the school and total years in the field of education. Each educator was given a pseudonym. Each was interviewed for approximately 45 minutes to an hour using a semi-structured interview protocol 
Table 2

Profile of Respondents

\begin{tabular}{|c|c|c|c|c|}
\hline Name & Gender & Assignment & $\begin{array}{l}\text { Years at } \\
\text { School }\end{array}$ & $\begin{array}{l}\text { Total Years } \\
\text { In Education }\end{array}$ \\
\hline Dr. Betty Johnson & $\mathrm{F}$ & Principal & 25 & 25 \\
\hline Chris Bentley & M & $7^{\text {th }}$ grade Mathematics & 6 & 11 \\
\hline Beth James & $\mathrm{F}$ & $7^{\text {th }}$ grade reading & 3 & 11 \\
\hline Jasmin Adler & $\mathrm{F}$ & $7^{\text {th }}$ grade Reading & 29 & 29 \\
\hline Brittney Smith & $\mathrm{F}$ & $7^{\text {th }}$ grade Science & 4 & 4 \\
\hline Jen Davis & $\mathrm{F}$ & Special Education & 4 & 13 \\
\hline Michelle Brody & $\mathrm{F}$ & Art & 1 & 10 \\
\hline Barb Buckner & $\mathrm{F}$ & Social Worker & 14 & 14 \\
\hline Connie Fields & $\mathrm{F}$ & $8^{\text {th }}$ grade Language Arts & 20 & 20 \\
\hline Laura Viking & $\mathrm{F}$ & $7^{\text {th }}$ grade Social Studies & 8 & 8 \\
\hline Judy Urk & $\mathrm{F}$ & $7^{\text {th }}$ grade Social Studies & 14 & 14 \\
\hline Lily Johnson & $\mathrm{F}$ & $8^{\text {th }}$ grade Language Arts & 6 & 6 \\
\hline Mia Enstrom & $\mathrm{F}$ & $8^{\text {th }}$ grade Social Studies & 22 & 22 \\
\hline Dr. Doug Mason & M & Assistant Superintendent & 7 & 27 \\
\hline Average & & & 11.4 & 15.5 \\
\hline
\end{tabular}

\section{Interviews}

Semi-structured interviews allowed the researcher to "listen in" as participants told their stories and shared their perceptions of how they changed to a standards-based grading practice. Interview sessions revealed the background of the participants, reconstructed the history of the procedural changes in grading, and uncovered their 
perspectives about the change. Audio recordings were coded and the verbal descriptions of the process of grading were reviewed to uncover emerging trends and themes (Merriam, 1998). The interview process was meant to uncover the subjects' interior knowledge. "An interview is literally an inter view, an inter-change of views between two persons conversing about a theme of mutual interest" (Kvale, 1996, p. 14). The strength of the interview approach was that it captured a multitude of views on the same topic. Interviews were conducted with attention given to quality not quantity. The researcher met with teachers for as long as they chose to engage in the interview process. Interviews ranged from 35 to 83 minutes and were not scheduled closely together to allow sufficient time for participants to uncover their stories. Time was given to focus on the purpose of the study (Seidman, 1991).

\section{Data Analysis Procedures}

Data analysis for this research centered on this study's research questions. Merriam (1998) defines data analysis as "the process of making sense out of the data" (p. 178). The research for this qualitative case study included a large portion of the data coming from verbal comments made by the participants during interviews and documentary records of the change process.

Analysis involved chunking of the data and synthesizing, in search of patterns that told a story to the researcher and that could be retold to the reader (Bodgan \& Biklan, 1998). Coding of the descriptive interviews and interpretation of the interview data was completed by the researcher. After interviews with teachers were coded, the codes were then organized into themes. Open coding was used to reduce the data into usable packets, and then axial coding was used to establish and then verify themes. 
First, the interviews were studied and then categorized into a few simple codes from statements of attitudes, values, and beliefs. Attitudes were recognized as comments made on how participants felt. Statements about frustration, exhaustion, and excitement about the process of change were some examples. Values noted the importance the participants placed on the change in the grading process. Participants voiced deep-seated opinions about their overarching philosophy on grading. Beliefs statements were comments made that tended to uncover the opinions of the participants about the change to a standards-based approach to grading. Next, these initial categories were scrutinized to find commonalities and differences in the data. Breaking down, examining, and labeling the data lead to a second categorization. Three final categories were used to help compare answers for this research: (a) descriptions of the change process, (b) successes and challenges in implementing standards-based grading, and (c) the perceptions of changes in teaching, learning, and assessment. From these categories, two themes emerged, discussed at length in Chapter IV.

\section{Ethical Considerations and Personal History}

Steven Covey (1989) notes that it is important first to understand before one can be understood. For this reason, the researcher attempted to see the change process through the experiences of the participants in this study. The researcher was a teacher at a preK-12 private school for a decade. He then spent 17 years as the principal of a suburban middle school housing sixth to eighth graders. While there, an unsuccessful attempt to change grading practices prompted an interest in report card grading. The experiences of the researcher in a similar setting could possibly interfere with the ability 
to understand all the participants in the study. The researcher is currently the superintendent of a private school with an ongoing interest in standards-based grading.

\section{Summary}

This study faced the challenges of many qualitative research projects, including obtaining sufficient data, organizing, and interpreting the data (Bryant, 2004). A large challenge for this dissertation was finding a school that met the necessary criteria to study. Standards-based grading is most popular at the elementary level and is just now beginning to take hold with secondary schools. The number of schools available for this case study was limited. Of the 623 middle-level schools in Illinois, the final sample included 17 potential sites, of which Wilderness Middle School served as the best sample for the purpose.

Once a school was located, the primary data for this study required school visits in order to conduct interviews with participants and gather documentation of the change processes. The interviews were conducted in a school location that was most convenient for the participants at their choice. Interview questions focused on teacher experiences in changing from traditional grading to standards-based grading. During the study, the researcher remained tolerant of ambiguity and listened with an empathetic ear in an effort to enter the mind of the participants. The researcher remained consistently aware of his potential bias and the role it could play in shaping the findings (Creswell, 2003; Merriam, 1998; Stake, 1995). The findings based on these methods are presented in Chapter IV and discussed in Chapter V. 


\section{CHAPTER IV}

\section{FINDINGS}

Traditional letter grading is an element in the educational system we are all familiar with, yet this grading system can often be misunderstood. Using a single symbol to translate the entirety of a students' performance is wrought with problems defined earlier in this paper. While not a perfect system, a standards-based approach to grading helps ensure grades are fair and valid and reflect only what a student knows and can do (Guskey, 2001). With the coming of the Common Core State Standards, now adopted as the Illinois Learning Standards, the significance of the change is more pronounced.

This chapter provides a detailed description of the findings that emerged from the evidence from Wilderness Middle School and its move to a standards-based approach to grading. The research was framed by these three questions:

1. How do educators describe the change process from traditional to standardsbased grading?

2. What are the major challenges and successes educators face while changing to a standards-based reporting system?

3. What impact has standards-based grading had on teaching and learning in the school?

Changes in grading philosophy will influence curriculum, instruction, and assessment practices and require changes to the familiar routines of teaching and collaboration. To be effective, such changes require a reliance of grading against a 
defined criterion-referenced curriculum and a new understanding of what grading is for.

While the benefits of a standards-based grading practice have been reviewed in this paper, changing to such a system in complicated. "The first step in implementing standards-based grading is to clearly articulate what students need to know and to be able to do as a result of schooling" (Heflebower et al., 2014, p. 11). Teacher bias is minimized in a standards-based approach, and the grade becomes more valid to consumers using grades to understand what a student knows and can do (Marzano, 2010). When teachers commit to selected standards and align those standards with assessments that are valid and reliable, students gain a valuable communication tool. "Communicating about student achievement is one of the most important parts of a teacher's job (Brookhart, 2004, p. 187).

Standards-based grading provides the target of what the actual goals are and explicitly requires a teacher to indicate at which level the student is reaching expectations. By eliminating extraneous behaviors, both negative and positive, what will be left is what the student knows and can do in the real world. By linking them to the grades, the standards are salient and become integrated into the work of schools. A teachers' grade book can now note specific standard coverage and student proficiency when compared to each standard. Ensuring high quality teachers' assessments that closely tie to measured standards is a critical component of a standards-based approach to grading. As a majority of states accept a common group of standards, a standards-based approach to grading provides a seamless method to report student progress on those standards. Districts can now use the language in standards directly on their report cards, as they did at Wilderness Middle School. 
At Wilderness, the site sampled in this study for their work in transitioning to standards-based grading, the effects of the change were observable, even not completely realized as intended. Overall, the transition was initiated with enthusiasm and for the right reasons. While the possibilities were embraced by administrators and some teachers, the transition was partial and complicated by unforeseen challenges. While the possibilities for what standards-based grading could accomplish were recognized, the needed shifts in understanding, requirements for professional learning, and ongoing stakeholder dialog were not fully appreciated. Overall, the transition was not acknowledged for the systemic nature of the change, resulting in some successes and some telling points of confusion. After interviewing 15 staff members and reviewing documentation, two major themes about the transition developed during this study: (a) the possibilities and challenges of creating systemic change to grading, and (b) special implementation considerations to a standards-based report card. In each case, staff perceptions were considered. Each of the three themes contains both a conceptual and logistical framework. In the conceptual framework, leaders had the opportunity and time to prepare both staff and parents for the heavy lifting that would require learning from all of them. The logistical framework is where implementation met theory as the technical problems of the change were encountered and responses developed.

\section{Theme 1: Creating Systemic Changes_Possibilities and Challenges}

The members of the Wilderness school community recognized the inadequacy of traditional grading practices and the potential harm these practices caused students. The school leadership recognized the need to create a grading and reporting system that could clarify what students knew and could do that separated these standards-based pieces from 
behavior and social-emotional development and other confounding factors. The school community decided to report to parents, students, and other schools with a comprehensive system based on standards. The leadership also realized that a change as significant as switching approaches on report cards is not an easy one. It takes a sustained effort, a commitment to ongoing staff development, and considerable effort to inform those outside the immediate school staff. Perceptions of why the change was made, the success of the implementation, and the usefulness of the new information were varied.

\section{Conceptual Challenges}

In the case of Wilderness Middle School, the change to a standards-based approach took a top-down approach. The assistant superintendent reviewed current grading practices and believed a better way could be found. While the staff at Wilderness was not unilaterally looking to make this change, there was a desire to move to a new report card without using letter grades, but the staff was not fully aware of the issues surrounding a traditional letter grade. When Wilderness Middle School began researching changing to a standards-based approach to their new report card the lack of available models indicated it would be a massive lift, and no one really knew what the change would look like as it was in process and following an initial implementation. The school leadership anticipated some of the conceptual challenges of the change and convened a committee to review policies on replacing current teacher practices.

The committee charged with overseeing the implementation read books by Marzano (2000) and O'Connor (2004) to prepare them intelligently discuss and plan for the change was a positive step. The book study provided researched based insight into practices to emulate. As a result, decisions were made to eliminate the use of zeros and 
minimize the use of homework as a grade component. By having a common language and reference points the committee was more easily able to reach consensus and commit to a defined change and begin to consider the professional development the change would require. By the leadership requiring additional learning as part of the requirement to serve on the committee it provided for a better pathway to success.

\section{Logistical Challenges}

While the conceptual challenges seemed to be well-anticipated, the logistical challenges did not go as well. As with many who take up this cause, the dynamics of the logistical change process may not have been fully appreciated by the leadership or participants. The number of standards to be reported, the actual creation of a reporting mechanism, and ancillary issues involving the new report card did not appear as anticipated. These technical issues were the first for Wilderness to recognize.

Wilderness Middle School focused more on the change in the report card than the paradigm shift for the community regarding standards (Guskey \& Bailey, 2001). A small population of parents was involved in committee work, and a forum was held prior to the implementation of the new reporting system, but how well the majority of parents understood the new reporting was unclear by those who participated in this study. While annual improvement plans included mention of the standards-based approach of grading, it was what the researcher did not uncover that is telling. A long-term plan for dealing with the change to a standards-based approach did not emerge in the document review and was not brought up by those interviewed.

The perception from teachers was not to push back against the top-down edict to change the grading process. Staff did not feel there was a well thought out staff 
development plan. Handwriting report cards, including too many standards for a teacher to manage and spending summers modifying the report cards, was difficult on teachers and morale. While most did not have a disdain for the new report cards, most mentioned the transition could have been handled better.

During the first year of implementation, one teacher noted the amount of paper that seemed to be wasted when errors were found only after using about 15,000 sheets of paper (30 reams). To some, this became known as the "Papercropolis of 2010." The school had an 8-page, hand-completed report card, which required teachers to complete their portion by reporting to the library and painstakingly writing standards and assigning grades. Teachers were not allowed to take this work to their rooms or home for fear that reports may be lost and work would need to be duplicated. This was later resolved in their second year by contracting with a company to complete computer generated report cards. A shorter version helped reduce resistance and included about seven standards per class was revised in year 3 (Appendix C).

Wilderness Middle School has a descriptive explanation of the grading procedures in the student handbook. The school uses a "Frequently Asked Question" (F.A.Q.) approach in explaining standards-based grading. The handbook includes a definition of standards-based grades, how they work, and how they differ from a traditional system. It also gives definitions of the five descriptors used to indicate student proficiency (i.e., Exceeds, Proficient, Basic, Below Basic, and Not Assessed). Also in the handbook, Wilderness Middle School describes the role of homework, zeros, averaging, attendance, academic dishonesty, and group work in an SBG system. However, the handbook reverts 
back to traditional grading when it defines its honor roll requirements and the athletic code of conduct. For example, instead of using a proficiency standard like an "All Exceeds" honor roll, Wilderness reverts back to attaining a specific GPA with A's, B's, and C's.

Another noticeable area of concern mentioned from the staff was that the community was not brought along in large enough numbers to eliminate what became the achievement grade. While the debate on external motivation for student learning may still occur, reporting mechanisms like the report card remain a factor in student efforts and recognition of those efforts (Guskey \& Bailey, 2001). "To get the parents to understand what the standards mean has been incredibly difficult. Most parents just look at the report card see the achievement grade, and they are done. They don't really care about the standards" (Bentley interview, May 6, 2013). This traditional report card element created a hybrid approach to the report card a Wilderness Middle School.

Well, there's some give and take that has to occur for any implementation of a new initiative, so that was one of those trade-offs that I was willing to accept as a part of that because it is moving us in the right direction.

(Mason interview, May 13, 2013)

The incompleteness of educator and parent understanding was further indicated by telling practices that suggested that standards-based grading was not fully understood and, therefore, not faithfully implemented. Wilderness staff in the study reported the need to keep a traditional grade for uses outside the needs of the classroom. Cited were athletic eligibility, parent/guardian rewards, and entrance consideration for eighth graders going into high school. Just as with any tool created to complete multiple jobs, Wilderness Middle school report card has its limitations. The blending of the standards-based 
approach with what Wilderness Middle School referred to as an achievement grade sent a confusing message about the new reporting system. For example, the eighth grade dance requires a $\mathrm{C}$ or better average for attendance, implying that the grade is the standard and belying the claim in belief that the school should emphasize internal motivation.

The staff reported that the achievement grade obscured the work on the standards being covered. These trade-offs can create a system more confusing than the one it replaces (Brookhart, 2001b). For some parents it was seen as the only relevant part of the report card. Did my child make the honor roll? Are they eligible for the wrestling meet? Can they attend the end of the year dance? These were all comments made by staff about the new reporting system and the confusion that resulted. The report card should be thought of as merely a communication tool. It is not a tool that can carry the burden of communicating a new understanding of standards in education. Averaging test scores does not give a complete picture of any one student. "Parents go by grade. The dinner dance is next week, and I want to know if my child can go?" (Enstrom interview, May 14, 2013).

Staff at Wilderness Middle School reported standards-based grading had the potential to open up a deeper level of communication on student progress, but there was little recognition of the learning required of everyone to enhance communication. As a 13-year veteran stated, "I think it kind of opens up that communication a little more and in theory parents would be complaining less about the grades when they know more about the issues" (Davis interview, May 6, 2013). The specifics offered in a standardsbased reporting system can communicate the strengths and weaknesses of students better 
than a single letter grade, but only in a context where communication is ongoing and the role of the report card in a system of learning supports is understood.

Wilderness Middle School began identifying the primary learning goals under the state standards and tracked how each student performed compared to those criteria. They created and adhered to performance indicators and reported to parents how children were doing against those benchmarks. The report card reflected well-defined learning standards that conveyed a meaning of what was to be learned and how the student's performance measured up to those standards each trimester. At Wilderness, this shift caused educators to meet frequently to individually review their students' performances in their classes. However, the school also felt it was not politically feasible to eliminate traditional grade entirely. This underscores the difficulty in relying on one reporting mechanism to meet everyone's needs and the complexity of changing grading systems. Ultimately, what the school discovered was that grading remains challenging when communicating more than just quantifying a student's achievement it the classroom.

Grading in any system requires professionals to make subjective judgments and the reader of the reports to interpret. In this case, those reading the report had not yet caught up with all the information provided. Teachers were asked to track and submit data to a report card consisting of eight pages. The staff did not report spending time on prioritizing standards at the start, and this became problematic during the first attempt at a standards-based report card.

The new amount of information reported by staff seemed to overwhelm many parents. Parents commonly asked staff why the report card was eight pages long. One teacher reported only one of 125 parents questioned the mark of one standard. One 
question was asked when over 1,500 grades were assigned. It seemed few outside of the school were using the information being provided.

By reverting back to a traditional grading practice, Wilderness sent a mixed message to the parents and students about the primary purpose of the reporting process. At Wilderness Middle School change focused on the form the new reporting system took as a technical matter, but perhaps not the function or the ongoing adaptations a systemic approach would require. The school failed to consider what message they were communicating to the students and families. The new reporting system was an attempt to demystify what a student knows and can do. According to participants in the study, the new report cards were to give a precise accounting of each child's skill. However, it appeared that parents tended to look at the new system in old ways:

I think we put two of them together, so we're still doing regular grading and then we're doing standards and we kind of mushed them together and I think that's what not working as well. I think if they didn't have an achievement grade to look at, the parents might be more proactive in looking at the standards. (Fields interview, May 13, 2013)

All the time spent by the teachers in measuring a student's aptitude against a particular standard was reported as largely unusable information by most parents. The form of the new report card was explained and accepted, but its function was lost upon the audience receiving it. The information on the report card was useful to educators, but teachers reported not many others outside the school used it.

The school succeeded in creating a better match between assessments and grades. This was evident in data gathered in team minutes and PLC reports. It was more reliable due to the consistency in which educators now used common assessments, and quality of student work was reported by staff to have improved. Potentially, this new reporting 
system could provide students with a better self-evaluation regarding their learning. The amount of information provided on the Wilderness report card is more than adequate to enhance student's opportunities to learn and grow.

In the end, it is clear that the report card is just one communication tool at a school's disposal. Effective grading systems must be used with exhaustive planning, thoughtful judgment by teachers, and clear and purposeful using the district's best communicative skills. An important issue during a report card's implementation has to be a concern for how this affects students (Guskey \& Bailey, 2001). It was clear during this research that the members of the Wilderness staff recognized the problems with the traditional methods of grading and researched and found a better platform that works to the benefit of all their students. While not perfect in their attempt to change, they have taken a step most middle-level schools are not able to successfully navigate and learned along the way.

\section{Theme 2: Challenges with Implementation}

Wilderness Middle School made the careful choice of changing to a standardsbased approach to grading for research-supported reasons. The change they created was intended not only to alter the appearance of their report card but to change the ways teachers think about what and how they communicate student progress. Here the conceptual and logistical frameworks were met with a higher level of success as the technical aspects of the change could be emphasized.

\section{Conceptual Challenges}

First, the school already incorporated the middle school teaming format during the school day. Second, to further support the initiative of SBG, the school district went to an 
early dismissal schedule each Friday to allow subject-specific collaboration. This support for collaboration that allowed teachers to work through issues of developing and launching the new report card demonstrated support and the resolve of the administration. In collaboration, teachers aligned their assessments to the CCSS, and those same assessments were then aligned to the new report cards. Curriculum became guaranteed by virtue of a deliberate attempt to match instruction with assessment and reporting. A clearly defined cycle of improvement was recognized at Wilderness Middle School (Figure 1).

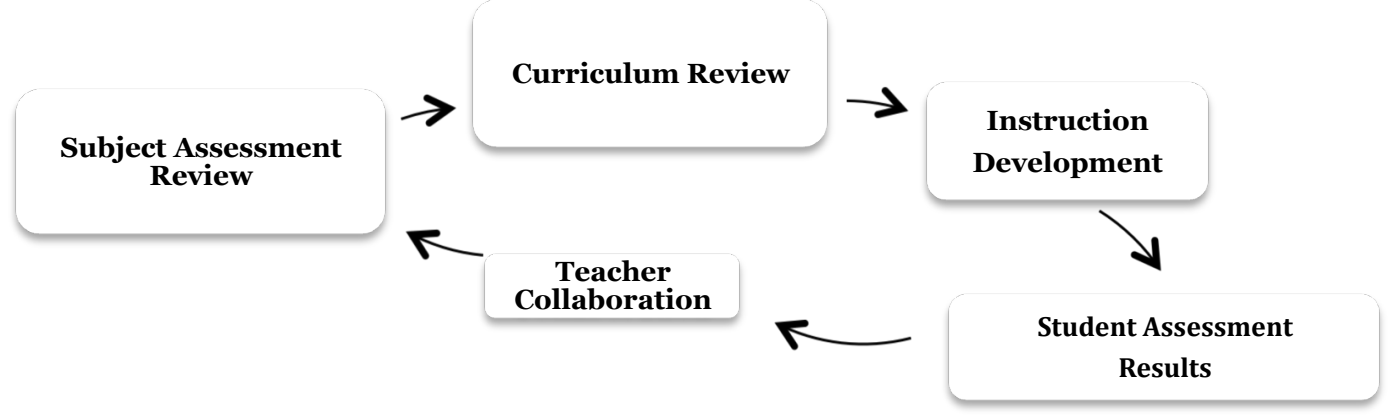

Figure 1. Cycle of Improvement at Wilderness Middle School

Teachers used the standards as the framework for the curriculum and provided guidance in instructional decisions. During the time used in teaming and professional learning community meetings, the staff reviewed both teacher-created assessment results and those of M.A.P. scores to proceed. The trimester report card now reflects what was covered in class and what the student mastered. Academic progress at Wilderness was now communicated using clearly defined criterion. Teachers reported increased confidence in explaining exactly what the expectations for students are and how students did in comparison to the CCSS. Teachers also developed a better understanding of the 
elements of the grading process and understood the strengths of a systems approach. "I think it's good for teachers. I think it forces them to look at their assignments and make sure that they are covering all the standards" (Enstrom interview, May 6, 2013).

\section{Logistical Challenges}

Wilderness staff reported that using a standards-based approach to grading enhanced teaching and assessment, helping the school align to the requirements of standards. Staff had adequate collaboration time built into their daily and weekly routines, driven by assessment aligned to standards. The conferencing sessions of teachers include professional conversations about curriculum and effective instructional strategies. Data are at the center of these meetings and include discussions on M.A.P. data and teacher-created assessments. These meetings created documentation resulting in direction for future instruction. This added teacher planning time was granted with the understanding that it would lead to a positive increase in student learning. Spending less time instructing students may be counterintuitive as an improvement measure, but so far this bold bet has paid off, according to Wilderness staff.

These collaborative structures create the professional learning culture necessary for major shift in practices to occur. Wilderness Middle School meeting minutes mention the grading process in September, October, November, March, and May, suggesting ongoing attention. While attending meetings as a participant observer with teachers of science and language arts and the Moose team, the researcher was able to view conversations centered on data and how students were doing in relation to a predetermined criterion. At Wilderness Middle School, the agreed-upon proficiency level was set at $80 \%$ or higher. This means that for each standard assessed, a student must 
score $80 \%$ or higher to be seen as proficient on that standard. There was also documentation of interventions provided for those below the $80 \%$ proficiency level. Teacher discussions focused on how to help the greatest number of students reach the $80 \%$ threshold.

The review also included an item analysis of each assessment to indicate strengths and weaknesses on each item by class. Teachers reviewed these reports and referred to each question and the percentage of students who selected the correct answer and each detractor (incorrect answer). Teachers reviewed the average and median test scores for each class, gathered a high and low score to look for outliers, and made predictions as to what gains they could expect if new teaching strategies were employed. Each of these items would later become evidence for the level of proficiency recorded on each student's standards-based report card.

These Learning Teams also used the Northwest Evaluation Associations (N.W.E.A.) online assessment tool called Measures of Academic Progress (M.A.P.) data. Teachers used these data to create a more objective starting point to measure growth. At Wilderness, this assessment was completed at the beginning, middle, and end of each school year. September was used as a baseline, winter as a progress check (and for the principals' evaluation) and a final time just before the end of the school year. Data were reported as Rausch Interval Unit (R.I.T.) band. This equal-interval vertical scale was used for growth norming or to compare a student to the CCSS, supporting the role of standards in driving the change to new assessment and reporting processes. This M.A.P. data could help validate the level of proficiency teachers report on the card. Since both the new 
standards-based report card and the M.A.P. data is criterion-referenced, one would expect some correlation. The achievement mark would not be a useful tool for this purpose.

Changing to a standards-based approach created more awareness of multiple assessment processes in standards-based systems. Teachers reported they have become more aware of the quality of their assessment and to which standards each of the questions in their assessments connect. "The tests are what really have changed, the actual tests themselves. We had to re-write a lot of tests to meet our standards and that's the biggest change that we've had" (Bentley interview, May 6, 2013).

A significant challenge in making the change to a standards-based approach was informing parents about how to read and use the new system of grading. Most staff members noted that parents did not seem to understand the new report card and often just wanted help finding the achievement grade.

I just think that the community involvement in how the grading system works is not clear so I think that's probably where a lot of parents get frustrated with it, but after I see the system and have been working with it then you have some clarity, but I don't know how well that's going to fly. (Urk interview, May 6, 2013)

While teachers spend every working day with the CCSS, most parents do not have a working understanding of the standards. In the first year of the implementation of the standards-based report card, the language arts teachers were reporting on 71 different areas of reading and writing. This overwhelmed teachers and also parents. A year later, Wilderness staff eliminated the sub-standards and reported on just 13 major areas (Appendix C). What remained was a staff that had a better understanding of the state standards, but it was unclear if the parents understood. Despite this step to simplify the report card, staff still reported most parents did not have a clear understanding of the new 
system. While the district conducted an annual assembly during the open house for parents, the message was not getting across to many after the first 3 years.

What the staff wanted was for the parents to use the information on the new report card. The hope was that parents would take a look at what their children were learning, what the standards were for each class, and see what it was that the teachers were trying to get across to the kids. The sentiment of staff is that the report card continues to be underutilized by most parents and students.

My impression, from people I know in the district as neighbors and friends and what we hear at conferences, is that it's the grade, and that's really all they pay attention to. They don't really take the time to look at the standards and see what the kids are learning" (Johnson interview, May 6, 2013).

The disconnect between what information the educators at W.M.S. provided and what parents and students were using from the new report card may be traced back to the lack of a defined purpose statement. The new report card changed to reflect a set of standards but the uses of the report card did not. By not taking the use into account, much of the information communicated on the card became lost in translation. The hybrid approach was limiting is its usefulness for both educators and parents.

The standards-based report card initiative at Wilderness began with a district level decision. According to Wilderness staff, changing to a new grading system was not something the staff embraced. At the bequest of the assistant superintendent in charge of curriculum, a committee, including staff, parents, and administrators, was organized. Book studies and committee meetings led to decisions to move from a traditional to a standards-based approach. The committee moved slowly and included staff, parents, and administration at both the building and district level. 
The district office provided the plan and monetary resources to create the grading change. We actually spent a considerable amount of time educating staff, whether it be with professional development, we worked with the Leadership and Learning Center and brought in individuals into the district to provide professional development to staff in terms of moving to a standards-based system and there were a variety of activities. (Mason interview, May 13, 2013)

Staff used institute days to unwrap standards, review homework procedures, and understand the elements of grading. The staff also began studying and crafting the first Wilderness Middle School standards-based report card. The first draft was not without its challenges. Hard copies were in the library, and teachers manually wrote their grades for each student. When a reading teacher with 135 student's reports on 15 sub-standards, it meant an overwhelming 2,000 entries placed on a report card by each teacher. The Committee designed modifications for the report card over the summer months. In year two, sub-standards were dropped and the teachers submitted their grades electronically. This was reported as a time saver by staff. Aside from the modifications recommended by the committee each summer, formal staff development on the report card appears to have concluded.

A significant benefit for students was the improved understanding of the state standards by the Wilderness staff and aligning curriculum with instruction and then assessment. Twelve of the 14 staff members interviewed commented on the improvements the new grading system had on their awareness of what the standards were. "I think that using the standards, all of them this year, has really helped me get to know the standards better, because I have to use them in my curriculum" (Fields interview, May 13, 2013). 
Here again, the staff at Wilderness shows a resolve to put their students first. This initiative took money, energy, and courage. Wilderness has set a course to build a better grading system. They have remained on that course for over four years now.

\section{Summary and Discussion of Major Findings}

While we cannot be certain how a change to a pure standards-based approach would have been received, the perception from staff was the hybrid approach may have delayed the full usefulness of the new report card as a learning tool. Parents were given opportunities to learn about the new standards approach to grading, but, by keeping the achievement grade, parents did not feel the need to educate themselves about the additional information provided.

The implementation of the standards-based approach to grading at Wilderness Middle School may not have been textbook in its rollout.

The problems were definitely not all anticipated. The report card gives good information for parents and parents were on the committee, but only maybe 20 percent, I would say, really look at the standards. Most of the parents just care about the letter grade. For the teachers it gives some information if they want to remediate. It also helps the parents if they want to help at home with all the online programs to help fill in the gaps. Yes, there were definitely some glitches. (Johnson interview, May 6, 2013)

This change was made as part of an initiative by the central office. While the intent was to improve current grade practices, the decision to change was not coming from the Wilderness staff or the parents of Wilderness students. Through training, the participants recognized the deficiencies of a traditional grading practice and began seeing benefits in the new approach. Yet, by underestimating the underlying conceptual shifts and the logistics of creating a new approach to grading, the staff at Wilderness Middle School expended much energy to find new solutions to the technical dilemmas inherent 
in the process. For example, teachers had to come to terms with which standards they were going to report, which seemed to take some focus away from student learning. The deeper miscalculation, however, was in retaining an achievement grade. In so doing, the educational staff inadvertently clouded the water for parents and overlooked the systemic effects that virtually guaranteed that they would have to rely on grades. As a result, the roll out of standards may have been compromised overall. While the change required teachers to become more intimate with the standards they were teaching, the community did not have the time to absorb these changes. Not having an active parent development component led to a report card that was underutilized in the community. It became evident, according to Dr. Mason, that the parents were not ready to move completely away from traditional grading practices,

Our community wasn't really quite ready for moving directly to a standards-based grading, so we took on a hybrid approach, as many districts have done within the process. So, we have a standards based component but we've also held onto a traditional letter grade as well within our reporting out piece" (Mason interview, May 13, 2013).

The disconnect between what information the educators at W.M.S. provided and what parents and students were using from the new report card may be traced back to the lack of a defined purpose statement. The new report card changed to reflect a set of standards, but the uses of the report card did not. By not taking the use into account, much of the information communicated on the card became lost in translation. The hybrid approach was limiting is its usefulness for both educators and parents.

While the staff was hard at work collaborating on assessment data, creating then revising the report card, only a small group from the community was aware of these efforts. Staff members were guardedly optimistic that over time these changes would 
have an impact on student learning, but at this time the report cards achievement grade remains the most important item for consumers.

Nonetheless, benefits did accrue to Wilderness as a result of what must be acknowledged as an ambitious, locally-initiated reform of grading to reflect standards and new approaches to curriculum, instruction, and assessment. Collaboration among staff were enhanced as the shift to standards-based practices moved through what educators might realistically anticipate when adopting reforms that require intense professional learning collaborations and community engagement. If Wilderness exhibited naiveté about the challenges of change, they are hardly alone. If these educators thought they were simply remaking their report card, they learned an invaluable lesson about the challenges of change as both conceptual and logistical.

Chapter V concludes this study with a discussion of the findings, raising once more the inherent possibilities and challenges of moving to standards-based reports cards which implied deeper, more systemic change than educators at Wilderness realized. 


\section{CHAPTER V}

\section{CONCLUSIONS, IMPLICATIONS, AND RECOMMENDATIONS}

In the American educational system, traditional report cards hold an iconic position that is not easily replaced, particularly when the requisite changes require fundamental changes to thinking and working. Creating a standards-based report card at the secondary level is difficult, and, when deciding to make this change, a leader should be thoroughly prepared for the challenges it brings. If the change is seen as a technical one, then the implementation will encounter difficulties without preparing for their inevitability. It is only when educators anticipate the challenges, knowing that ongoing attention will be required, that the systemic nature of reform becomes possible. As with Wilderness Middle School, an understanding of grading history, grading purposes, current grading practices, and what kind of systemic effort would be required could help set the direction for change.

\section{Review of Purpose}

The purpose of this study was to assist school leaders engaging in the process of changing to a standards-based report card. This study focused on one middle school, which was three years into the change process. Through a qualitative approach, patterns emerged that may be beneficial for other educational leaders who choose to attempt this adaptive change. This study is not a road map for all schools to follow, but rather a glimpse into one school's journey that may help other schools with the process of changing to a standards-based approach to grading. 
The change to a standards-based platform is complicated and takes patience. If a school is to be successful in making a change as significant as changing a report card, long-term planning is a significant hurdle to overcome. The change should occur at a pace that the district, school, parents, and students can absorb and be clearly linked and integrated into a system of changes.

\section{Review of Design}

This study employed a qualitative methodology and a phenomenological approach to uncover the experiences of one middle school in northern Illinois as it moved from a traditional grading practice to a standards-based approach over a three-year period. The design of the study required the researcher to advance the knowledge and expertise of the reader, and then allow the reader to plan a course of action for future exploration based on need. The researcher's goal in this case study was to interpret and uncover new meaning through the stories and data collected (Stake, 1995).

\section{What Has Been Learned}

For Wilderness Middle School, the initiative for the change appeared to have been crafted from the top down. The district office mandated a new approach to reporting and orchestrated the change with the use of a committee. It was then through committee that the timelines and staff development plans for the standards-based report card were developed. As with many schools undertaking the change to a standards-based approach to their report card, the committee first reached out to other schools that had already begun the process of change but found few models to emulate. Wilderness Middle School was doing pioneering work for which they can be commended. 
Work from key researchers in the area of assessment and grading was at the center of the report card reform at Wilderness. Through book studies, collaborative reflection on grading practices started. Administration, teachers, and parents reviewed some of the most popular literature on grading practices and recommended planned change. Teachers used the work of these and other authors in professional learning communities to eliminate poor grading practices and held discussions concerning directions the building needed to take.

Through interviews and document review, W.M.S. transitioned from a traditional grading system to a standards-based approach which was a process more than an event, which included augmenting teacher collaboration time and devoting ongoing attention. Three years into a new grading system, the school continued to modify the reporting system each summer. While the school was successful in reducing and even eliminating a report card with many well-documented flaws, the school had not been able to inform all of its constituents as to the greater purpose of the new reporting system or to eliminate systemic uses of grades, as in the use of grades for athletic eligibility.

Familiar teacher practices, like taking homework completion as an important contributing factor in the final grade, now have a decreased role in the students' final grade. Non-academic factors, including behavior, are communicated to families through the use of what Wilderness Middle School calls "learner characteristics." These elements are required assessments by each of the teachers in every subject. The characteristics address specific behaviors like respect, effort, cooperation, and following directions. The use of learner characteristics is a compromise enabling teachers to communicate behavioral tendency in their students. Completion of homework, cooperation during 
group work, and the effort placed in making up missed labs, quizzes, and papers can be documented through the use of learner characteristics. Other report cards refer to these as work keys or effort grades.

What Wilderness attempted to do was create a reporting system that gave a valid look at a student's progress and informed parents as to the strengths and challenges each child faced. The hybrid approach was an attempt to appease the needs of the parents and others who used the results of the report card. The hybrid approach was an example of how conceptual challenges changed the approach Wilderness Middle School took in standards-based grading. The need for a traditional grade may not have been thought through as members of the school community were surprised by the durability of the achievement grade. By focusing on the conceptual challenges of the change to a standards-based approach, this is an example of an adaptive challenge that requires communication and collaboration, not a technical solution that compromised more than it intended to. By operating a dual system, Wilderness sent mixed messages about standards-based grading and the role of grades in other school-wide systems. Fortunately, possibilities to change the message and make systemic changes remain as options, offered as conclusions below.

\section{Limitations of the Study}

Ambiguity and complexity make a universal conclusion unrealistic for a qualitative study such as this one. The primary benefit of this study is to offer guidance for educators to increase the chance of making a successful transition to a standardsbased approach to the middle level report card from both practical and conceptual perspectives. The new information from this study is just one middle level schools 
experience and may not translate in other situations. The conclusions to follow are generalities that may be useful in guiding others to the research and practice about a middle school's transition to standards-based grading.

\section{Conclusions}

Five major conclusions resulted from this study that can be applied to move the standards-based grading reform forward at Wilderness and elsewhere. The four conclusions include: (a) starting with a well-defined purpose; (b) bringing community along; (c) resisting a hybrid approach; (d) planning for long-term change; and (e) employ a pilot program. In each case, Wilderness Middle School serves as an example of a partially realized change in grading and reporting.

\section{Conclusion 1: Have a Well-Defined Purpose to the New Report Card}

Habit two of Steven Covey's (1989) book, The Seven Habits of Highly Effective People, reminds us to "Begin with the end in mind." Nothing may be more sound advice for the educational leader who is beginning the journey of changing to a new approach to report cards than that simple phrase. Knowing and being able to explain to other administrators, teachers, parents, and students the purpose for turning upside down a system that has been in place for over 200 years is paramount.

Knowing the specifics of what and why changes are being made helps all those involved to keep the focus as the report card changes. Ambiguity at the start may lead to a hybrid report card trying to serve too many purposes. At Wilderness Middle School, it was not clear to everyone what the new report card was supposed to convey. Parents and those running school programs needed the traditional grade to reward or punish student achievement. 
School programs, such as dances, athletics, and honor roll lists, were not strongly considered when creating a purpose statement for a new report card. Many families established contracts with their children that promised gifts for a minimum competency shown on their report card. Sorting children is an old paradigm that still holds many captive. Winners and losers when it comes to grading means we can arrive more easily at a valedictorian, salutatorian, National Honor Society recipients, and handing out scholarship dollars.

In a standards-based approach, students simply complying with teachers can be replaced by a more accurate reflection of what a child can do as compared to a knowable target. This change will not be seen as a positive by all families. Parents are responsible for their child and their child alone. Understandably, parents will inevitably push back in a new system that appears to negatively affect their child. If we now are going to demand teachers show success with every child then we need to find a better way to report progress than with a single number or letter grade. The place to start the conversation may be around a well-crafted purpose statement.

Educational leaders should reflect on how the change will impact incentive programs, honor roll lists, and eligibility requirements. Not having and communicating a strong purpose statement may have led to a report card that was misunderstood and underutilized by parents and students, according to the W.M.S. staff. If leaders do not, they may find it necessary to take a hybrid approach, like W.M.S.

Creating a purpose statement and then reflecting back to it often may help provide a report card that communicates more honestly with what students can show and do. Leaders who believe the standards movement is here to stay will need to invest in time 
and energy to show parents and students how this will change how schools report progress.

When we create a well thought-out purpose statement, every decision regarding the change is measured against that declaration. If a decision fits, it can become adopted; if it does not, then we must change or disregard the change as not meeting the new report card's purpose.

\section{Conclusion 2: Development-Bring the Community Along}

Explaining the new report card format at the beginning of the school year or parent teacher conferences will not be adequate. Families will require collaborative learning options, just as teachers do. Newsletters, having a web presence, and parent organizations could be used effectively to inform the greatest number of parents of the overall change, but this must be followed-up with conversations and training. As with the educational staff, this should remain an ongoing priority. There may never be a day when educational leaders can cross this off their to-do list.

Creating a change in the report card is adaptive in nature so ongoing learning will be required of everyone. Educators need to justify the change and clearly define what is happening and why is not the only need for the staff. Parents do not have time for collaboration like educational professionals do but they will make time to complain about changes if they are not included. Educational leaders would be wise to develop a mechanism to engage parents broadly in the new reporting system. Leaders could offer advice as to how to use the new system in old ways.

Creating a standards-based report card is a process. There may be many versions of the new report card before the school settles on one, and even this may well be 
temporary as reforms press educators for ongoing change. At Wilderness Middle School, they agreed to review three versions of the new report card in the first 3 years. A committee takes advice from parent groups and its teachers and meets each summer. The first revisions included finding an electronic means to complete the task of grading and eliminating sub-standards from the report card.

Informing the community on how and why a change to a standards-based approach to grading is being made will likely be slow and ongoing. Every opportunity to inform and explain the new system should be taken. Families move into and out of schools each month and having a parent meeting at the beginning of the year may be missed. Ongoing opportunities have to be sought and everyone's talents on the committee should be utilized to engage a broader community to understand and support the change.

The primary purpose of grading is to communicate the status of student learning. Research points to the importance of placing the purpose directly on the reporting systems (Guskey, 1999). Report cards should be explicit about their purpose. An example of a purpose statement is as follows: The purpose of this report card is to give parents and others a detailed description of what students know and could do as measured against the Common Core State Standards for their grade level. It is intended to inform parents and students about academic progress.

\section{Conclusion 3: Go All In-Resist a Hybrid Approach}

Wilderness Middle School staff reported frustration with the use of the report card from parents after it was sent home. Most parents reported the new format was confusing, and they just wanted to know the traditional letter grade. "Merely tweaking the details of a grading system can result in a system that makes even less sense than the one it was 
intended to replace” (Brookhart, 2011, p. 12). Despite teacher's reportedly spending hours examining each and every CCSS and assessing hundreds of areas each trimester, this information went unused by many parents. If eligibility to play sports and the status as an honor roll recipient was upheld, students were unaffected by the new reporting system. Staff members reported frustration with the hours that went into the new report card just to hear, "Just tell me if they made the honor roll." The bigger issue of motivating students in new ways is far-off but becomes possible as school and community are engaged in understanding standards as represented in new assessment and reporting systems.

As the standards-based change is implemented it is important for educational leaders to realize not every parent will see the changes as necessary or beneficial for their children. For those that benefit from a traditional grading system, the old way of schooling provides a clear path to eligibility, awards, recognition, college, and scholarships. Anticipating the needs of these parents may allow for school committees working on changing the grading system to come up with alternatives for some of the traditional uses for grades. Determining how to deal with athletic eligibility, class rank, grade point averages, and high school recommendations on the front end may avoid the use of a hybrid approach as a way to appease parents.

While it may have been necessary to reach a compromise on keeping the old system and merging it with the new, ultimately it may provide the excuse for many not to use the new information to help foster learning. The concrete guidance that parents could be using with their children to improve is lost. Helping parents grasp the new format will likely cause everyone involved to reframe what he or she knows and believes about 
grades and grading, but that should be the point. If educational leaders are going to summon the courage to take on changing the report card, the purpose of that change should dictate they go all the way if they want to communicate effectively with students, parents, and staff.

\section{Conclusion 4: Have a 3-5 Year Written Plan for Change}

Wilderness Middle School noted in its school improvement plans the decision to “establish grading guidelines, create new report card” (Wilderness Middle School, Improvement Plan, 2009-10). This was one of the five actions they intended to take during the school year to improve proficiency on the state assessment. The five activities had 22 actionable activities.

Making the change to a standards-based approach to grading is time and resource intensive. Leaders should create a detailed plan several years out to assure that the budgetary and time constraints do not derail efforts.

Although school leaders would undoubtedly like to align their reporting procedures with the same standards and assessment that guide instructional programs, most lack the time and resources to do so. (Guskey, Swan, \& Jung, 2011, p. 53)

By carefully planning out each of the steps the school community needs to take, a leader may avoid wasting valuable time or energy by anticipating what the reform will really require before making it the focus of a school or district. While a blueprint for what to include may be different for each school, common elements are seen in the literature that can help school staff anticipate the commitment involved. Timelines for each school and district will vary due to individual needs and the resources of time and money.

Establishing a strong team composed of both school and community and engaging in 
professional development with a consultant are good places to start.

Creating a well-defined purpose and belief statement will help keep the committee focused and serve as a pillar of stability moving forward. Absent a firm conviction, a school may have a hybrid approach to the new report card which will likely lead to confusion. Trying to appease those who wish to use the new report card in old ways may prove to be problematic to the goal of showing the reader what a student can demonstrate and do against a predetermined standard.

Leaders should ask the group what success will look like and how it will be measured for the community. How will the committee solicit feedback during the process? How will information be disseminated once the new report card is created?

Wilderness Middle School reported only limited success reaching parents and community members once the new report card system started. A face-to-face meeting at the beginning of the year did not prove to be completely effective for W.M.S. Perhaps using email, streaming, and posted video would prove effective (Heflbower et al., 2014). Further engagement of the community can support ambitious initiatives as well (Chadwick, 2004).

\section{Conclusion 5: Employ a Pilot Program}

Research also indicates there may be a benefit to introducing the new report card in limited fashion (Brookhart, 2011). Allowing for one team to pilot the new report card may help schools uncover problems or find unexpected celebrations. Both of these can be helpful in selling the new system to parents, students, and staff. Leaders should not forget that teachers have to become familiar with all the standards they are to teach and likely 
create or revise classroom assessments during this time. As with W.M.S., time becomes an important commodity that should not be overlooked.

Schools concerned with continuing to configuring a GPA or class rank would be wise to take into account how a gradual change would affect those numbers as students move up grade levels. A second system of accounting may be required until those students exit the eighth grade. Working with receiving high schools to support the change will be necessary as well.

School leaders may want to include in their long-term plan revision of homework policy, student goal setting, resource allocation (conference attendance, book studies, consultant fees), and a new report card distribution schedule (i.e., revise sixth grade this year, seventh the year after, and eighth grade the year after seventh). There are many elements and both intended and unintended outcomes to a change this profound. Take your time and get input from others in the school community.

\section{Implications for School Leaders}

As Wilderness Middle School found, there is little in making a change to a standards-based report card that is easy. If it is in the ethos of a visionary school leader to desire all his students to do well then a change in grading may be required. The need for a system that provides support rather than sorts and sifts students is essential. School leaders are advised to be patient and have a well-defined plan to minimize the adverse effects of making the change. A change that can clarify what a student knows and can do can also elicit an emotional response from staff and families. Leaders need to do their homework and involve as many people as practically possible in the planning stages. 
Starting with a well-defined purpose statement like the one given earlier in this paper provides parents, students, and staff a detailed description of what comprises a grade and why. Recognizing that the standards-based grade is a measurement against a specific set of standards and the student's academic progress toward those standards is critical. "Parents are often concerned about changes to a grading system because grades play such an important role in class ranks, grade point averages, scholarship awards, and other important factors that contribute to a student's success in college and careers" (Hoflbower, Hoegh, \& Warrick, 2014, p. 55). It is critical that these factors be addressed in planning.

While the purpose statement is a good starting point, leaders are cautioned to go slow. According to Doug Reeves (2009), for successful change, "leaders should seek short-term wins to gain a long term change." Do not be in a hurry to implement a new report card before the school and parent community understand the reason for the change, the purpose the new report card will serve, and the timeline for the change. Teaching staff need time to learn standards and develop assessments with proficiency scales (rubrics) to assess where students are in relation to those standards. Only then will grades stand a chance of being reliable and valid.

As noted in Marzano (2000), a leader must provide strong logic for the new system. The primary responsibility of the school leader is to help educate the group as it progresses through the grading change. The leader needs to pull together resources, organize meetings with stakeholders, and maintain momentum by the committee. The change to a standards-based report card is not the type of change to be made using a topdown model of decision making. Research from Brookhart (2011a), Guskey (2009a), 
Marzano (2000), and Reeves (2009) all caution against making the change to a standardsbased reporting system, as Wilderness did, without significant understanding and commitment by staff and parents.

The vision of a leader is imperative, and energy to see the change through to its conclusion is critical. The change at Wilderness Middle School was the vision of the assistant superintendent. It was fueled by one administrator who experienced traditional grading as a parent and recognized the problems with the century-old system. He convened a committee consisting of teaching staff, parents, and other administrators. After book studies, conferencing, and school visits, the committee recommendations were adopted by the Board of Education.

After further committee work, a new standards-based report card was adopted. The 8-page, handwritten report proved time-consuming and overwhelming for teachers. The report card included all the sub-standards and reportedly used over 30 reams of paper for the 800 students. A shortened electronic version was adopted in the second year, and a committee reviews the feedback about the report card each summer. Technical challenges matter, and the adaptations that staff make will have to accommodate them and deeper challenges as well that include thinking about grades and the uses to which grades are commonly put.

In the end, Wilderness Middle School designed a hybrid report card that had two separate and distinct goals. While the new format was more descriptive than the traditional letter grade system, those outside of the school influence wanted to keep using report cards in a similar manner. This dichotomy may have minimized the impact of student performance reported by teachers and capitulated to those who needed a 
traditional grade. The school renamed the traditional grade an achievement grade, but this did not alter the meaning of grades, so familiar to everyone.

\section{Recommendations for Further Practice}

Future studies on the transition to a standards-based approach to grading are recommended. This study was focused on just one middle school in Illinois. As more schools look to change their grading practices to a SBG approach different ways to the systemic change will emerge. Further phenomenological case studies may uncover a variety of approaches leading to a change in grading. Wilderness Middle School includes a small sample set and may not be the model for successful transition. New pathways may exist for leaders to employing different perspectives on driving school improvement initiatives (Zimmerman, 2006). Additional questions have been left unexplored by this study and may lead to qualitative or quantitative study:

1. Does school size play a role in the transitioning to a standards-based approach? Does standards-based grading at the middle level stand a better chance taking place in a system with multiple middle schools?

2. If the change initiative comes from the teachers, does it stand a better chance of succeeding?

3. What elements are essential in the professional development of staff when making the change to a standards-based approach to grading?

4. What personal leadership traits and qualities does it take to successfully navigate staff, parents, and students through a change from the traditional reporting system? 


\section{Concluding Remarks}

It takes courage for any educational leader to attempt what the staff at Wilderness Middle School and hundreds of other secondary schools are now trying. Traditional grading practices have existed for centuries, and any attempt to change them will likely be met with resistance. The standards-based approach to grading has the opportunity to best show what a student knows and can do when measured against a predetermined set of standards.

In the past decade, researchers like Brookhart, Guskey, Marzano, O’Connor, and Wormeli brought the discussion of report card grading to the educational community. Now a vibrant and robust debate is occurring as standards increasingly drive education policy. Finding articles, seminars, and dissertations is becoming easier. Over the past decade this researcher has gone from exploring the simple math of grading to reviewing how it fits into the educational process of learning.

This is still not an easy topic to discuss, much less change. Linda Stevens, Director of Curriculum and Assessment of Lake Washington School District in Washington State, may sum it up best,

This is not a task for the faint of heart....All reform on a district-wide scale is tough, but moving a system to true standards-based grading is extraordinarily tough, long-term work and requires district leadership to tenaciously do the right thing for students. Waging war against the status quo requires the willingness to tackle layer after layer of difficulties in order to lead the way to new purposeful assessment and grading practice. (Heflebower et al., 2014, p. 87)

For those brave enough to attempt the change to a standards-based approach at the middle level, this researcher hopes the findings in this study aid in some way. 


\section{REFERENCES}

Adams, J., \& Kirst, M. (1998). New demands and concepts for educational accountability: Striving for results in an era of excellence. Handbook of research in education administration. Washington, DC: American Association of Educational Researchers.

Ainsworth, L. (2003). Unwrapping the standards: A simple process to make standards manageable. Denver, CO: Advanced Learning Press.

Allen, N., McClellan, C., Stoeckel, J., \& National Center for Education Statistics (2005). NAEP 1999 long-term trend technical analysis report: Three decades of student performance. (NCES 2005-484) National Center for Education Statistics, Retrieved from ERIC database.

Anderson, S. E. (1997). Understanding teacher change: Revisiting the concerns based adoption model. Malden, MA: Blackwell.

Ardovino, J., Hollingsworth, J., \& Ybarra, S. (2000). Multiple measures: Accurate ways to assess student assessment ( $1^{\text {st }} \mathrm{ed}$.). Thousand Oaks, CA: Corwin Press.

Argyris, C., \& Schön, D. (1978). Organizational learning: A theory of action perspective, Reading, MA: Addison Wesley.

Atkinson, P., \& Coffey, A. (1996). Making sense of qualitative data: Complimentary research strategies. Thousand Oaks, CA: SAGE Publications.

Barton, P. E. (2009). National education standards: Getting beneath the surface. Princeton, NJ: Educational Testing Service

Bass, B. (1998). Transformational leadership: Industry, military, and educational impact. Mahwah, NJ: Erlbaum.

Berliners, D. C., \& Biddle, B. J. (1995). The manufactured crisis: Myths, fraud, and the attack on America's public schools. New York, NY: Addison-Wesley.

Berridge, G. G. (2006). A qualitative study of stakeholders' beliefs about the use of a standards-based academic reporting system. Unpublished doctoral dissertation, Indiana State University, Terre Haute, IN. 
Black, P., \& Wiliam, D. (1998). Inside the black box: Raising standards through classroom assessment. Phi Delta Kappan, 80(2), 139-148.

Boeije, H. (2002). A purposeful approach to the constant comparative method in the analysis of qualitative interviews. Quality and Quantity, 36(4), 391-409.

Bogdan, R. C., \& Biklen, S. K. (1998). Qualitative research in education: An introduction to theory and methods $\left(3^{\text {rd }}\right.$ ed.). Needham Heights, MA: Allyn \& Bacon.

Bolman, L. G., \& Deal, T. E. (1997). Reframing organizations ( $2^{\text {nd }}$ ed.). San Francisco, CA: Jossey-Bass.

Bolman, L. G., \& Deal, T. E. (2003). Reframing organizations: Artistry, choice, and leadership. San Francisco, CA: Jossey-Bass.

Booth, W. C., Colomb, G. G., \& Williams, J. M. (2008). The craft of research $\left(3^{\text {rd }}\right.$ ed.). Chicago, IL: University of Chicago Press.

Bracey, G. (2009). Basic information. Phi Delta Kappan, 91(2), 97-98. Retrieved from Advanced Placement Source database.

Brookhart, S. M. (1994). Teachers' grading: Practice and theory. Applied Measurement in Education, 7(4), 279-302.

Brookhart, S. M. (2004). Grading (1 ${ }^{\text {st }}$ ed.). Upper Saddle River, NJ: Pearson.

Brookhart, S. M. (2011a). Grading and learning: Practices that support student achievement. Bloomington, IN: Solution Tree Press.

Brookhart, S. M. (2011b). Starting the conversation about grading. Educational Leadership, 69(3), 10-14.

Bryant, M.T. (2004). The portable dissertation advisor. Thousand Oaks, CA: Corwin Press.

Burns, J. M. (2003). Transformational leadership: A new pursuit of happiness. New York: Atlantic Monthly Press.

Bush, H. W. (1991). 1991 Inaugural Address, Washington, DC: US Government Printing Office.

Butler, S. M., \& McMunn, N.D. (2006). A teacher's guide to classroom assessment: Understanding and using assessment to improve student learning. San Francisco, CA: Jossey-Bass. 
Carnegie Forum on Education and the Economy. (1986). A nation prepared: Teachers for the $21^{\text {st }}$ century. The report of the task force on teaching as a profession. New York, NY: Carnegie Corporation.

Cherniss, A. (2008). Standards based report card: Teachers' perceptions on the development, transition, and implementation. Dissertation, University of Southern California, Los Angeles, CA. Retrieved on 12/20/2011 from http://gradworks.umi.com/33/11/3311106.html

Colby, S. A. (1999). Grading in a standards-based system. Educational Leadership, 56(6) 52-55.

Council of Chief State School Officers \& National Governors Association for Best Practices. (2010). Common Core State Standards initiative. Washington, DC: Retrieved 08/12/2011 from www.corestandards.org/the-standards

Covey, S. R. (1989). The seven habits of highly effective people: Restoring the character ethic. New York, NY: Simon \& Schuster.

Creswell, J. W. (2003). Research design: Qualitative, quantitative, and mixed methods approaches $\left(2^{\text {nd }}\right.$ ed.). Chicago, IL: University of Chicago.

Cross, L. H., \& Frary, R. B. (1996). Hodgepodge grading: Endorsed by students and teachers alike. Paper presented at the annual meeting of the National Council on Measurement in Education, New York. Retrieved 12/11/2011 from EBSCO host.

Darling-Hammond, L. (2010). The flat world and education: How America's commitment to equity will determine our future. New York, NY: Teachers College Press.

Deddah, H, Main, E., \& Fulkerson, S. (2010). Eight steps to meaningful grading: Moving from traditional grading to standards-based grading improves student learning in one Michigan middle school. Phi Delta Kappan, 91(7), 53-58.

Denzin, N. K., \& Lincoln, Y. S. (2008). The landscape of qualitative research ( ${ }^{\text {rd }}$ ed.). Los Angeles, CA: Sage.

Diegmueller, K. (1995). Running out of steam. Education Week, 14(29), 4-5.

DuFour, R., DuFour, R., Eaker, R., \& Karhanek, G. (2004). Whatever it takes: How professional learning communities respond when kids don't learn ( $\left.1^{\text {st }} \mathrm{ed}.\right)$. Bloomington, IN: National Educational Service.

Elmore, R. F. (2002). Bridging the gap between standards and achievement. Washington, DC: Albert Shanker Institute. 
Erickson, J. A. (2010). Grading practices: The third rail. Principal Leadership, 10(7), 22-26.

Erickson, J. A. (2011). How grading reform changed our school. Educational Leadership, 69(3), 66-70.

Flyvbjerg, B. (2006). Five misunderstandings about case-study research. Qualitative Inquiry, 12(2), 219-245.

Fullan, M. (1993). Change forces: Probing the depths of educational reform. Levittown, PA: Falmer Press.

Fullan, M. (2001). Leading in a culture of change: Being effective in complex times $\left(1^{\text {st }}\right.$ ed.). San Francisco, CA: Jossey-Bass.

Fullan, M. (2010). Motion leadership: The skinny on becoming change savvy. Thousand Oaks, CA: Corwin Press.

Fullan, M., \& Miles, M. B. (1992). Getting reforms right: What works and what doesn't. Phi Delta Kappan, 73(10), 745-752.

Grant, J. (2007). The death of common sense in our schools and what you can do about it! Peterborough, NH: Crystal Springs Books.

Grenda, J. P. (2011). Instances and principles of distributed leadership: A multiple case study of Illinois middle school principals' leadership practices. (Unpublished doctoral dissertation) University of Illinois, Urbana.

Guskey, T. R. (2001). Helping standards make the grade. Educational Leadership, 59(1), 20-27.

Guskey, T. R. (2002). How's my kid doing? A parent's guide to grades, marks, and report cards. San Francisco: Jossey-Bass.

Guskey, T. R. (2004a). Are zeros your ultimate weapon? Education Digest, 70(3), 5.

Guskey, T. R. (2004b). Stability and change in high school grades. San Diego, CA: American Education Research Association.

Guskey, T. R. (2005, April). The battle over report cards: Developing effective grading and reporting systems. Presentation at the annual ASCD Conference, Orlando, Fl.

Guskey, T. R. (2006, June). "It wasn't fair!": Educators' recollection of their experiences as students with grading. Paper presented at the annual meeting of the American Educational Research Association, San Francisco, CA. 
Guskey, T. R. (2009a). Practical solutions for serious problems in standards-based grading. Thousand Oaks, CA: Corwin Press.

Guskey, T. R. (2009b). The principal as assessment leader. Thousand Oaks, CA: Corwin Press.

Guskey, T. R. (2011). Five obstacles to grading reform. Educational Leadership, 69(3), $16-21$.

Guskey, T. R., \& Bailey, J. M. (2001). Developing grading and reporting systems for student learning. Thousand Oaks, CA: SAGE Publications.

Guskey, T. R., \& Bailey, J. M. (2010). Developing standards-based report cards. Thousand Oaks, CA: SAGE Publication.

Guskey, T. R., \& Jung, L. A. (2006). The challenges of standards-based grading: A wellplanned report card can help parents relate standards to their children. Leadership Compass, 4(2).

Guskey, T.R., Swan, G. M., \& Jung, L.A. (2011). Grades that mean something: Kentucky develops standards-based report cards. Phi Delta Kappan, 92(2), 5257.

Hafer, A. (2000). Prisoners of the paradigm: What school board members, legislators, and community leaders must know to reform American public education. Boulder, CO: FalCo Books.

Hallinger, P. (2003). Leading educational change: Reflections on the practice of instructional and transformational leadership. Cambridge Journal of Education, 33(3), 329-351.

Hamilton, L. S., Stecher, B. M., \& Yuan, K. (2008). Standards-based reform in the United States: History, research, and future directions. Washington, DC: Rand Corporation.

Hargreaves, A., \& Fullan, M. (2009). Change wars. Bloomington, IN: Solution Tree Press.

Hattie, J. (2009). Visible learning: A synthesis of over 800 meta-analyses relating to achievement. New York, NY: Routledge.

Heath, C., \& Heath, D. (2009). Switch: How to change things when change is hard. New York, NY: Broadway Books.

Heflebower, T., Hoegh, J.K., \& Warrick (2014). A school leader's guide to standardsbased grading. Bloomington, IN: Marzano Research Laboratory. 
Heifetz, R. A., Linsky, M., \& Grashow, A. (2009). Practice of adaptive leadership: Tools and tactics for changing your organization and the world. Cambridge, MA: Belknap Press of Harvard University Press.

Heifetz, R. A. (1994). Leadership without easy answers. Cambridge, MA: Belknap Press of Harvard University Press.

Illinois State Board of Education. (1997). Illinois State Learning Standards. Retrieved May 26, 2010, from http://www.isbe.state.il.us/ils/social_science/standards.htm.

Johnson, J. K. S. (2001). The grading of elementary student performance on a standards-based report card [Dissertation]. Retrieved from ProQuest. (UMI 3013976).

Joseph, L. B. (Ed.). (2001). Education policy for the 21 $1^{\text {st }}$ century: Challenges and opportunities in standards-based reform. Chicago, IL: University of Illinois Press.

Jung, L., \& Guskey, T. (2007). Standards-based grading and reporting. Teaching Exceptional Children, 40(2), 48-53.

Klein, D. (2003). A brief history of American k-12 mathematics education in the $20^{\text {th }}$ century. In J. Royer (Ed.), Mathematical cognition. New York, NY: Information Age.

Koerner, T. (1988). In search of excellence-A talk with Tom Peters about the principalship. A "Bulletin" Special. NASSP Bulletin, 72(512), 36-45. Retrieved from ERIC database.

Kohn, A. (1992). No contest: The case against competition. New York, NY: Houghton Mifflin.

Kohn, A. (1998). What to look for in a classroom ... and other essays. San Francisco, CA: Jossey-Bass.

Kohn, A. (2004). What does it mean to be well educated? And more essays on standards, grading, and other follies. Boston: Beacon Press.

Kohn, A. (2011). The case against grades. Educational Leadership, 69(3), 28-33.

Kozol, J. (2005). The shame of the nation. New York, NY: Three Rivers.

Kvale, S. (1996). Interviews: An introduction to qualitative research interviewing. Thousand Oaks, CA: SAGE.

Lambert, L. (1998). How to build leadership capacity. Educational Leadership, 55(7), 17-19. 
Leithwood, K., \& Steinbach, R. (1991). Indicators of transformational leadership in everyday problem solving of school administration. Journal of Personnel Evaluation in Education. [Electronic version,] 221-224.

Lindahl, R. A. (2010). Framing school improvement as deuteron learning: The road less traveled. Planning and Changing, 41(3/4), 234-248.

Muhammad, A. (2009). Transformational school culture: How to overcome staff division. Bloomington, IN: Solution Press.

Marzano, R. J. (2000). Transforming classroom grading. Alexandria, VA: Association for Supervision and Curriculum Development.

Marzano, R. J. (2001). Classroom instruction that works: Research-based strategies for increasing student achievement ( $1^{\text {st }}$ ed.). Alexandria, VA: Association for Supervision and Curriculum Development.

Marzano, R. J. (2003). What works in schools: Translating research into action. Alexandria, VA: Association for Supervision and Curriculum Development.

Marzano, R. J. (2006). Classroom assessment and grading that work ( $1^{\text {st }}$ ed.). Alexandria, VA: Association for Supervision and Curriculum Development.

Marzano, R. J. (2007). The art and science of teaching: A comprehensive framework for effective instruction ( $1^{\text {st }}$ ed.). Alexandria, VA: Association for Supervision and Curriculum Development.

Marzano, R. J. (2010). Formative assessment \& standards-based grading: Classroom strategies that work. Alexandra, VA: Association for Supervision and Curriculum Development.

Marzano, R. J., \& Heflebower, T. (2011). Grades that show what we know. Educational Leadership, 69(3), 34-39.

Marzano, R. J., \& Kendall, J. S. (1996). A comprehensive guide to designing standardsbased districts, schools, and classrooms ( $1^{\text {st }} \mathrm{ed}$.). Alexandria, VA: Association for Supervision and Curriculum Development.

Marzano, R., Waters, J. T., \& McNulty, B. (2005). School leadership that works: From research to results. Alexandria, VA: ASCD.

Massell, D. (2001). The theory and practice of using data to build capacity: State and local strategies and their effects. In S. H. Fuhrman (Ed.), From the capitol to the classroom: Standards-based reform in the states. One hundredth yearbook of the National Society for the Study of Education (pp. 148-169). Chicago, IL: National Society for the Study of Education. 
Maxwell, J. C. (2000). Failing forward: Turning mistakes into stepping stones for success. Nashville, TN: Thomas Nelson.

McNunn, N., Schenck, P., \& McColskey, W. (2003). Standards-based assessment, grading, and reporting in classrooms: Can district training and support change teacher practice? Paper presented at the annual meeting of the American Educational Research Association, Chicago, IL.

Meier, D. \& Wood, G. (Eds.) (2004). Many children left behind: How the No Child Left Behind Act is damaging our children and our schools. Boston: Beacon Press.

Merriam, S. B. (1998). Qualitative research and case study applications in education. San Francisco, CA: Jossey-Bass.

National Center for Educational Statistics. (2009). The nation's report card: 2007 at a glance. NCES 2009-486. National Center for Educational Statistics. Retrieved from ERIC database 8/10/2010.

National Commission on Excellence in Education. (1983). A Nation at Risk: The imperative for educational reform. Washington, DC: U.S. Government Printing Office.

No Child Left Behind Act, 107-110, 115 STAT. 1425 (2002).

O'Connor, K. (2002). How to grade for learning: Linking grades to standards (2 ${ }^{\text {nd }}$ ed.). Thousand Oaks, CA: Corwin Press.

O'Connor, K. (2005). How to challenge 14 traditional and inappropriate ways to determine grades. Presentation at annual ASCD conference, Orlando, FL.

O'Connor, K. (2007). A repair kit for grading: 15 fixes for broken grades $\left(1^{\text {st }} \mathrm{ed}\right.$.). Portland, OR: Educational Testing Service.

O'Connor, K. (2009). How to grade for learning: Linking grades to standards ( ${ }^{\text {rd }}$ ed.). Thousand Oaks, CA: Corwin Press.

O’Connor, K., \& Wormeli, R. (2011). Reporting student learning. Educational Leadership, 69(3), 40-44.

Peterson, P. E. (2010). Save our schools: From Horace Mann to virtual learning. Cambridge, MA: Belknap Press of Harvard University Press.

Pollack, J. E. (2009). Improving student learning one principal at a time. Alexandria, VA: Association for Supervision and Curriculum Development. 
Popham, W. J. (2004). America's "failing" schools: How parents and teachers can cope with No Child Left Behind. New York, NY: Routledge Falmer.

Porter, A. (2011). In common core, little to cheer about. Education Week, 30(37), 24-25.

Randall, J., \& Engelhard, G. (2008). Differences between teachers' grading practices in elementary and middle schools. Journal of Educational Research, 102(3), 19586.

Ravitch, D. (2010). The death and life of the great American school system: How testing and choice are undermining education. New York, NY: Basic Books.

Reeves, D. B. (2004). Accountability for learning: How teachers and school leaders can take charge $\left(1^{\text {st }}\right.$ ed.). Alexandria, VA: Association for Supervision and Curriculum Development.

Reeves, D. B. (2007). Ahead of the curve: The power of assessment to transform teaching and learning. Bloomington, IN: Solution Tree Press.

Reeves, D. B. (2008). Reframing teacher leadership: To improve your school. Alexandria, VA: Association for Supervision and Curriculum Development.

Reeves, D. B. (2009). Leading change in your school: How to conquer myths, build commitment, and get results. Alexandria, VA. Association for Supervision and Curriculum Development.

Reeves, D. B. (2011). Taking the grading conversation public. Educational Leadership, 69(3), 76-81.

Romanoski, M. H. (2004). Student obsession with grades and achievement. Kappan Delta Pi Record, 40, 149-151.

Saldana, J. (2010). The coding manual for qualitative researchers. Thousand Oaks, CA: SAGE.

Schlechty, P. C. (2002). Working on the work: An action plan for teachers, principals, and superintendents. San Francisco, CA: Jossey-Bass.

Schlechty, P. C. (2005). Creating great schools: Six critical systems at the heart of educational innovation. San Francisco, CA: Jossey-Bass.

Schmidt, W. H., Houang, R., \& Shakrani, S. (2009). International lessons about national standards. Lansing, MI: Michigan State University.

Scriffiny, P. (2008). Seven reasons for standards-based grading. Educational Leadership, 66(2) 70-74. 
Seidman, I. E. (1991). Interviewing as qualitative research: A guide for researchers in education and the social sciences. New York, NY: Teachers College Press.

Shepard, L. (1995). Using assessment to improve learning. Educational Leadership, $53(5) 38-43$.

Smith, M., O'Day, J., \& Cohen, D. (1991). A national curriculum in the United States? Educational Leadership, 49(1), 74. Retrieved on 10/04/2010, from Middle Search Plus database

Spring, J. (1997). Political agendas for education: From the Christian coalition to the green party. Mahwah, NJ: Lawrence Erlbaum Associates.

Spring, J. (2005). Conflict of interests: The politics of American education. New York, NY: McGraw Hill.

Spring, J. (2010). Political agendas for education: From change we can believe in to putting America first ( $4^{\text {th }}$ ed.). New York: Routledge Taylor \& Francis Group.

Stake, R. E. (1995). The art case of case study research. Thousand Oaks, CA: SAGE.

Stiggins, R. J. (2001). Student-involved classroom assessment ( $3^{\text {rd }}$ ed.). Upper Saddle River, NJ: Merrill Prentice Hall.

Stiggins, R. J. (2002). Assessment crisis: The absence of assessment for learning. Phi Delta Kappan, 83(10), 758-765.

Stiggins, R. J., Arter, J., Chappuis, J., \& Chappuis, S. (2004). Classroom assessment for student learning: Doing it right-Using it well. Portland, OR: Assessment Training Institute.

Taylor, F. W. 2005 [1916]. The principles of scientific management. In J. M. Shafritz, J. S. Ott, \& Y. S. Jang (Eds.), Classics of organization theory $\left(6^{\text {th }} \mathrm{ed}\right)$, Belmont, CA: Thomson-Wadsworth.

U.S. Department of Education. (1983). A nation at risk: The imperative for educational reform. U.S. Department of Education. Retrieved April 7, 2010, from http://www2.ed.gov/pubs/NatAtRisk/recomm.html

U.S. Department of Education. (2002). No child left behind act. U.S. Department of Education. Retrieved October 17, 2009, from www.ed.gov/nclb/accountability/index.html.

U.S. Department of Education. (2009). Race to the top. U.S. Department of Education. Retrieved August 1, 2010, from http://www2.ed.gov/programs/racetothetop/index.html 
Wagner, T., \& Kegan, R. (2006). Change leadership: A practical guide to transforming our schools. San Francisco, CA: Jossey-Bass.

Wheatley, M. (1992). Leadership and the new science: discovering order in a chaotic world. Berrett-Koehler Publishers.

Whitney, D. T., Culligan, J. J., \& Brooksher, P. T. (2006). Truth in grading: Troubling issues with learning assessment. Lincoln, NE: iUniverse.

Winger, T. (2005). Grading to communicate. Educational Leadership, 63(3), 61-65.

Wormeli, R. (2006a). Fair isn't always equal. Portland, ME: Steinhouse.

Wormeli, R. (2006b). Accountability: Teaching through assessment and feedback, not grading. American Secondary Education, (34)3, 14-27.

Wormeli, R. (2011). Redos and retakes done right. Educational Leadership, 69(3), 2226.

Yin, R. K. (2009). Case study research: Design and methods ( $4^{\text {th }}$ ed.). Thousand Oaks, CA: SAGE.

Zimmerman, J. (2006). Why some teachers resist change and what principals can do about it. NASSP Bulletin: 90 (3) 238-249. 
APPENDIX A

LETTER OF CONSENT 
Dear

(Name of Participant)

Federal and university regulations require signed consent for participation in research involving human subjects. Information regarding the present study is provided below to help you decide whether you wish to voluntarily partake in the study. After reading the statements, please indicate your willingness to be involved in the study by signing this letter. You will be given copy of this consent form for your records. Please be informed that you are free to end your participation at any time with no penalty imposed. If at any time, prior to, during, or after your participation is completed, you have any questions or concerns regarding this study or if you have any questions about your rights as a participant in this research or if you feel you have been placed at risk, you can contact the Research Ethics \& Compliance Office at Illinois State University at (xxx) xxxxxxx.

Title of Research: Transitioning to a Standards-based Grading Model at the Middle Level

Principal Investigator: Dr. Dianne Gardner

Co-Principal Investigator: Jeffrey Szymczak

Department: Educational Administration and Foundations, Illinois State University

Procedure: I am a graduate student under the direction of Dr. Dianne Gardner in the College of Educational Administration and Foundations at Illinois State University. I am conducting a research study on standards-based grading practices. In order to add to the body of knowledge on standards-based grading practices, I wish to learn more about what practices and processes you have been using. I am requesting your participation, which will involve a short survey, possible interview sessions and I may observe you in a team or faculty meeting.

If you agree to participate in this study, you will be asked to complete an emailed or paper-based survey questionnaire. The two surveys contain the same questions; only the format for administration is different. Should you prefer a paper copy of the survey, one will be emailed or mailed to you upon request. In this survey, you will be asked questions about your history with Wilderness Middle School and your experiences in moving towards a standards-based grading system. The survey will take approximately 5-10 minutes of your time. Prior to beginning the survey, please indicate your willingness to submit your data. This consent letter acknowledges that you have granted permission to the researcher to document your responses.

If selected to participate in the study, you will be interviewed at your school or mutually agreeable off -site location In order to represent your experiences and ideas fully, a digital audio-recording will be made of our interview. I will listen to the recordings and a professional transcription service will make convert them into text to enable analysis. No audio recordings will be made public.

Please be advised that your participation in this study is voluntary, and you may withdraw at any time. If you do choose to withdraw, there will be no penalty of any kind. In addition, throughout surveys or interview, you are not expected to discuss any material that is emotionally sensitive or will make you feel uncomfortable in any capacity. Your input will be used in a written report regarding this research topic, and results of this study may be published. However, your identification will remain confidential, and I will take all precautions to protect your privacy. Results of the study will only be reported as an aggregate. Finally, the information you provide will not be used in any way to impact assessment of your employment performance. 
Risks and Discomforts: This study involves no risk of physical injury or discomfort. I will ensure that all information and findings are kept confidential. While very slight, social and reputational risks are possible. Views and beliefs of individuals may not be those exposed publically in the school and district. However, during the survey or interview or at any other point during the study, you have the right to skip over any question that makes you feel uncomfortable. If you choose not to participate or withdraw from this study at any time, there will be no penalty of any kind. Please be advised that the results of this study will be published, but a pseudonym will be assigned and your actual name will not be used. I will take all precautions to maintain confidentiality before, during and after the study.

Benefits: Although there may be no direct benefit to you, the possible benefit of your participation is to be a contributing participant in research that will add to the body of knowledge on moving to a standards-based grading practice at the middle level. Those participating may assist those studying the field of educational leadership. While it is hoped that you will benefit from the opportunity to discuss your views and opinions, there may be no other direct benefit to you as a result of your participation.

Confidentiality: Any information collected during the course of this study will be kept in a locked filing cabinet in the co-principal investigator's office. Your results will be combined with those of other participants and they will be studied only in this fashion. If the data are used for conference presentations, publications in research journals, or for teaching purposes, no names or identifiers will be used. Any data collected and used will be destroyed one year from completion of the study.

I certify that I have read and understand this consent form and agree that known risks to me have been explained to my satisfaction and I understand that 1 will receive no compensation for participating in this research. I certify that I am 18 years of age or older. My participation in this research is given voluntarily. I understand that I may discontinue participation at any time without penalty or loss of any benefits to which I may otherwise be entitled. I certify that I have been given a copy of this consent form to take with me.

If you have any questions concerning this research study, please call me at (xxx) xxx-xxxx.

Thank you very much for your willingness to participate in this research study.

Sincerely,

Jeffrey Szymczak

Participant's Printed Name

Participant's Signature

If you have questions on research participants' rights, and/or would like to file research related injury or adverse effect. Contact the Research Ethics \& Compliance Office at Illinois State University: (309) 438-2529. 


\section{APPENDIX B}

\section{OBSERVATIONAL GRADING PROTOCOL FRAMEWORK}




\begin{tabular}{|c|c|c|}
\hline TraditionalGrading & TransitionalGrading & Standards-BasedGrading \\
\hline $\begin{array}{l}\text { Included in grade: Includes many extraneous } \\
\text { elements that are included in the grading process. } \\
\text { These may include attendance, attitude/behavior, } \\
\text { participation, extra credit, homework/practice, and } \\
\text { tests/quizzes, projects. }\end{array}$ & $\begin{array}{l}\text { Included in grade: Staff is often struggling with } \\
\text { elements of traditional grading. Some traditional } \\
\text { elements begin to be eliminated, but grades are not } \\
\text { yet tied to a discernible learning standard. Elements } \\
\text { like attendance, attitude/behavior, participation, } \\
\text { extra credit, and homework/practice are scrutinized, } \\
\text { but not necessarily abolished. }\end{array}$ & $\begin{array}{l}\text { Included in grade: Educators would be focusing on } \\
\text { the measuring students against only the designated } \\
\text { standards. Extraneous elements are all but } \\
\text { eliminated from the grading. }\end{array}$ \\
\hline $\begin{array}{l}\text { Teacher Practice: Grading is a function of } \\
\text { "tradition" and is rarely thought of as problematic. } \\
\text { Arithmetic such as "averaging" or "point total" are the } \\
\text { two popular methods to configure a grade. Little or no } \\
\text { discussion is held on the subject. Problems are seen } \\
\text { as with the student (i.e. the student is lazy, has low } \\
\text { abilities or skills, or is a behavior issue). }\end{array}$ & $\begin{array}{l}\text { Teacher Practice: Staff is often investigating } \\
\text { different ways to grade their students. The impact of } \\
\text { removing homework and extra credit. Discussion on } \\
\text { viewing grades as a method to separate ability levels } \\
\text { from the calculation of grades may be discussed. }\end{array}$ & $\begin{array}{l}\text { Teacher Practice: Staff is looking to connect } \\
\text { activities and learning to a set of identified standards. } \\
\text { They are looking to find the best learning experiences } \\
\text { to maximize a students learning. When one } \\
\text { experience does not work, they collaborate to find } \\
\text { others. }\end{array}$ \\
\hline $\begin{array}{l}\text { Report Cards: A single letter or number represents } \\
\text { all elements of grading. The document is rarely } \\
\text { longer than one page. This type of report card most } \\
\text { students and parents are accustomed to seeing. }\end{array}$ & $\begin{array}{l}\text { Report Cards: Letter grades are often accompanied } \\
\text { by comments or another symbol to express effort, } \\
\text { progress, or attitude. This type of report card may be } \\
2-3 \text { pages in length. }\end{array}$ & $\begin{array}{l}\text { Report Cards: Reporting systems compare a } \\
\text { student's work to a standard. Each subject area may } \\
\text { have several indicators noted. This reporting system } \\
\text { could be more than 2- } 10 \text { pages in length. }\end{array}$ \\
\hline $\begin{array}{l}\text { Parent/Teacher Communication: } \\
\text { Communication tends to be more reactive. Discipline } \\
\text { problems or poor grades may require a parent contact. } \\
\text { Conferences are teacher centered and directive. The } \\
\text { goal is often to "fix" the child. }\end{array}$ & $\begin{array}{l}\text { Parent/Teacher Communication: Staff may be } \\
\text { inquiring about better ways to communicate with } \\
\text { parents. Less traditional methods may include } \\
\text { Student-Led Conferencing, parent university nights, or } \\
\text { other meet and greet opportunities where parents, } \\
\text { staff, and students can communicate about the child's } \\
\text { needs. The goal is to communicate about the } \\
\text { student's accomplishments. }\end{array}$ & $\begin{array}{l}\text { Parent/Teacher Communication: Staff in a S-B } \\
\text { grading school would be tying the products of a } \\
\text { student as measured against an identified standard. } \\
\text { The conversation would center on what the child, } \\
\text { parent, and staff members can do to help the student } \\
\text { achieve those standards not yet attained or strive for } \\
\text { others. }\end{array}$ \\
\hline $\begin{array}{l}\text { Standardized Assessment Reports: Reports like } \\
\text { the CoGAT, AIMSWeb Reading fluency, Explore, } \\
\text { Measurement for Academic Progress (MAP), or ISAT } \\
\text { assessments are not used to direct instruction. They } \\
\text { are seen as an indicator as of that day (benchmarks) } \\
\text { and not usually used except to enter or exit students } \\
\text { from programs. }\end{array}$ & $\begin{array}{l}\text { Standardized Assessment Reports: Reports are } \\
\text { reviewed by staff then curriculum decisions may be } \\
\text { made based on the data provided in the reports. } \\
\text { Teachers begin being trained how to on using the data } \\
\text { provided in the reports to direct curriculum decisions. } \\
\text { Decisions still may be made in isolation and by subject } \\
\text { or grade level. }\end{array}$ & $\begin{array}{l}\text { Standardized Assessment Reports: Reports are } \\
\text { often seen as a way to validate what teachers are } \\
\text { seeing from students on the standard-based } \\
\text { assessments. They are used to re-direct curriculum } \\
\text { for individuals and meet a student's needs. They are } \\
\text { seen as a diagnostic tool for the teacher as well as the } \\
\text { student. The process is very collaborative in design. } \\
\text { Decisions are made as a larger group. }\end{array}$ \\
\hline $\begin{array}{l}\text { Teacher Meetings: Meeting time conversing on } \\
\text { grading centers around securing students with } \\
\text { missing work. The use of zero's is likely in place and } \\
\text { phrases similar to "student responsibility" are used. } \\
\text { Grades are often the tool used to encourage wanted } \\
\text { behaviors and to curb unwanted ones. }\end{array}$ & $\begin{array}{l}\text { Teacher Meetings: Staff is seeking a better way to } \\
\text { communicate student progress to parents. } \\
\text { Communication and collaboration on grading is often } \\
\text { spent investigating ideas. Since the grading system is } \\
\text { not fully in place much would still need to be } \\
\text { discussed. Professional Learning Community time is } \\
\text { often incorporated with its four tenets (DuFour, } \\
\text { 2006). }\end{array}$ & $\begin{array}{l}\text { Teacher Meetings: Staff meeting time could be } \\
\text { spent on strategies to get students to be proficient on } \\
\text { standards. Since the reporting system is fully } \\
\text { operational and tied to specific indicators, staff would } \\
\text { be free to focus solely on individual student's needs. } \\
\text { "What do I need to do as an instructor to get the } \\
\text { student to the next level?" We would expect to see } \\
\text { more instructional planning. }\end{array}$ \\
\hline $\begin{array}{l}\text { Standardized Assessment Reports: Teacher web } \\
\text { pages will often display a grading scale. Since a web } \\
\text { based document is not a requirement for standards- } \\
\text { based grading this may not always be evident. }\end{array}$ & $\begin{array}{l}\text { Standardized Assessment Reports: Grading } \\
\text { scales may still be posted online. The school or } \\
\text { district may have information about meetings on } \\
\text { grading or documents under review. Since a web } \\
\text { based document is not a requirement for standards- } \\
\text { based grading this may not always be evident. }\end{array}$ & $\begin{array}{l}\text { Standardized Assessment Reports: } \\
\text { School/district reporting system will normally be } \\
\text { evident. However, it is noted a web-based document } \\
\text { is not a requirement for standards-based grading this } \\
\text { may not always be evident. }\end{array}$ \\
\hline $\begin{array}{l}\text { School Open Houses/Curriculum Nights: } \\
\text { During meetings held early in the year, teachers may } \\
\text { hand out upcoming activities and discuss expectations } \\
\text { for students.Parents may be given a grading scale, } \\
\text { rubric, syllabus, or outline of the class. }\end{array}$ & $\begin{array}{l}\text { School Open Houses/Curriculum Nights: If a } \\
\text { change in grading has recently been introduced, a } \\
\text { thorough explanation of the new grading system may } \\
\text { occur. Many questions would need to be answered } \\
\text { and a Frequently Asked Question (F.A.Q) may be a } \\
\text { document provided or on the net. }\end{array}$ & $\begin{array}{l}\text { School Open Houses/Curriculum Nights: Open } \\
\text { house or curriculum nights are less about the grade } \\
\text { and centered mainly on the standards to be covered in } \\
\text { the upcoming weeks/months. Standards-based } \\
\text { grades have been established as a reflective method of } \\
\text { reporting where a student is in relation to a given } \\
\text { standard. }\end{array}$ \\
\hline $\begin{array}{l}\text { Homework: Homework to many teachers is an } \\
\text { important element to the grading process. Teacher } \\
\text { may speak of the responsibility or work ethic of a } \\
\text { student as they complete (or do not complete) } \\
\text { homework. Teacher may give points for completion } \\
\text { or use the grade to offset poor performance on } \\
\text { tests/quizzes. }\end{array}$ & $\begin{array}{l}\text { Homework: The role of homework in the grading } \\
\text { and learning process may begin to be challenged. } \\
\text { Many educators will see it as necessary practice for } \\
\text { most of their students. Procedures and staff } \\
\text { discussions may begin to change. }\end{array}$ & $\begin{array}{l}\text { Homework: Homework is seen as important, but } \\
\text { only practice. Grading homework has been } \\
\text { abandoned. Students are still given opportunities to } \\
\text { practice (homework), but the grade is seldom or never } \\
\text { used as an entry in the grade book. }\end{array}$ \\
\hline $\begin{array}{l}\text { Student Awareness: Students are often acutely } \\
\text { aware of the their percentage or point total. When a } \\
\text { new assignment is given the students often want to } \\
\text { know the worth of the assignment and the weight. } \\
\text { The teacher may hear statements like, "How many PO } \\
\text { points is this worth?" }\end{array}$ & $\begin{array}{l}\text { Student Awareness: Students may first become } \\
\text { aware of the standard they are trying to reach. } \\
\text { Rubrics may give a clearer understanding of what is } \\
\text { expected. Target boards may even show examples of } \\
\text { acceptable work. The students are aware of the } \\
\text { standard they are trying to achieve. } \\
\text { Students are still often aware of the point value or } \\
\text { weight of each assignment. }\end{array}$ & $\begin{array}{l}\text { Student Awareness: Teachers ensure } \\
\text { Metacognition is part of the learning process. } \\
\text { Students are not only aware of the standards to be } \\
\text { learned but also where they are in relationship to that } \\
\text { standard. } \\
\text { Teachers post standards when planning and note } \\
\text { standards on board in classroom. In addition, the } \\
\text { students would know and understand what steps are } \\
\text { necessary to achieve each standard. Learning is } \\
\text { emphasized over grades. }\end{array}$ \\
\hline
\end{tabular}


APPENDIX C

WILDERNESS REPORT CARDS 


\section{Seventh Grade Report Card - page 1}

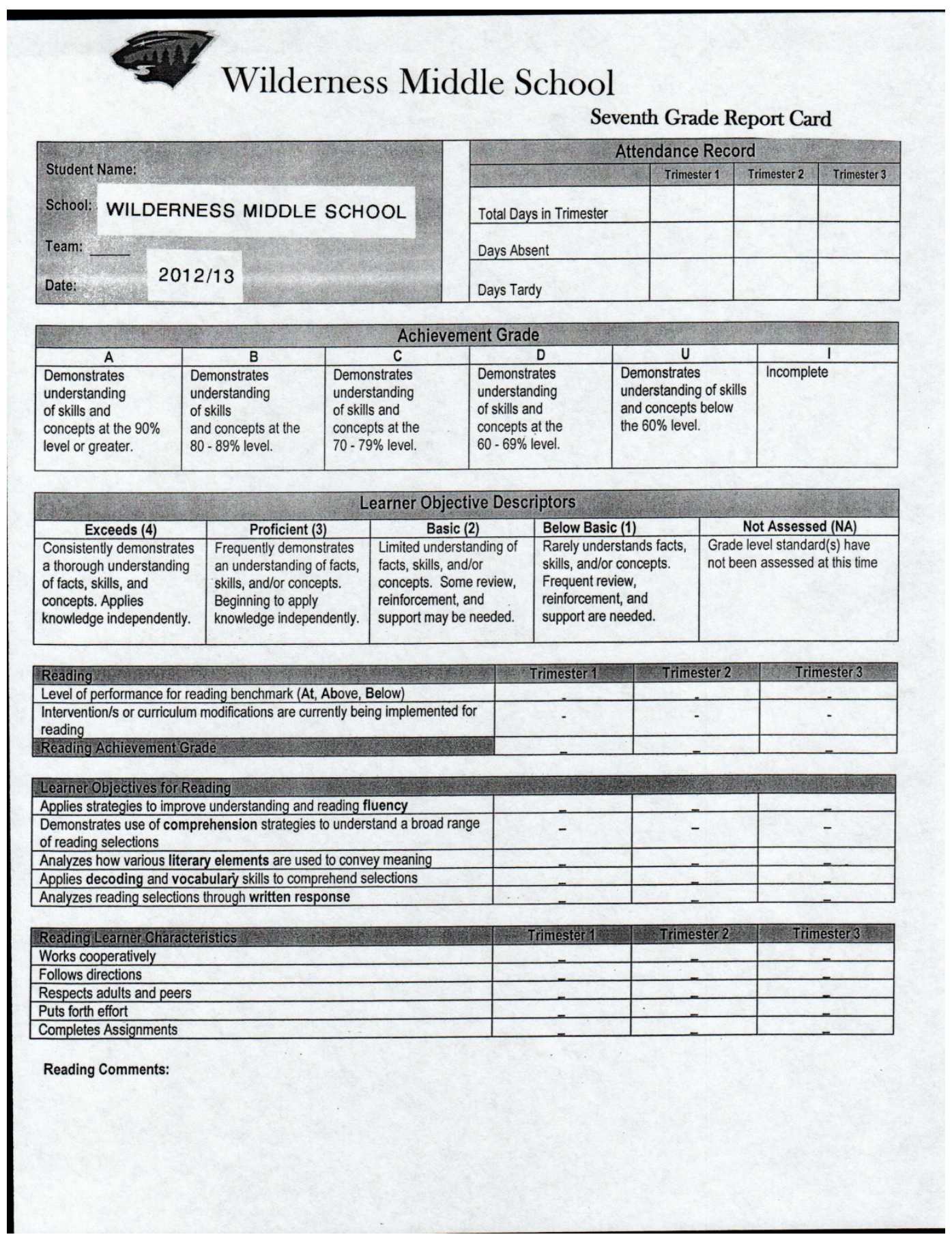


Seventh Grade Report Card - page 2

Wilderness Middle School

Seventh Grade Report Card

\begin{tabular}{|l|c|c|c|}
\hline Language Arts & Trimester 1 & Trimester 2 & Trimester 3 \\
\hline Level of performance for language arts (At, Above, Below) & - & - & - \\
\hline $\begin{array}{l}\text { Intervention/s or curriculum modifications are currently being implemented for } \\
\text { language arts }\end{array}$ & - & - & \\
\hline Language Arts Achievement Grade & - & - & \\
\hline
\end{tabular}

Language Arts Achievement Grade

\begin{tabular}{|c|c|c|c|}
\hline \multirow{2}{*}{\multicolumn{4}{|c|}{$\begin{array}{l}\text { Learner Objectives for Language Arts } \\
\text { Applies writing strategies to a variety of contexts and tasks }\end{array}$}} \\
\hline & & & \\
\hline $\begin{array}{l}\text { Implements the writing process and traits of good writing in a variety of } \\
\text { tasks }\end{array}$ & - & - & - \\
\hline $\begin{array}{l}\text { Demonstrates a command of the conventions of standard English when } \\
\text { writing, speaking, or listening. }\end{array}$ & - & - & - \\
\hline Applies word study strategies in daily writing & & - & \\
\hline
\end{tabular}

Applies listening and speaking strategies to a variety of contexts and tasks

\begin{tabular}{|l|c|c|c|}
\hline Language Arts Learner Characteristics & Trimester 1 & Trimester 2 & Trimester 3 \\
\hline Works cooperatively & - & - & \\
\hline Follows directions & - & - & - \\
\hline Respects adults and peers & - & - & \\
\hline Puts forth effort & - & - & \\
\hline Completes Assignments & - & - & - \\
\hline
\end{tabular}

Completes Assignments

Language Arts Comments:

Mathematics

Level of performance for mathematics (At, Above, Below, Accelerated,

Honors)

Intervention/s or curriculum modifications are currently being-implemented for mathematics

Mathematics Achievement Grade

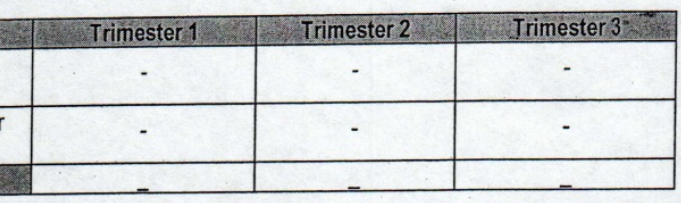

Learner Objectives for Mathematics

Demonstrates and applies a knowledge and sense of numbers

Estimates, makes and uses measurements of objects

Uses algebraic methods to identify patterns and relationships to solve

problems

Uses geometric methods to analyze, categorize and draw conclusions about

points, lines, polygons, area and perimeter

Collects, organizes and analyzes data using statistical methods

Uses planning and processing skills to solve problems

Mathematics Learner Characteristics

Works cooperatively

Follows directions

Respects adults and peers

Puts forth effort

Completes Assignments

\begin{tabular}{|c|c|c|c|}
\hline & Trimester-1 & Trimester 2 & Trimester 3 \\
\hline & - & - & - \\
\hline & - & - & - \\
\hline & - & - & - \\
\hline
\end{tabular}

Mathematics Comments: 
Seventh Grade Report Card - page 3

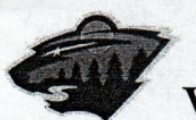

Wilderness Middle School

Seventh Grade Report Card

\begin{tabular}{|l|c|c|c|}
\hline Science & Trimester 1 & Trimester 2 & Trimester 3 \\
\hline Level of performance for science (At, Above, Below) & - & - & - \\
\hline $\begin{array}{l}\text { Intervention/s or curriculum modifications are currently being implemented for } \\
\text { science }\end{array}$ & - & - & \\
\hline Science Achievement Grade & - & - & \\
\hline
\end{tabular}

\begin{tabular}{|c|c|c|c|}
\hline \multicolumn{4}{|l|}{ Learner Objectives for Science } \\
\hline $\begin{array}{l}\text { Knows and applies the concepts, principles and processes of scientific } \\
\text { inquiry }\end{array}$ & - & - & - \\
\hline \multicolumn{4}{|l|}{ Knows and applies concepts of laboratory safety } \\
\hline $\begin{array}{l}\text { Knows and applies concepts that describe force and motion and the } \\
\text { principles that explain them }\end{array}$ & - & - & - \\
\hline $\begin{array}{l}\text { Knows and applies concepts that explain the composition and structure of } \\
\text { the universe and Earth's place in it }\end{array}$ & - & - & - \\
\hline $\begin{array}{l}\text { Knows and applies concepts that describe properties of matter and energy } \\
\text { and the interactions between them }\end{array}$ & - & - & - \\
\hline $\begin{array}{l}\text { Knows and applies concepts that explain how living things function, adapt } \\
\text { and change }\end{array}$ & - & - & - \\
\hline $\begin{array}{l}\text { Knows and applies concepts that describe the features and processes of the } \\
\text { Earth and its resources }\end{array}$ & - & - & - \\
\hline
\end{tabular}

\begin{tabular}{|l|c|c|c|}
\hline Science Learner Characteristics & Trimester 1 & Trimester 2 & Trimester 3 \\
\hline Works cooperatively & - & - & - \\
\hline Follows directions & - & - & \\
\hline Respects adults and peers & - & - & \\
\hline Puts forth effort & - & - & \\
\hline Completes Assignments & - & - & - \\
\hline
\end{tabular}

Science Comments: 
Seventh Grade Report Card - page 4

\section{Wilderness Middle School}

Seventh Grade Report Card

\begin{tabular}{|c|c|c|c|}
\hline $\begin{array}{l}\text { Social Science } \\
\text { Level of performance for social science (At }\end{array}$ & Trimester 1 & Trimester 2 & Trimester 3 \\
\hline $\begin{array}{l}\text { Level of performance for social science (At, Above, Below) } \\
\text { Intervention/s or curriculum modifications a }\end{array}$ & & & \\
\hline $\begin{array}{l}\text { Intervention/s or curriculum modifications are currently being implemented for } \\
\text { social science }\end{array}$ & - & - & - \\
\hline Social Science Achievement Grade & & & \\
\hline \multicolumn{4}{|l|}{$\begin{array}{l}\text { Learner Objectives for Social Science } \\
\text { Understands political systems, with an emphasis on the United States }\end{array}$} \\
\hline Understands economic systems, with an emphasis on the United States & & & \\
\hline $\begin{array}{l}\text { Understands events, trends, individuals and movements shaping the history } \\
\text { of Illinois, the United States and other nations }\end{array}$ & - & - & - \\
\hline $\begin{array}{l}\text { Understands world geography and the effects of geography on society, with } \\
\text { an emphasis on the United States } \\
\text { Understands social systems }\end{array}$ & - & - & - \\
\hline Understands social systems, with an emphasis on the United States & & & \\
\hline \multirow{2}{*}{\multicolumn{4}{|c|}{ Social Science Learner Characteristics }} \\
\hline & Trimester 1 & Trimester 2 & Trimester 3 \\
\hline \multirow{2}{*}{\multicolumn{4}{|c|}{$\begin{array}{l}\text { Follows directions } \\
\text { Respects adults and neers }\end{array}$}} \\
\hline \multirow{2}{*}{\multicolumn{4}{|c|}{$\begin{array}{l}\text { Respects adults and peers } \\
\text { Puts forth effort }\end{array}$}} \\
\hline \multirow{2}{*}{\multicolumn{4}{|c|}{ Puts forth effort }} \\
\hline & & & \\
\hline Completes Assignments & & & \\
\hline
\end{tabular}




\section{Seventh Grade Report Card - page 5}

\section{Wili Wilderness Middle School}

Seventh Grade Report Card

\begin{tabular}{|c|c|c|c|}
\hline $\begin{array}{l}\text { Encore } \\
\text { Art Achievement Grade (if anolicable) }\end{array}$ & Trimester 1 & Trimester 2 & Trimester 3 \\
\hline \multirow{2}{*}{\multicolumn{4}{|c|}{$\begin{array}{l}\text { Art Achievement Grade (if applicable) } \\
\text { Learner Objectives for Art }\end{array}$}} \\
\hline & & & \\
\hline \multicolumn{4}{|l|}{ Demonstrates understanding of art elements and principles } \\
\hline $\begin{array}{l}\text { Comprehends and applies understanding of diverse art media and artistic } \\
\text { techniques }\end{array}$ & - & - & - \\
\hline \multirow{2}{*}{\multicolumn{4}{|c|}{$\begin{array}{l}\text { Spanish Achievement Grade (if applicable) } \\
\text { Learner Objectives for Spanish }\end{array}$}} \\
\hline & & & \\
\hline \multicolumn{4}{|l|}{ Uses proper pronunciation and intonation } \\
\hline \multirow{2}{*}{\multicolumn{4}{|c|}{$\begin{array}{l}\text { Comprehends and applies key vocabulary terms and written passages } \\
\text { Uses appropriate grammar, punctuation and capitalization }\end{array}$}} \\
\hline & & & \\
\hline \multicolumn{4}{|l|}{$\begin{array}{l}\text { Band Achievement Grade (if applicable) } \\
\text { Learner Objectives for Band }\end{array}$} \\
\hline \multicolumn{4}{|l|}{ Learner Objectives for Band } \\
\hline $\begin{array}{l}\text { Demonstrates proper performance techniques by demonstrating appropriate } \\
\text { instrument use and care }\end{array}$ & - & - & - \\
\hline $\begin{array}{l}\text { Demonstrates proper performance techniques by playing with the correct } \\
\text { sound production }\end{array}$ & - & - & - \\
\hline \multicolumn{4}{|l|}{$\begin{array}{l}\text { Performs according to written musical notation by reading notes correctly } \\
\text { Performs according to written musical notation by readin } r \text { rythms }\end{array}$} \\
\hline \multirow{2}{*}{\multicolumn{4}{|c|}{$\begin{array}{l}\text { Performs according to written musical notation by reading rhythms correctly } \\
\text { Recognizes varied styles of music by using correct music terminology }\end{array}$}} \\
\hline & & & \\
\hline \multirow{2}{*}{\multicolumn{4}{|c|}{$\begin{array}{l}\text { Recognizes varied styles of music through discussion of performances } \\
\text { Physical Education Achievement Grade }\end{array}$}} \\
\hline Physical Education Achievement Grade & & & \\
\hline Learner Objectives for Physical Education & & & \\
\hline $\begin{array}{l}\text { Demonstrates individual responsibility, cooperation, and team building } \\
\text { skills }\end{array}$ & - & - & - \\
\hline \multicolumn{4}{|l|}{ Demonstrates knowledge of rules, safety, and game strategies } \\
\hline \multicolumn{4}{|l|}{ Demonstrates sport-specific skills } \\
\hline \multirow{2}{*}{\multicolumn{4}{|c|}{$\begin{array}{l}\text { Demonstrates knowledge of the importance of fitness and lifetime activities } \\
\text { Learner Characteristics for Physical Education }\end{array}$}} \\
\hline & & & \\
\hline \multicolumn{4}{|l|}{ Wears required gym uniform } \\
\hline \multicolumn{4}{|l|}{ Wears required athletic shoes } \\
\hline \multirow{2}{*}{\multicolumn{4}{|c|}{$\begin{array}{l}\text { Respects adults, peers, and equipment } \\
\text { Arrives to class on time }\end{array}$}} \\
\hline & & & \\
\hline \multicolumn{4}{|l|}{ Health Achievement Grade } \\
\hline \multirow{2}{*}{\multicolumn{4}{|c|}{$\begin{array}{l}\text { Learner Objectives for Health } \\
\text { Understands the importance of proper nutrition and self-image }\end{array}$}} \\
\hline & & & \\
\hline $\begin{array}{l}\text { Recognizes peer pressure situations and understands responsible decision } \\
\text { making skills }\end{array}$ & - & - & - \\
\hline \multicolumn{4}{|l|}{$\begin{array}{l}\text { Understands the effects of substance abuse } \\
\text { Understands basic safety and first aid }\end{array}$} \\
\hline \\
\hline & & & \\
\hline \multicolumn{4}{|l|}{ Prepared for class } \\
\hline Follows directions & & & \\
\hline \multicolumn{4}{|l|}{ 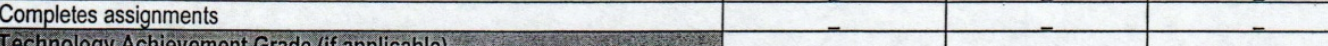 } \\
\hline \multirow{2}{*}{\multicolumn{4}{|c|}{$\begin{array}{l}\text { Technology Achievement Grade (if applicable) } \\
\text { Learner Objectives for Technology }\end{array}$}} \\
\hline & & & \\
\hline Comprehends computer terminology & & & \\
\hline Uses home row position and proper key strokes on keyboard & & & \\
\hline Demonstrates age appropriate knowledge of Microsoft Office applications & & & \\
\hline Exhibits responsible and ethical use of technology & & & \\
\hline
\end{tabular}


Seventh Grade Report Card - page 6

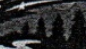

Wilderness Middle School

Seventh Grade Report Card

\begin{tabular}{|l|c|c|c|}
\hline Encore Learner Characteristics & Trimester 1 & Trimester 2 & Trimester 3 \\
\hline Works cooperatively & - & - & \\
\hline Follows directions & - & - & \\
\hline Respects adults and peers & - & - & \\
\hline Puts forth effort & - & - & \\
\hline Completes Assignments & & & \\
\hline Advisory Learner Characteristics & & & \\
\hline Takes home Friday folder and brings it back with proper signatures & & & \\
\hline Participates in character development activities & & & \\
\hline Participates in sustained silent reading & & & \\
\hline Cooperates in advisory activities & & & \\
\hline
\end{tabular}

Comments:

\begin{tabular}{|l|c|c|c|}
\hline Learner Objectives for English Language Learners (if applicable) & Trimester 1 & Trimester 2 & Trimester 3 \\
\hline Demonstrates academic language skills & - & & \\
\hline Demonstrates social language skills & - & & - \\
\hline
\end{tabular}

Comments:

\begin{tabular}{|c|c|c|c|}
\hline $\begin{array}{l}\text { Learner Upjectives for Support Class (if applicable) } \\
\text { Implements study skills and strategies that }\end{array}$ & Trimester 1 & Trimester 2 & Trimester 3 \\
\hline Demonstrates understanding of concepts and skills taught in core classes & - & - & - \\
\hline Self Advocates & - & - & - \\
\hline Works cooperatively with peers and teachers & - & - & - \\
\hline
\end{tabular}

Comments:

Trimester 1 Overall Comments:

Trimester 2 Overall Comments:

Trimester 3 Overall Comments:

$\square$ Promoted to next grade level 
Eighth Grade Report Card - page 1

\section{Wilderness Middle School}

Eighth Grade Report Card

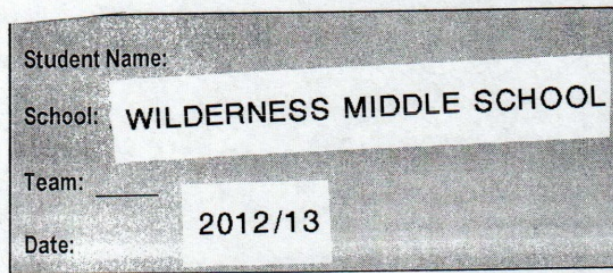

\begin{tabular}{|l|l|l|l|}
\hline \multicolumn{3}{|c|}{ Attendance Record } \\
\hline & Trimester 1 & Trimester 2 & Trimester 3 \\
\hline Total Days in Trimester & & & \\
\hline Days Absent & & & \\
\hline Days Tardy & & & \\
\hline
\end{tabular}

\begin{tabular}{|c|c|c|c|c|c|}
\hline \multicolumn{6}{|c|}{ Achievement Grade } \\
\hline$A$ & B & $C$ & D & U & 1 \\
\hline $\begin{array}{l}\text { Demonstrates } \\
\text { understanding } \\
\text { of skills and } \\
\text { concepts at the } 90 \% \\
\text { level or greater. }\end{array}$ & $\begin{array}{l}\text { Demonstrates } \\
\text { understanding } \\
\text { of skills } \\
\text { and concepts at the } \\
80-89 \% \text { level. }\end{array}$ & $\begin{array}{l}\text { Demonstrates } \\
\text { understanding } \\
\text { of skills and } \\
\text { concepts at the } \\
70-79 \% \text { level. }\end{array}$ & $\begin{array}{l}\text { Demonstrates } \\
\text { understanding } \\
\text { of skills and } \\
\text { concepts at the } \\
60-69 \% \text { level. }\end{array}$ & $\begin{array}{l}\text { Demonstrates } \\
\text { understanding of skills } \\
\text { and concepts below } \\
\text { the } 60 \% \text { level. }\end{array}$ & Incomplete \\
\hline
\end{tabular}

\begin{tabular}{|c|c|c|c|c|}
\hline \multicolumn{5}{|c|}{ Learner Objective Descriptors } \\
\hline Exceeds (4) & Proficient (3) & Basic (2) & Below Basic (1) & Not Assessed (NA) \\
\hline $\begin{array}{l}\text { Consistently demonstrates } \\
\text { a thorough understanding } \\
\text { of facts, skills, and } \\
\text { concepts. Applies } \\
\text { knowledge independently. }\end{array}$ & $\begin{array}{l}\text { Frequently demonstrates } \\
\text { an understanding of facts, } \\
\text { skills, and/or concepts. } \\
\text { Beginning to apply } \\
\text { knowledge independently. }\end{array}$ & $\begin{array}{l}\text { Limited understanding of } \\
\text { facts, skills, and/or } \\
\text { concepts. Some review, } \\
\text { reinforcement, and } \\
\text { support may be needed. }\end{array}$ & $\begin{array}{l}\text { Rarely understands facts, } \\
\text { skills, and/or concepts. } \\
\text { Frequent review, } \\
\text { reinforcement, and } \\
\text { support are needed. }\end{array}$ & $\begin{array}{l}\text { Grade level standard(s) have } \\
\text { not been assessed at this time }\end{array}$ \\
\hline
\end{tabular}

Reading

\begin{tabular}{l} 
Level of performance for reading benchmark (At, Above, Below) \\
\hline
\end{tabular}

\begin{tabular}{l} 
Level of performance for reading benchmark (At, Above, Below) \\
\hline Intervention/s or curriculum modifications are currently being implemented for
\end{tabular}

reading

Reading Achievement Grade

\begin{tabular}{|c|c|c|c|}
\hline & Trimester 1 & Trimester 2 & Trimester 3 \\
\hline & - & - & - \\
\hline & - & - & - \\
\hline
\end{tabular}

Learner Objectives for Reading

Applies strategies to improve understanding and reading fluency

Demonstrates use of comprehension strategies to understand a broad range

of reading selections

Analyzes how various literary elements are used to convey meaning

Applies decoding and vocabulary skills to comprehend selections

Analyzes reading selections through written response

\begin{tabular}{|l|c|c|c|}
\hline Reading Learner Characteristics & Trimester 1 & Trimester 2 & Trimester 3 \\
\hline Works cooperatively & - & - & \\
\hline Follows directions & - & - & \\
\hline Respects adults and peers & - & - & \\
\hline Puts forth effort & - & - & \\
\hline Completes Assignments & & - \\
\hline
\end{tabular}

Reading Comments: 
Eighth Grade Report Card - page 2

\section{Wilderness Middle School}

Eighth Grade Report Card

\begin{tabular}{|c|c|c|c|}
\hline Language Arts & Trimester 1 & Trimester 2 & Trimester 3 \\
\hline \multicolumn{4}{|l|}{ Level of performance for language arts (At, Above, Below) } \\
\hline $\begin{array}{l}\text { Intervention/s or curriculum modifications are currently being implemented for } \\
\text { language arts }\end{array}$ & - & - & - \\
\hline \multicolumn{4}{|l|}{ Language Arts Achievement Grade } \\
\hline \multicolumn{4}{|l|}{ Learner Objectives for Language Aits } \\
\hline \multicolumn{4}{|l|}{ Applies writing strategies to a variety of contexts and tasks } \\
\hline $\begin{array}{l}\text { Implements the writing process and traits of good writing in a variety of } \\
\text { tasks }\end{array}$ & - & - & - \\
\hline $\begin{array}{l}\text { Demonstrates a command of the conventions of standard English when } \\
\text { writing, speaking, or listening. }\end{array}$ & - & - & - \\
\hline Applies word study strategies in daily writing & & & \\
\hline \multicolumn{4}{|l|}{ Applies listening and speaking strategies to a variety of contexts and tasks } \\
\hline Language Arts Learner Characteristics & Trimester 1 & Trimester 2 & Trimester 3 \\
\hline \multicolumn{4}{|l|}{ Works cooperatively } \\
\hline \multicolumn{4}{|l|}{ Follows directions } \\
\hline \multicolumn{4}{|l|}{ Respects adults and peers } \\
\hline Puts forth effort & & & \\
\hline Completes Assignments & & & \\
\hline
\end{tabular}

\section{Language Arts Comments:}

\begin{tabular}{|l|c|c|}
\hline Mathematics & Trimester 1 & Trimester 2 \\
\hline $\begin{array}{l}\text { Level of performance for mathematics (At, Above, Below, Accelerated, } \\
\text { Honors) }\end{array}$ & - & - \\
\hline $\begin{array}{l}\text { Intervention/s or curriculum modifications are currently being implemented for } \\
\text { mathematics }\end{array}$ & - & - \\
\hline Mathematics Achievement Grade & - & - \\
\hline
\end{tabular}

\begin{tabular}{|l|l|l|}
\hline Learner Objectives for Mathematics & & \\
\hline Demonstrates and applies a knowledge and sense of numbers & & - \\
\hline Estimates, makes and uses measurements of objects & - & - \\
\hline $\begin{array}{l}\text { Uses algebraic methods to identify patterns and relationships to solve } \\
\text { problems }\end{array}$ & - & - \\
\hline $\begin{array}{l}\text { Uses geometric methods to analyze, categorize and draw conclusions about } \\
\text { points, lines, polygons, area and perimeter }\end{array}$ & - & - \\
\hline Collects, organizes and analyzes data using statistical methods & & - \\
\hline Uses planning and processing skills to solve problems & & - \\
\hline
\end{tabular}

\begin{tabular}{|l|c|c|c|}
\hline Mathematics Learner Characteristics & Trimester 1 & Trimester 2 & Trimester 3 \\
\hline Works cooperatively & & & \\
\hline Follows directions & & & - \\
\hline Respects adults and peers & - & & - \\
\hline Puts forth effort & - & & - \\
\hline Completes Assignments & & & - \\
\hline
\end{tabular}

Mathematics Comments: 
Eighth Grade Report Card - page 3

\section{$=1$ \\ 5 Wilderness Middle School}

Eighth Grade Report Card

\begin{tabular}{|l|l|l|l|}
\hline Science & Trimester 1 & Trimester 2 & Trimester 3 \\
\hline Level of performance for science (At, Above, Below) & & - & - \\
\hline $\begin{array}{l}\text { Intervention/s or curriculum modifications are currently being implemented for } \\
\text { science }\end{array}$ & & & - \\
\hline Science Achievement Grade & & - & - \\
\hline $\begin{array}{l}\text { Learner Objectives for Science } \\
\text { chems and explains the processes in which matter and energy can interact in }\end{array}$ & - & - & - \\
\hline $\begin{array}{l}\text { Models and describes the chemical and physical characteristics of matter } \\
\text { including atoms, molecules, elements, and compounds }\end{array}$ & - & - \\
\hline $\begin{array}{l}\text { Identifies, compares, and explains the interrelatedness between the structures } \\
\text { and functions of human body systems }\end{array}$ & - & - \\
\hline $\begin{array}{l}\text { Describes and attributes the effects of major disorders present in organs, } \\
\text { tissues, and systems }\end{array}$ & - & - \\
\hline Explains and demonstrates how forces and Newton's Laws affect motion & - & - \\
\hline $\begin{array}{l}\text { Identifies and relates the concepts of Work, Power, and Energy to real-life } \\
\text { experiences }\end{array}$ & - & - \\
\hline $\begin{array}{l}\text { Effectively designs experiments, poses testable questions, collects data, } \\
\text { interprets results, and shares conclusions (Scientific Inquiry) }\end{array}$ & - & - \\
\hline
\end{tabular}

interprets results, and shares conclusions (Scientific Inquiry)

\begin{tabular}{|l|c|c|c|}
\hline Science Learner Characteristics & Trimester 1 & Trimester 2 & Trimester 3 \\
\hline Works cooperatively & - & - & \\
\hline Follows directions & - & - & - \\
\hline Respects adults and peers & - & - & \\
\hline Puts forth effort & - & - & \\
\hline Completes Assignments & & & - \\
\hline
\end{tabular}

Science Comments: 
Eighth Grade Report Card - page 4

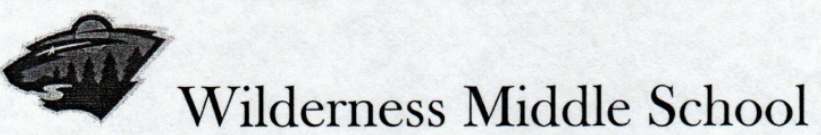

Eighth Grade Report Card

\begin{tabular}{l}
\hline \begin{tabular}{l|l|l|l|}
\hline Social Science & Trimester 1 & Trimester 2 & Trimester 3 \\
\hline Level of performance for social science (At, Above, Below) & - & - & \\
\hline $\begin{array}{l}\text { Intervention/s or curriculum modifications are currently being implemented for } \\
\text { social science }\end{array}$ & - & - & \\
\hline Social Science Achievement Grade & & & \\
\hline
\end{tabular} \\
\begin{tabular}{|l|l|l|l|}
\hline Learner Objectives for Social Science \\
\hline $\begin{array}{l}\text { Differentiajes between political systems, with an emphasis on the United } \\
\text { States }\end{array}$ \\
\hline $\begin{array}{l}\text { Recognizes the impact of economic systems on history, with an emphasis on } \\
\text { the United States }\end{array}$ & - & - & - \\
\hline $\begin{array}{l}\text { Analyzes events, trends, individuals and movements shaping the history of } \\
\text { llinois, the United States, and other nations }\end{array}$ & - & - & - \\
\hline $\begin{array}{l}\text { Relates world geography and the effects of geography to society, with } \\
\text { an emphasis on the United States }\end{array}$ & - & - & - \\
\hline Classifies social systems, with an emphasis on the United States & - & - & - \\
\hline
\end{tabular}
\end{tabular}

\begin{tabular}{|l|c|c|c|}
\hline Social Science Learner Characteristics & Trimester 1 & Trimester 2 & Trimester 3 \\
\hline Works cooperatively & - & - & \\
\hline Follows directions & - & - & \\
\hline Respects adults and peers & - & - & \\
\hline Puts forth effort & - & - & \\
\hline Completes Assignments & - & - & \\
\hline
\end{tabular}

Social Science Comments: 
Eighth Grade Report Card - page 5

\section{Wilderness Middle School}

Eighth Grade Report Card

\begin{tabular}{|c|c|c|c|}
\hline Encore & Trimester 1 & Trimester 2 & Trimester 3 \\
\hline \multicolumn{4}{|l|}{$\begin{array}{l}\text { Encore } \\
\text { Art Achievement Grade (if applicable) }\end{array}$} \\
\hline \multicolumn{4}{|l|}{$\begin{array}{l}\text { Art Achievement Grade (it applicable) } \\
\text { Learner Objectives for Art }\end{array}$} \\
\hline \multicolumn{4}{|l|}{$\begin{array}{l}\text { Learner Objectives for Art } \\
\text { Demonstrates understanding of art elements and principles }\end{array}$} \\
\hline $\begin{array}{l}\text { Comprehends and applies understanding of diverse art media and artistic } \\
\text { techniques }\end{array}$ & - & - & - \\
\hline \multicolumn{4}{|l|}{$\begin{array}{l}\text { techniques } \\
\text { Spanish Achievement Grade (if applicable) }\end{array}$} \\
\hline \multicolumn{4}{|l|}{$\begin{array}{l}\text { Spanish Achievement Grade (it applicable) } \\
\text { Learner Objectives for Spanish }\end{array}$} \\
\hline \multicolumn{4}{|l|}{$\begin{array}{l}\text { Learner Objectives for Spanish } \\
\text { Uses proper pronunciation and intonation }\end{array}$} \\
\hline \multicolumn{4}{|l|}{$\begin{array}{l}\text { Uses proper pronunclation and intonation } \\
\text { Comprehends and applies key vocabulary terms and written passages }\end{array}$} \\
\hline \multicolumn{4}{|l|}{$\begin{array}{l}\text { Comprehends and applies key vocabulary terms and writion passages } \\
\text { Uses appropriate grammar, punctuation and capitalization }\end{array}$} \\
\hline \multicolumn{4}{|l|}{ Band Achievement Grade (if applicable) } \\
\hline \multicolumn{4}{|l|}{$\begin{array}{l}\text { Band Achievement Grade (II appilcapie) } \\
\text { Learner Objectives for Band }\end{array}$} \\
\hline $\begin{array}{l}\text { Demonstrates proper performance techniques by demonstrating appropriate } \\
\text { instrument use and care }\end{array}$ & - & - & - \\
\hline $\begin{array}{l}\text { Demonstrates proper performance techniques by playing with the correct } \\
\text { sound production }\end{array}$ & - & - & - \\
\hline \multicolumn{4}{|l|}{$\begin{array}{l}\text { Sound production } \\
\text { Performs according to written musical notation by reading notes correctly }\end{array}$} \\
\hline \multicolumn{4}{|l|}{ Performs according to written musical notation by reading rhythms correctly } \\
\hline \multirow{2}{*}{\multicolumn{4}{|c|}{ Recognizes varied styles of music by using correct music terminology }} \\
\hline Recognizes varied styles of music through discussion of performances & & & \\
\hline \multicolumn{4}{|l|}{ Physical Education Achievement Grade } \\
\hline \multicolumn{4}{|l|}{ Learner Objectives for Physical Education } \\
\hline $\begin{array}{l}\text { Demonstrates individual responsibility, cooperation, and team building } \\
\text { skills }\end{array}$ & - & - & - \\
\hline \multicolumn{4}{|l|}{$\begin{array}{l}\text { skills } \\
\text { Demonstrates knowledge of rules, safety, and game strategies }\end{array}$} \\
\hline \multicolumn{4}{|l|}{$\begin{array}{l}\text { Demonstrates knowleage of rules, sarety, and gamle strategits } \\
\text { Demonstrates sport-specific skills }\end{array}$} \\
\hline \multicolumn{4}{|l|}{ Demonstrates knowledge of the importance of fitness and lifetime activities } \\
\hline \multicolumn{4}{|l|}{ Learner Characteristics for Physical Education } \\
\hline \multicolumn{4}{|l|}{ Wears required gym uniform } \\
\hline \multicolumn{4}{|l|}{ Wears required gym unirorm } \\
\hline \multicolumn{4}{|l|}{ Respects adults, peers, and equipment } \\
\hline \multicolumn{4}{|l|}{ Arrives to class on time } \\
\hline \multirow{2}{*}{\multicolumn{4}{|c|}{ Learner Objectives for Health }} \\
\hline & & & \\
\hline Recognizes the signs of abusive behaviors & & & \\
\hline Demonstrates an understanding of Communicable Diseases (STD's) & & & \\
\hline $\begin{array}{l}\text { Understands and describes the functions of body systems (endocrine } \\
\text { system, male \& female reproductive systems, \& pregnancy \& child birth }\end{array}$ & - & - & - \\
\hline $\begin{array}{l}\text { Demonstrates an understanding of life skills (effective communication \& } \\
\text { decision making skills) }\end{array}$ & - & - & - \\
\hline Learner Characteristics for Health & & & \\
\hline Prepared for class & & & \\
\hline Follows directions & & & \\
\hline Completes assignments & & & \\
\hline Technology Achievement Grade (if applicable) & & & \\
\hline Learner Objectives for Technology & & & \\
\hline Comprehends computer terminology & & & \\
\hline Uses home row position and proper key strokes on keyboard & & & \\
\hline Demonstrates age appropriate knowledge of Microsoft Office applications & & & \\
\hline Exhibits responsible and ethical use of technology & & & \\
\hline
\end{tabular}


Eighth Grade Report Card - page 6

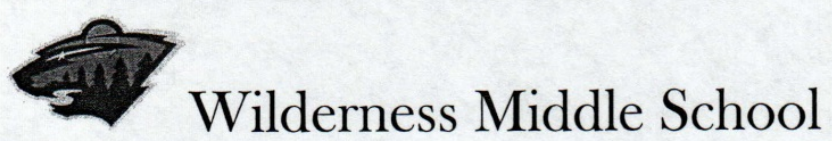

Eighth Grade Report Card

\begin{tabular}{|l|c|c|c|}
\hline Encore Learner Characteristics & Trimester 1 & Trimester 2 & Trimester 3 \\
\hline Works cooperatively & - & - & \\
\hline Follows directions & - & - & \\
\hline Respects adults and peers & - & - & \\
\hline Puts forth effort & - & - & \\
\hline Completes Assignments & - & & \\
\hline Advisory Learner Characteristics & - & & \\
\hline Takes home Friday folder and brings it back with proper signatures & & & \\
\hline Participates in character development activities & & & \\
\hline Participates in sustained silent reading & & & - \\
\hline Cooperates in advisory activities & & \\
\hline
\end{tabular}

Comments:

\begin{tabular}{|c|c|c|c|}
\hline Learner Objectives for English Language Learners (if applicable) & Trimester 1 & Trimester 2 & Trimester 3 \\
\hline Demonstrates academic language skills & & & \\
\hline Demonstrates social language skills & - & - & - \\
\hline
\end{tabular}

Comments:

\begin{tabular}{|l|c|c|}
\hline Learner Objectives for Support Class (if applicable) & Trimester 1 & Trimester 2 \\
\hline Implements study skills and strategies that promote academic success & - & - \\
\hline Demonstrates understanding of concepts and skills taught in core classes & - & - \\
\hline Self Advocates & - & - \\
\hline Works cooperatively with peers and teachers & - & - \\
\hline
\end{tabular}

Comments:

Trimester 1 Overall Comments:

Trimester 2 Overall Comments:

Trimester 3 Overall Comments:

$\square$ Promoted to next grade level 
APPENDIX D

WILDERNESS SEVENTH AND EIGHTH GRADE LEARNING OBJECTIVES 
Seventh Grade Learning Objectives - page 1

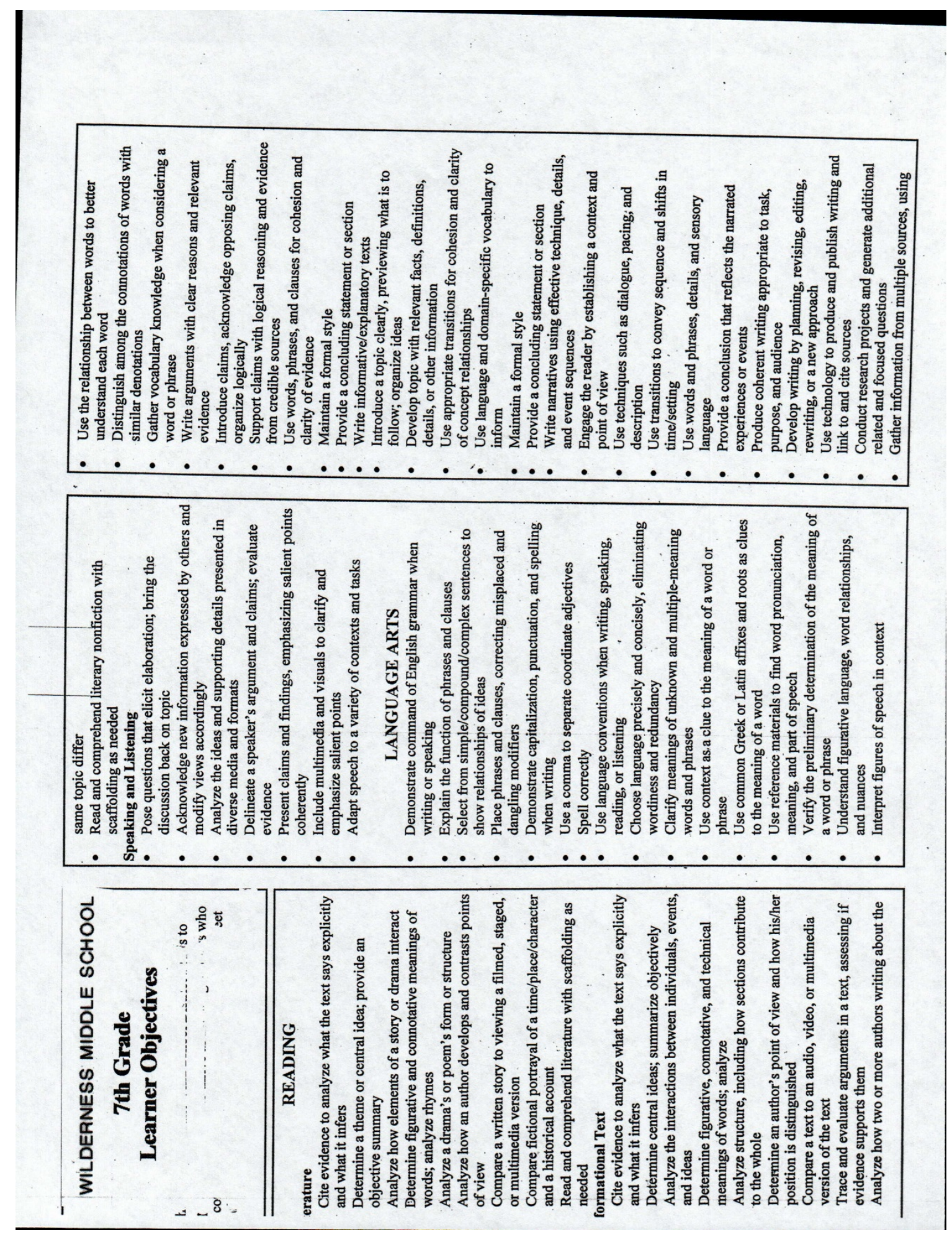


Seventh Grade Learning Objectives - page 2
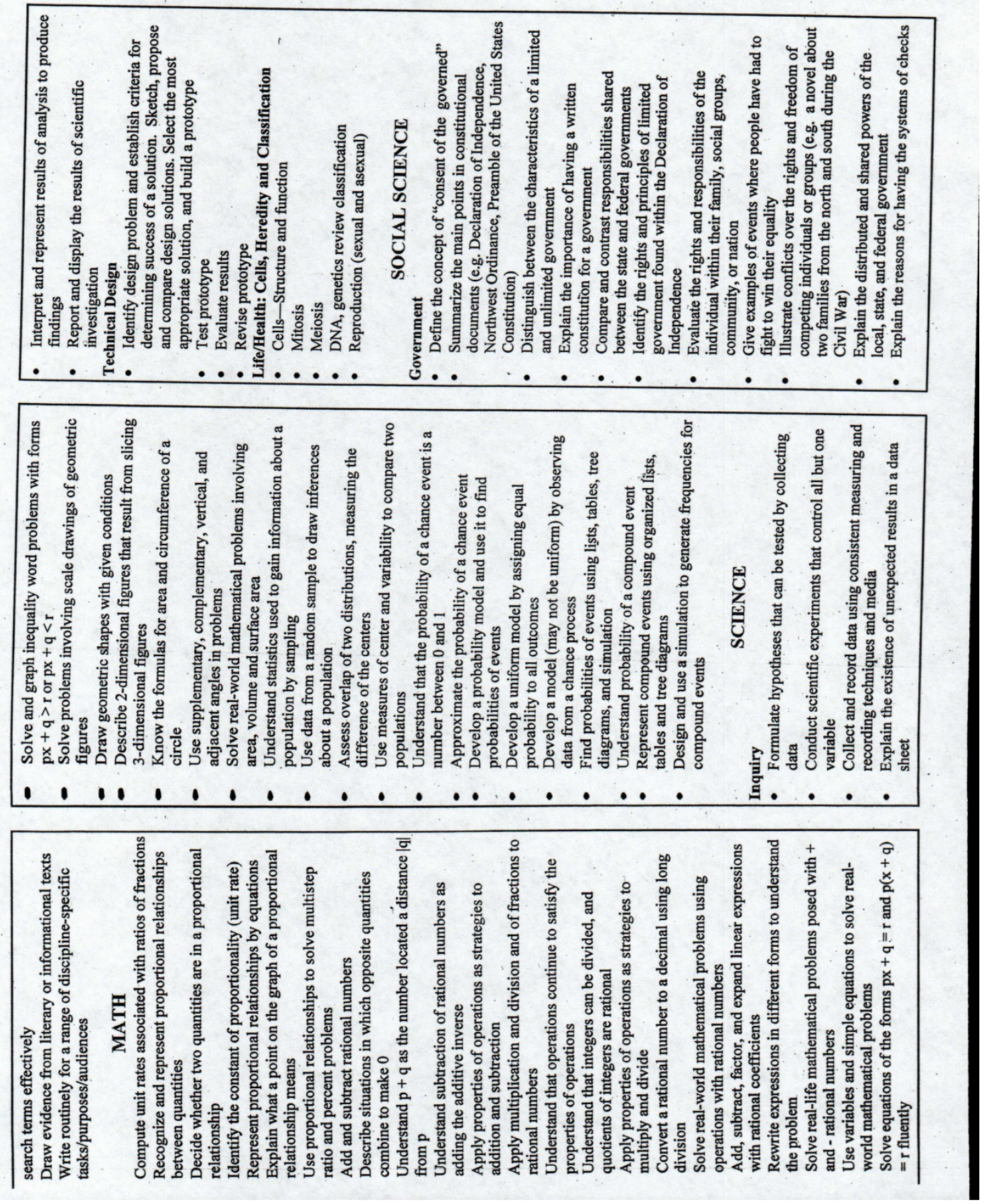
Seventh Grade Learning Objectives - page 3
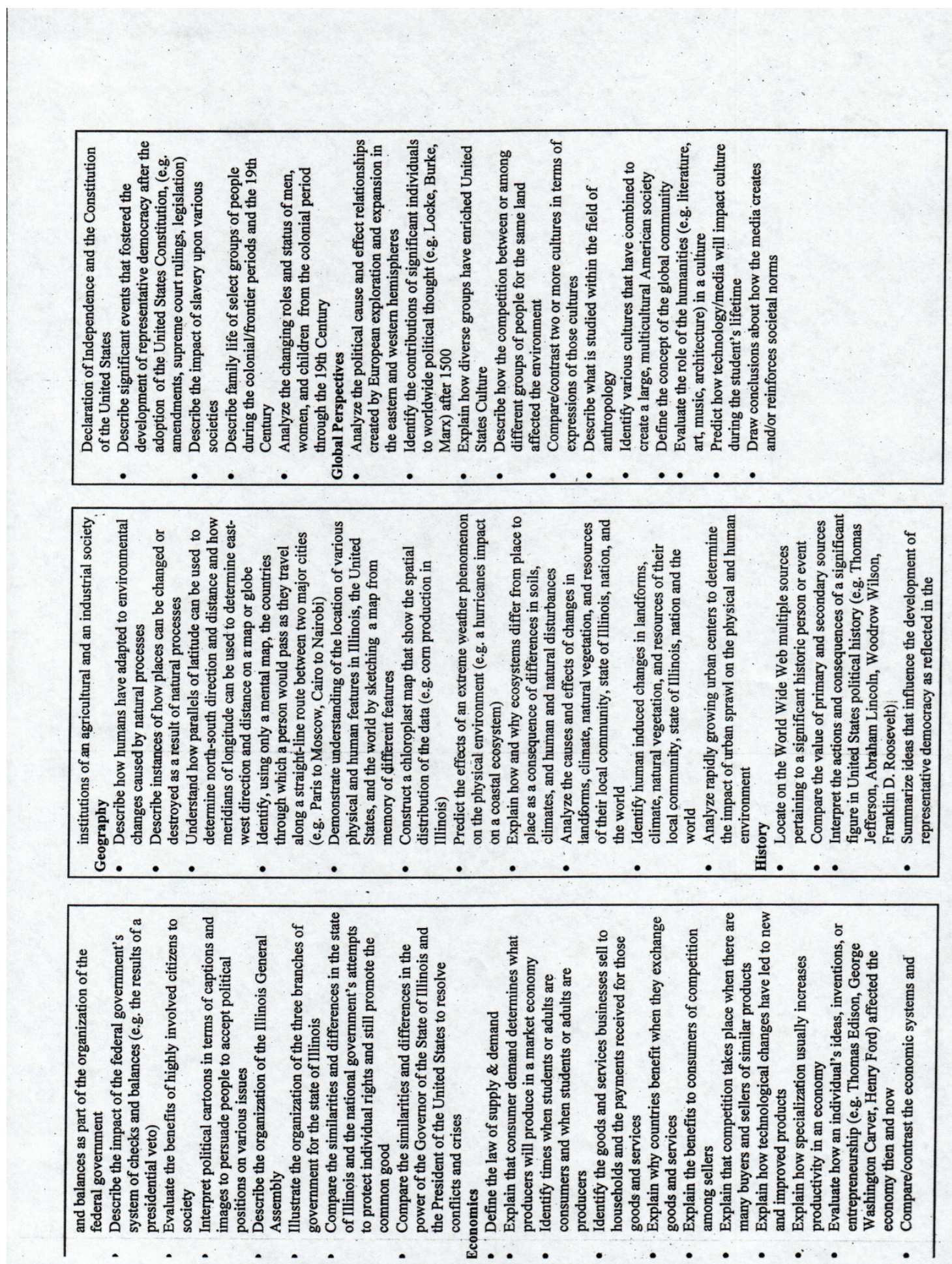
Eighth Grade Learning Objectives - page 1
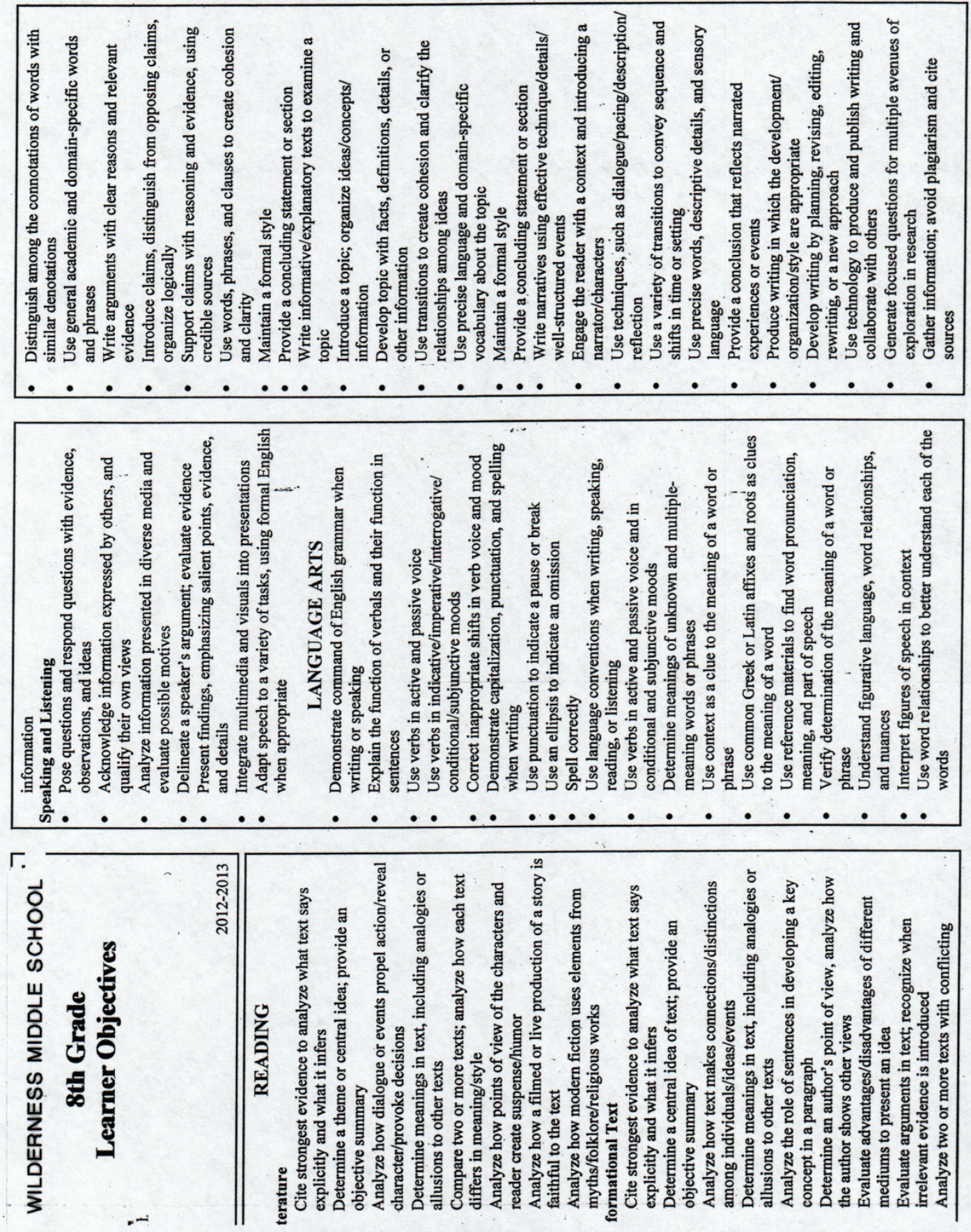
Eighth Grade Learning Objectives - page 2
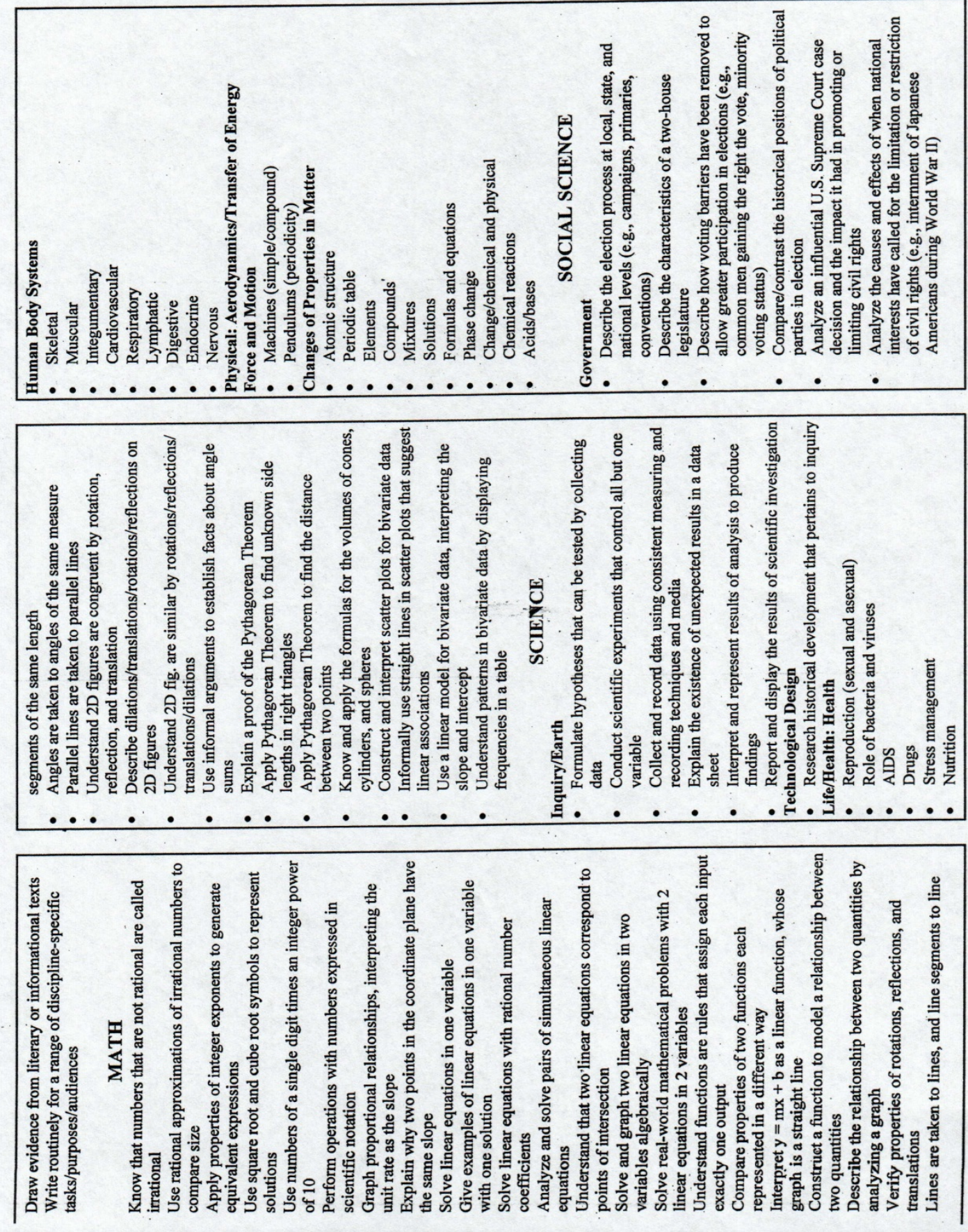
Eighth Grade Learning Objectives - page 3
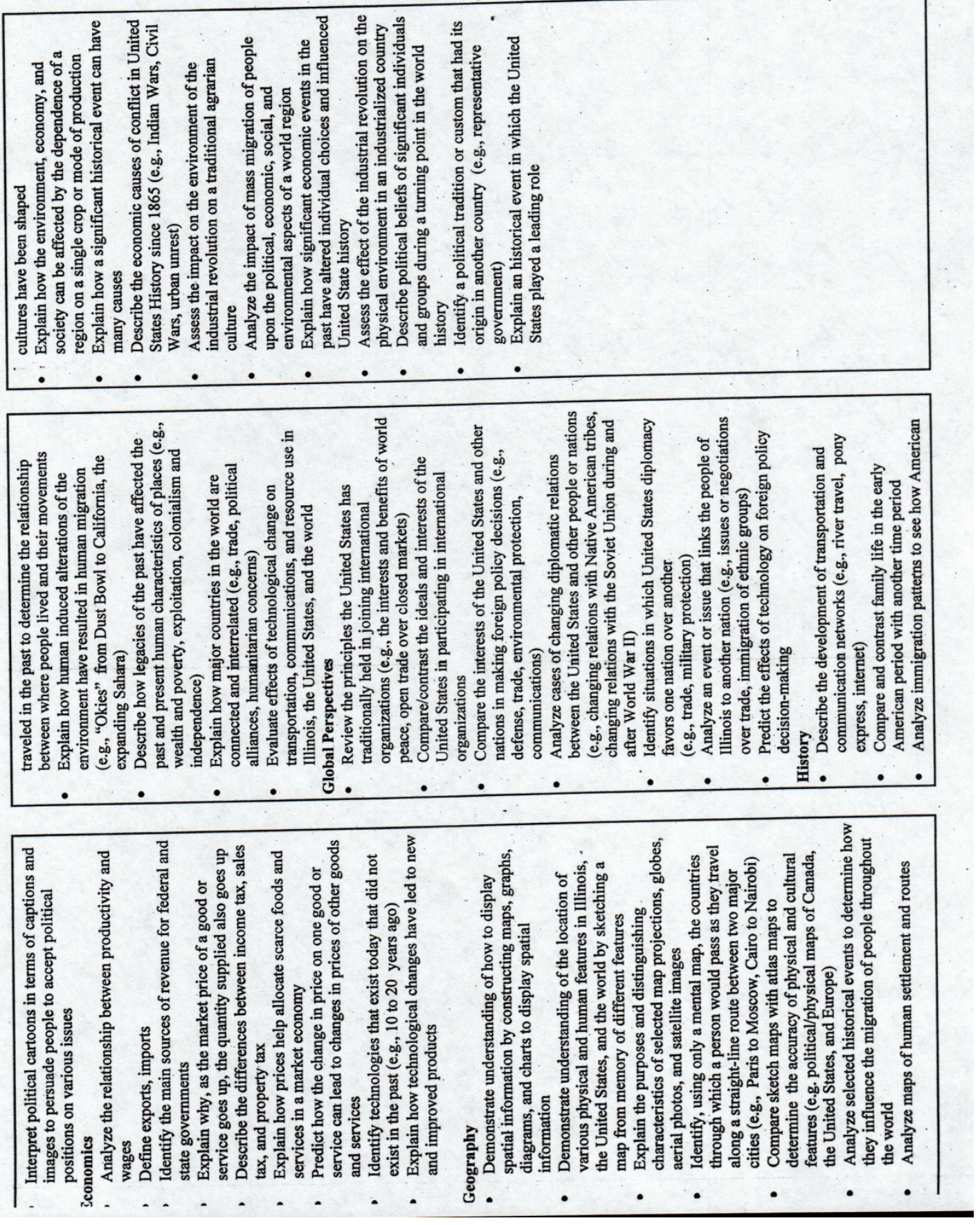
APPENDIX E

INTERVIEW PROTOCOL 


\section{Research Protocol Questions}

\section{How do middle school educators describe their experiences of moving from a traditional grading system to a standards-based grading system?}

Overarching questions in bold. Emphasis underlined. Protocol questions to be asked during interviews listed after letter (not in order of questioning).

1. How do educators describe the change process from traditional to standardsbased grading?

a. Describe the experiences you have had with grading as an instructor to begin your career. (Provide a timeline of events if possible).

b. How has your thinking changed since the idea of standards-based grading was implemented?

c. What supports or instruction was provided to you and/or the staff to make the change to a standards-based system?

2. How do educators' perceptions of student learning change during the move to a standards-based reporting system?

a. What do you believe to be the main purposes of grading?

b. Have these beliefs changed after implementation of standards-based grading? (If so, describe these changes).

3. What are the major challenges and successes educators face while changing to a standards-based reporting system?

a. Significant change is usually very difficult, what were challenges involved with making the change to a standards-based approach to grading?

b. What do you believe are the advantages of standards-based grading practices?

c. What have you experienced to be shortcomings of standards-based grading practices?

d. What do you see as challenges ahead in the area of standards-based grading?

4. What impact has standards-based grading had on teaching and learning in the school?

a. Describe your past and current practices on how you report student progress.

b. How has your change in grading changed your teaching methodology?

c. Have you noticed any changes in your students that you would attribute to the change in grading?

5. What are the implications in the assessment process for leading the change from traditional to standards-based grading?

a. Describe the changes you have made in assessment since implementing a standards-based grading system.

b. Explain how changes in assessment practices have impacted students learning 
APPENDIX F

SURVEY PROTOCOL 


\section{Survey Protocol}

Please complete this brief survey. Answer the questions below about your experiences with: 1) standards-based grading approaches and processes and 2) changing from traditional to standards-based grading.

1. How long have you been teaching?

2. When did you join the staff of (NAME) school?

3. Were you working at this school when standards-based grading was first discussed?

4. Were you working at this school when this school changed to a standards-based grading approach?

5. What subject do you teach?

6. Explain briefly your experiences with changing from traditional grading to assigning grades based on learning standards?

7. Are you willing to be considered as an interview participant for a study of schools that changed from traditional grades to standards-based grades?

If yes, provide contact information. Name and email address. 
APPENDIX G

PRINCIPAL SURVEY PROTOCOL 


\section{Phone Interview Protocol}

For principals school with potential to be studied

1. Give me a brief description of your standards-based report card?

2. Were you working at this school when standards-based grading was first implemented?

3. Can I send you a letter of support signifying your willingness to participate in my study on standards-based grading? 
APPENDIX H

PRINCIPAL LETTER OF SUPPORT 
$\mathrm{I}$, , agree to participate in the study entitled, "Transitioning to

Standards-Based Grading Model at the Middle Level”. I understand the study will require staff being surveyed, interviewed for about an hour, documents reviewed, and observations of faculty in team meetings.

Please be advised that your participation in this study is voluntary, and you may withdraw at any time. If you do choose to withdraw, there will be no penalty of any kind. In addition, throughout surveys or interview, you are not expected to discuss any material that is emotionally sensitive or will make you feel uncomfortable in any capacity. Your input will be used in a written report regarding this research topic, and results of this study may be published. However, the identification of your school will remain confidential, and I will take all precautions to protect your schools privacy. $\mathrm{X}$ (Signature of Principal)

Professionally, Jeffrey Szymczak, Ph.D. Candidate Illinois State University

If you have questions on research participants' rights, and/or would like to file research related injury or adverse effect. Contact the Research Ethics \& Compliance Office at Illinois State University: (XXX) XXX-XXXX. 